\title{
Pharmacological Characterization of Novel Opioid Receptor Ligands Aimed at Reducing the Development of Tolerance
}

\author{
Jason Randall Healy \\ West Virginia University
}

Follow this and additional works at: https://researchrepository.wvu.edu/etd

\section{Recommended Citation}

Healy, Jason Randall, "Pharmacological Characterization of Novel Opioid Receptor Ligands Aimed at Reducing the Development of Tolerance" (2014). Graduate Theses, Dissertations, and Problem Reports. 616.

https://researchrepository.wvu.edu/etd/616

This Dissertation is protected by copyright and/or related rights. It has been brought to you by the The Research Repository @ WVU with permission from the rights-holder(s). You are free to use this Dissertation in any way that is permitted by the copyright and related rights legislation that applies to your use. For other uses you must obtain permission from the rights-holder(s) directly, unless additional rights are indicated by a Creative Commons license in the record and/ or on the work itself. This Dissertation has been accepted for inclusion in WVU Graduate Theses, Dissertations, and Problem Reports collection by an authorized administrator of The Research Repository @ WVU.

For more information, please contact researchrepository@mail.wvu.edu. 
Pharmacological Characterization of Novel Opioid Receptor Ligands Aimed at Reducing the Development of Tolerance

\author{
Jason Randall Healy
}

A dissertation submitted to the School of Pharmacy at West Virginia University in partial fulfillment of the requirements for the degree of

Doctor of Philosophy in Pharmaceutical and Pharmacological Sciences

Rae R. Matsumoto, Ph.D., Chair

Andrew Coop, Ph.D. Jason D. Huber, Ph.D. Stephen G. Graber, Ph.D. Charles D. Ponte, Pharm.D.

Department of Basic Pharmaceutical Sciences Morgantown, West Virginia

2013

Keywords: Antinociception, conformationally sampled pharmacophore, delta antagonist, mu agonist, opioid receptor, tolerance

Copyright 2013 Jason Randall Healy 


\title{
ABSTRACT
}

\section{Pharmacological Characterization of Novel Opioid Receptor Ligands Aimed at Reducing the Development of Tolerance}

\author{
Jason Randall Healy
}

The three opioid receptor subtypes, mu $(\mu)$, delta $(\delta)$ and kappa $(\kappa)$ have long been associated with analgesia. Traditional opioid analgesics exert their effects through $\mu$ receptors located in the CNS. Recent studies suggest that the development of opioid analgesics displaying dual properties of $\mu$ agonism and $\delta$ antagonism could be of benefit by retaining potent analgesic properties while reducing the development of tolerance with chronic administration. UMB 425 displays high affinity at the $\mu$ receptor $\left(\mathrm{K}_{\mathrm{i}}=3.2 \pm 0.14 \mathrm{nM}\right)$, moderate affinity at the $\delta$ and $\mathrm{K}$ receptor In vitro $\left[{ }^{35}\right.$ S]GTPYS functional assay results indicate that UMB 425 acts as partial agonist at the $\mu$ receptor, whilst having competitive antagonistic properties at the $\delta$ receptor. UMB 425 displays potent acute analgesic activity in vivo for both the hot plate and tail-flick assays, comparable to morphine itself. To ensure proper opioid-induced mechanisms pretreatment studies were performed using naloxone, a non-selective opioid antagonist, and nor-BNI, a selective $\mathrm{K}$-antagonist. Naloxone attenuates the analgesic effects induced by an acute $\mathrm{ED}_{90}$ of UMB 425, while nor-BNI shows no significant reduction. A chronic dosing paradigm was designed to determine UMB 425 induced analgesic tolerance. UMB 425 maintains significantly higher levels of analgesia compared to morphine on the fifth day of this chronic dosing paradigm. A dose-response challenge performed on the sixth day of this paradigm indicates a smaller shift in respective $E_{50}$ values for UMB 425 as compared to morphine for both the tail-flick (1.3-/6.4-fold) and hot plate (3.0-/7.8-fold) assays, effectively demonstrating reduced analgesic tolerance liabilities for UMB 425. 


\section{Dedicated to}

My loving mother

\section{Shirl Lamaster Healy}

The loving memory of my late father

Randall Lawrence Healy

The continuous support from my best friend

Elizabeth Rose Earley 


\section{ACKNOWLEDGMENTS}

My upmost gratitude to my mentor Dr. Rae R. Matsumoto. She provided me with ample opportunities for success. I am grateful for her support and guidance while at West Virginia University.

I would also like to acknowledge my committee members, Dr. Andy Coop, Dr. Jason D. Huber,

Dr. Stephen G. Graber, and Dr. Charles D. Ponte, for their guidance and insight.

Special thanks to the laboratory of Dr. Andrew Coop and Dr. Alexander MacKerell at the University Of Maryland School Of Pharmacy for the synthesis and molecular modeling of compounds for my studies.

I would also like to acknowledge the support I received from the members of the Matsumoto laboratory during my tenure. 


\section{TABLE OF CONTENTS}

ABSTRACT

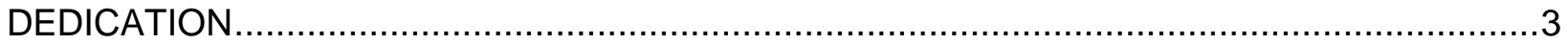

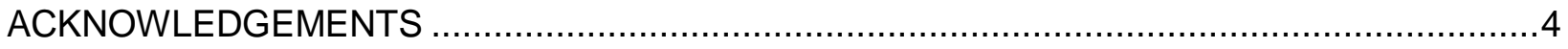

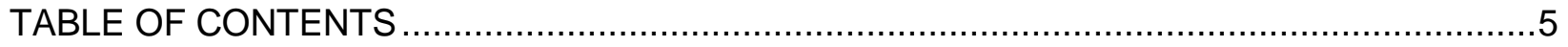

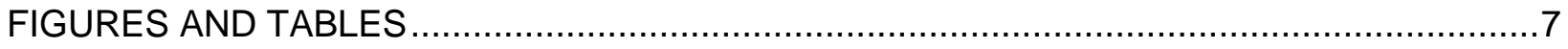

ABBREVIATIONS

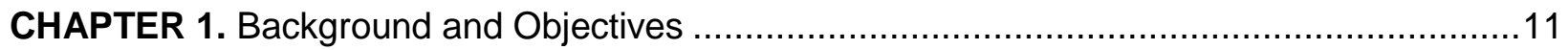

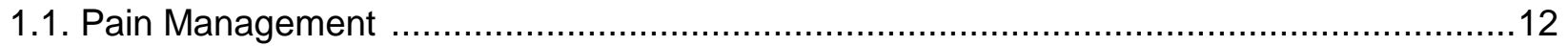

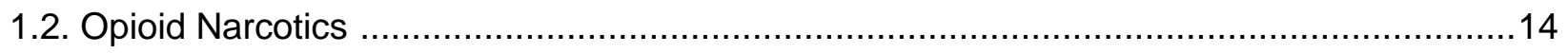

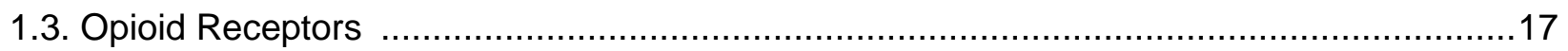

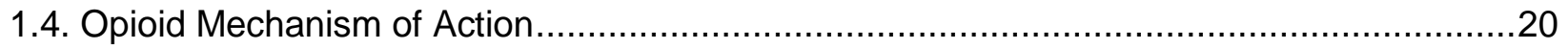

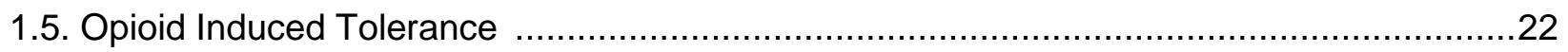

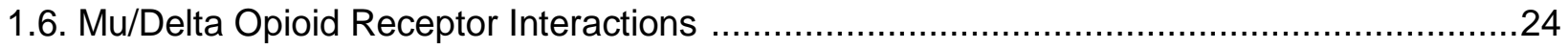

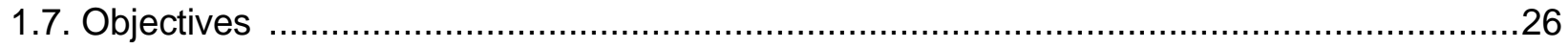

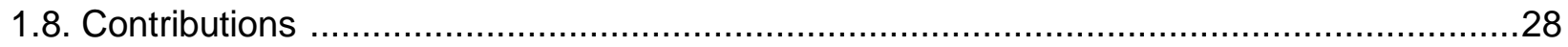

CHAPTER 2. Structural Optimization of Mixed Mu Agonist/Delta Antagonist Ligands...............29

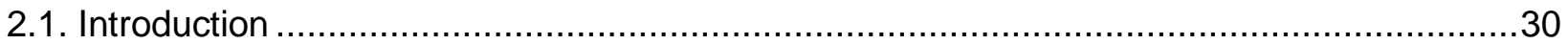

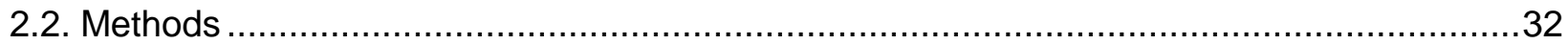

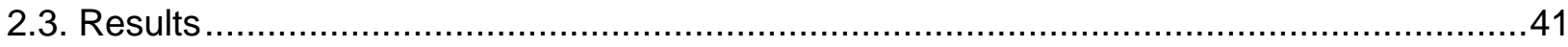

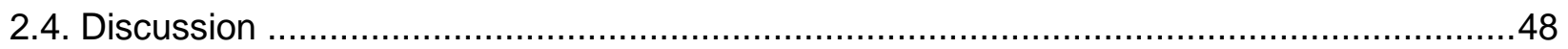

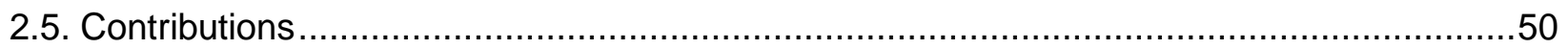

CHAPTER 3. Antinociceptive Activity of Novel UMB Opioid Ligands In Vivo............................51

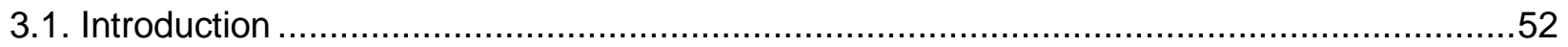

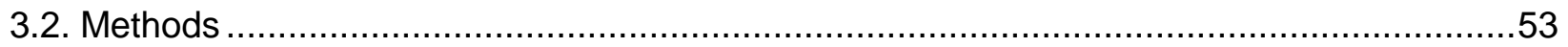

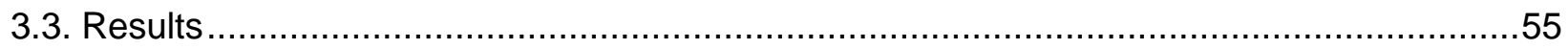

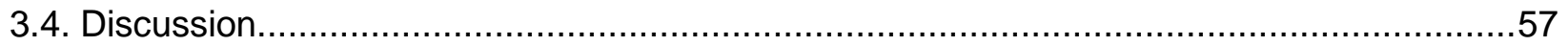

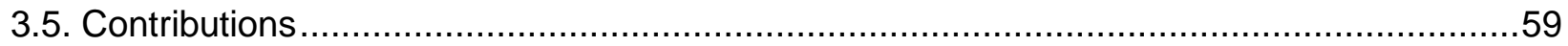

CHAPTER 4. Evaluation of Tolerance Liabilities of Novel UMB Opioid Ligands In Vivo............60

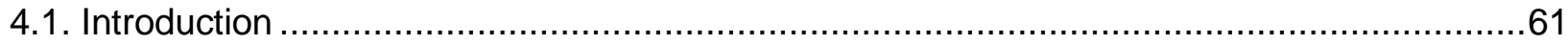

4.2. Methods

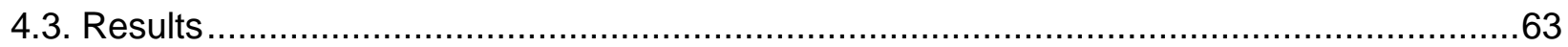

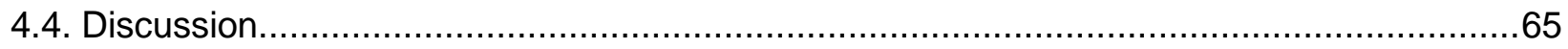

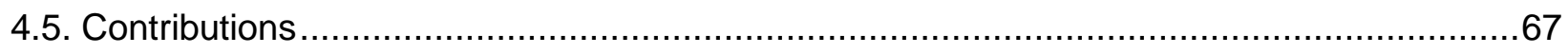




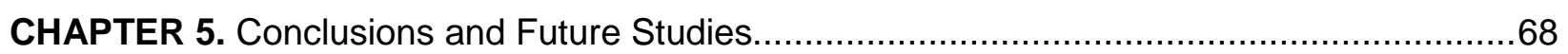

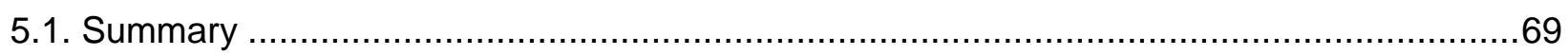

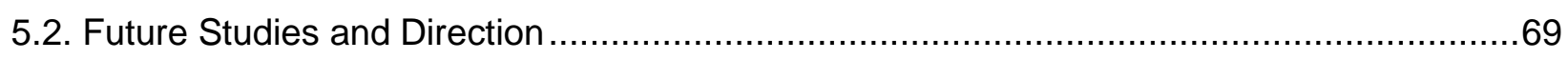

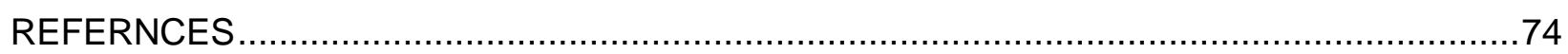

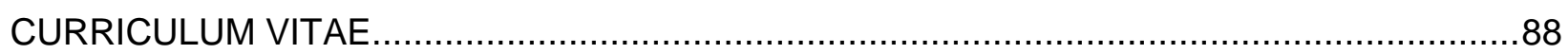




\section{LIST OF FIGURES}

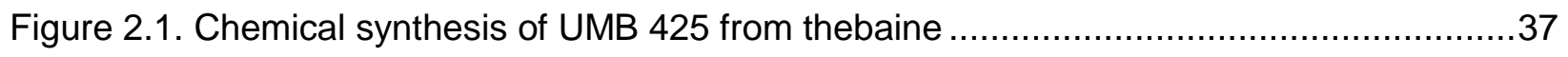

Figure 2.2. Compounds included in the $\delta$ receptor CSP training set...................................... 39

Figure 2.3. N-O distance and N-C9-O angle probability distributions.................................48

Figure 3.1. Acute dose- and time-response curves for s.c. morphine and UMB 425 treatment for the hot plate and tail-flick assays

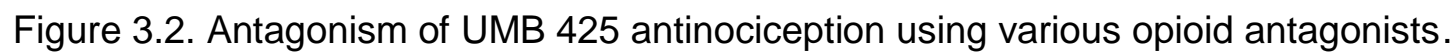

Figure 4.1. Antinociceptive tolerance development for morphine and UMB 425 for the hot plate and tail-flick assays. .64 


\section{LIST OF TABLES}

Table 1.1. Opioid narcotic chemical classifications. 15

Table 2.1. Top five $\delta$ receptor conformationally sampled pharmacophore models that define the final predictive model

Table 2.2. Comparison between experimental and calculated efficacy values for compounds in training set 41

Table 2.3. $\mathrm{K}_{\mathrm{i}}(\mathrm{nM})$ of standard opioid compounds at various subtypes ..................................41

Table 2.4. Chemical structure and binding affinities $\left(\mathrm{K}_{i} \mathrm{~S}\right)$ of UMB opioid ligands 42

Table 2.5. $\left[{ }^{35} \mathrm{~S}\right] \mathrm{GTP} \mathrm{S}$ results for standard opioid compounds: $\mathrm{EC}_{50}$ and $\% \mathrm{E}_{\max } \ldots \ldots \ldots \ldots \ldots \ldots . . . . . . . . .45$

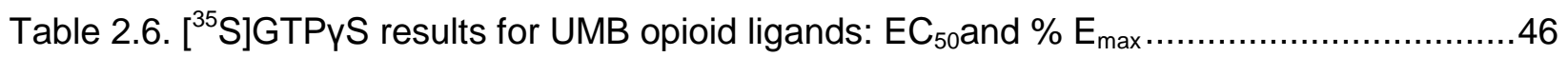

Table 2.7. $\left[{ }^{35} \mathrm{~S}\right] \mathrm{GTP}$ S results for standard opioid compounds and UMB ligands: $\mathrm{pA}_{2}$ .47

Table 3.1. $\mathrm{ED}_{50}$ values for morphine and UMB 425 in the acute treatment paradigm ...............56

Table 4.1. $\mathrm{ED}_{50}$ values for morphine and UMB 425 in the tolerance treatment paradigm .........65 


\section{ABBREVIATIONS}

5-HT, serotonin; 7TM, seven transmembrane; $A B C 1$, ATP binding cassette; $A C$, adenylate cyclase; ANOVA, analysis of variance; ASIC, acid-sensing ion channel; BBB, blood-brain barrier; $\mathrm{BCA}$, bicinchoninic acid; $\mathrm{BL}$, baseline latencies; $\mathrm{BSA}$, bovine serum albumin; BW373U86, ( \pm )-4-((a- $\left.R^{\star}\right)-\alpha-\left(\left(2 S^{\star}, 5 R^{\star}\right)-4-A l l y l-2,5\right.$-dimethyl-1-piperazinyl)-3-hydroxybenzyl)- $N, N$ diethyl-benzamide; $\mathrm{Ca}^{2+}$, calcium; cAMP, cyclic adenosine monophosphate; CGRP, calcitonin gene-related peptide; $\mathrm{CHO}$, Chinese hamster ovary; $\mathrm{CL}$, cutoff latency; CNS, central nervous system; COX, cyclooxygenase; CPM, counts per minutes; CSP, conformationally sampled pharmacophore; CREB, CAMP response element-binding protein; CYP450, cytochrome p450; DAMGO, [D-Ala ${ }^{2}, \mathrm{~N}-\mathrm{MePhe}^{4}$, Gly-ol]-enkephalin; DMEM, Dulbecco's modified Eagle's medium; DPDPE, [D-Pen ${ }^{2,5}$-enkephalin; (E)-BNTX, [(E)-benzylidenenaltrexone]; FBS, fetal bovine serum; GABA, v-aminobutyric acid; GDP, guanosine diphosphate; GIRK, G-protein gated inwardly rectifying potassium channel; G-protein, guanine nucleotide binding protein; GPCR, Gprotein coupled receptor; GRK, G-protein receptor kinase; GTP, guanosine triphosphate; GTPYS, guanosine 5'-O-[gamma-thio]triphosphate; hDOR, human $\delta$ opioid receptor; hKOR, human $\mathrm{k}$ opioid receptor; hMOR, human $\mu$ opioid receptor; i.p., intraperitoneal; IPSP, inhibitory postsynaptic potential; $\mathrm{K}^{+}$, potassium; LAH, lithium aluminum hydride; MAPK, mitogen-activated protein kinase; MPE, maximum possible effect; $\mathrm{Na}^{+}$, sodium; $\mathrm{NE}$, norepinephrine; NMDA, $\mathrm{N}$ methyl-D-aspartate; NOP-R, nociceptin receptor; nor-BNI, norbinaltorphimine; NSAIDs, nonsteroidal anti-inflammatory agents; Pd/C, palladium on carbon; PDYN, prodynorphin; PENK, proenkephalin; P-gp, P-glycoprotein; PKA, protein kinase A; PKC, protein kinase C; POMC, proopiomelanocortin; RGS protein, regulator of G-protein signaling; SAR, structure activity relationship; s.c., subcutaneous; S.E.M., standard error of the mean; SIOM, 7spiroindanyloxymorphone; $t_{1 / 2}$, half-life; THF, tetrahydrofuran; TL, testing latencies; TRP, transient receptor potential; Tyr-Gly-Gly-Phe-Met/Leu, Tyrosine-Glycine-Glycine-PhenylalanineMethionine/Leucine $\quad U 69,953, \quad N$-methyl-2-phenyl- $N-[(5 R, 7 S, 8 S)-7$-(pyrrolidin-1-yl)-1- 
oxaspiro[4.5]dec-8-yl]acetamide; UGT2B7, UDP-Glucuronosyltransferase-2B7; UMB 425, 4a,9dihydroxy-7a-(hydroxymethyl)-3-methyl-2,3,4,4a,5,6-hexahydro-1H-4,12-methanobenzofuro[3,2e]isoquinolin-7(7aH)-one; WHO, World Health Organization 


\section{CHAPTER 1}

\section{BACKGROUND AND OBJECTIVE}




\subsection{Pain Management}

Pain management is an ever-changing field, such that effective pharmacotherapeutic intervention is different from one patient to the next. While the definition of pain is continuously debated, an all-encompassing definition stems from the International Association for the Study of Pain Committee on Taxonomy, which defines pain as "an unpleasant sensory and emotional experience associated with actual or potential tissue damage, or described in terms of such damage," where furthermore, "Pain is always subjective. Each individual learns the application of the word through experience related to injury in real life (1)."

1.1.1. Pain Terminology. Pain is an elaborate pathological condition(s) that can be categorized based on the manifestation of symptoms. Acute pain persists up until noxious stimuli are removed or until the underlying pathological condition subsides (2). On the contrary, chronic pain persists for an extended period of time and is defined as "pain that extends beyond the expected period of healing (3)." These definitions of pain are overly simplified; more focused terminology addresses the array of pain sensations felt in these conditions. Nociceptive pain occurs as a result of nociceptor stimulation and is categorized as visceral, deep somatic or superficial somatic pain. Visceral pain is diffuse, dull and difficult to localize (4). Deep somatic pain is a result of sprains and broken bones that activate nociceptors in muscles, bones and/or joints (5). Superficial somatic pain is induced by nociceptors in the skin and is sharp and localized (6). Neuropathic pain is persistent and is a result of malfunction to the nervous system leading to a loss of sensation or paraesthesic and dysesthesic sensations that are abnormal and uncomfortable (7). Phantom pain sensations stem from an absent limb whether by amputation or congenital limb deficiency (8).

1.1.2. WHO Pain Assessment. The World Health Organization (WHO) was the first to develop a set of guidelines for the use of drugs for pain management. Medical care providers assess and treat patient pain using a wide array of agents ranging from non-opioid drugs with low side-effect liabilities to potent opioid narcotics. Paracetamol and non-steroidal anti- 
inflammatory agents (NSAIDs) are traditionally used for the treatment of mild pain and induce their effects via cyclooxygenase (COX) enzymatic inhibition, thereby reducing prostaglandin inflammatory mediator production. However, these drugs lack the efficacy to be used solely in more severe pain states. Opioid narcotics encompass a wide variety of drugs used to treat moderate-to-severe pain, including the well-known drug morphine. Opioid narcotics are prescribed as a stand-alone or in combination with non-opioids (i.e. Percocet, Vicodin). These commercial formulations are readily available and are intended to reduce opioid-related side effects while providing ample pain-relief or "analgesia". The analgesic effect is a result of decreased pain perception, decreased pain reaction and/or increased pain tolerance. In addition, extended release formulations of opioid analgesics are readily available and designed to minimize tampering and misuse (9).

1.1.3. Adjuvants for Pain Management. Adjuvants are drugs that do not traditionally produce analgesia on their own, but produce synergistic effects when given in combination with analgesic agents. Adjuvants are prescribed during treatment as recommended by the medical care provider. Steroids (10), antidepressants (11), anti-arrhythmics (12), anti-convulsants (13), local anesthetics (13), anti-cholinergics (14), muscle relaxants (15) and $\alpha_{2}$ agonists (16) are adjuvant agents used for various pain states and are potential alternatives to opioid narcotics in certain conditions of chronic pain. In addition, the use of cannabinoids has also emerged as an attractive, albeit controversial, alternative to opioids (17). Unfortunately, adjuvants themselves are not without their share of side effects and concerns (18). As such, opioid narcotics continue to be the traditional standards for individuals suffering from cancer pain, post-operative pain or pain from other severe trauma $(19,20)$. Opioid narcotics induce a wide range of analgesic activity through numerous routes of administration, making them an ideal candidate for pain management pharmacotherapy. 


\subsection{Opioid Narcotics}

Opioid narcotics encompass a wide variety of psychoactive chemicals whose primary effects are induced through the central nervous system. The natural extract from the poppy plant papaver somniferum "opium" has been used therapeutically as far back as 2nd century Greece. Opium alkaloids isolated from the poppy plant are known as "opiates". Alkaloids include morphine, codeine, thebaine and other minor alkaloids. The term "opioid" refers to opioid narcotics that are at least part synthetic and are not found in nature. Opioid narcotics have long been associated with the treatment of moderate-to-severe pain, ranging from acute postoperative pain to long-term chronic pain of cancer patients. The most common physiological effects associated with opioid use include: sedation, dizziness, nausea, vomiting, constipation, physical dependence, tolerance and respiratory depression, while less common physiological effects include: hyperalgesia, immunologic and hormonal dysfunction, muscle rigidity and myoclonus (21).

1.2.1. Opioid Chemical Classifications. Opioid narcotics can be broken down into four classes (Figure 1.1): (i) phenanthrenes, (ii) benzomorphans, (iii) phenylpiperidines and (iv) diphenylheptanes (22). Phenanthrenes are considered the standard opioids and depict the classical opioid pharmacophore; this class is composed of strong agonists and includes morphine, codeine, hydromorphone and oxymorphone among others. The prototypical benzomorphan opioid is pentazocine, which exhibits mixed agonist/antagonist effects and produces undesirable dysphoric effects. Phenylpiperidine opioids include the strong agonist fentanyl and subsequent derivatives. The primary opioid in the diphenylheptane class is the agonist methadone. Lastly, tramadol is a unique opioid narcotic that does not fit into any of the four standard opioid classes and also been shown to interact with $y$-aminobutyric acid (GABA), catecholamine and serotonergic receptors (23). 
Table 1.1. Opioid narcotic chemical classifications.

\begin{tabular}{|l|l|}
\hline & Drug Name \\
\hline
\end{tabular}

Other than as an analgesic agent, opioids are prescribed for several other clinical indications. Dextromethorphan is an active ingredient common in many over-the-counter antitussive or "cough suppressing" drugs. Loperamide acts within the myenteric plexus of the 
large intestine to treat diarrhea. Buprenorphine and methadone are both indicated for the treatment of opioid dependence.

1.2.2. Opioid Pharmacokinetics. Opioid narcotics can be administered through numerous routes. The route of administration is largely responsible for onset of effect as well as the overall duration of action (24). The oral route of administration is most convenience for the patient. Oral preparations of the gold standard morphine result in lower rates of bioavailability due in part to presystemic metabolism but offers a longer duration of action than other routes of administration (25). Opioids that are highly lipophilic can be administered via intranasal, transdermal, sublingual routes of administration or even as a suppository (26). Additional routes of administration (i.e. subcutaneous, intramuscular, intrathecal) can prolong and produce heightened analgesic responses, but are inconveniently more invasive (26). Intravenous preparations of morphine act almost immediately, but do not readily cross the blood-brainbarrier like that of more lipohilic agents, including heroin (25).

Opioid narcotics are typically metabolized through phase I cytochrome p450 (CYP450) and phase II glucoronidation processes. Morphine undergoes phase II UDPGlucuronosyltransferase-2B7 (UGT2B7) metabolism (27) yielding it's two major metabolites, morphine-6-glucoronide and morphine-3-glucoronide, both of which are readily able to cross the blood-brain barrier (BBB) (25). Morphine-6-glucoronide is highly efficacious and more potent than morphine itself, thereby contributing to the overall analgesic activity of morphine (28). Morphine-3-glucoronide does not induce analgesia (29). The half-life $\left(t_{1 / 2}\right)$ of morphine is typically 2-3 hours, but can vary depending on the experimental factors and individual patients (30).

1.2.3. Clinical implications of opioid narcotics. Long term opioid pharmacotherapy continues to rise; the United States utilizes over $80 \%$ of the world's supply of opioids, including $99 \%$ of the hydrocodone supply (31). Regrettably, the incidental death rate also continues to rise, where increasing dosing regimens has led to increased cases of accidental overdose (32). 
Opioid intoxication is marked not only by respiratory depression but also drowsiness, euphoria and miosis (33). In cases of accidental overdose, opioid induced anoxia can result in death in as little as 1-3 hours (34). The therapeutically limiting side effects leave primary care physicians uneasy of their use as governing bodies are becoming increasingly circumspect (35-38). Unfortunately, this often leads to the undertreatment of patient pain (21). The subsequent consequences are costly as lost productivity is estimated to be greater than $\$ 60$ billion annually for active workers with pain (39). Adequate pre-surgical analgesia has been shown to decrease post-operative pain and recovery time (40). Furthermore, the overall well being of the patient is also at risk with so called "analgesic gaps" that arise during post-operative pain management (41).

Side effect liabilities can progressively worsen with the development of tolerance. Opioid-induced tolerance decreases drug potency, which is detrimental to patients as the discomfort from side effect liabilities outweighs reduced pain relief (42). Tolerance increases the risks of physical and psychological dependency, such that an individual can become addicted to their use and undergo withdrawal upon their discontinuation. Among psychotherapeutic drugs, opioid narcotics have the highest prevalence of abuse and dependence (43). A balance needs to be achieved that allows access to opioid narcotics for proper use while incorporating strategies to prevent potential misuse. As such, a novel opioid analgesic with reduced tolerance liabilities could potentially alleviate many of the concerns associated with opioid narcotic use, leading to reduced health care costs as well as provide increased economic and health benefits.

\subsection{Opioid Receptors}

Opioid receptors are seven transmembrane G-protein coupled receptors (44) located in the central nervous system, peripheral nervous system and gastrointestinal tract (45). They belong to the class A4 subfamily of seven transmembrane (7TM) G-protein coupled receptors (GPCRs) (46), coupling to heterotrimeric guanine nucleotide binding proteins (G-proteins), most notably pertussis-toxin sensitive $G_{i} / G_{0}$ proteins $(44)$, but also $G_{s}(47,48)$ and pertussis-toxin 
insensitive $G_{z}$ proteins (49). In 1973, an opiate receptor was first identified using radioligand binding techniques (50). To date three classical opioid receptor subtypes have been identified:

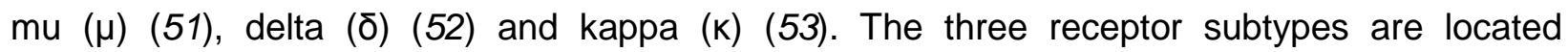
throughout the nervous system, in somatic and visceral sensory neurons, spinal cord projections and interneurons (45). Genes encoding each of the three opioid receptor subtypes have been isolated and are known as Oprm, Oprd1 and Oprk1 for the $\mu, \delta$ and $\mathrm{k}$ receptor subtypes, respectively (54). Genetic polymorphisms of human opioid receptor genes can alter analgesic activity as well as tolerance and dependence liabilities (55). The three classic receptor subtypes display $\sim 60 \%$ amino acid sequence identity $(44,56)$. The greatest homology is seen within the transmembrane helices and the most diversity is seen within the respective $\mathrm{N}$ - and $\mathrm{C}$ termini as well as the extracellular loops (56). Each receptor subtype also includes several characterized variants $\left(\mu_{1-3}, \delta_{1-2}, \mathrm{~K}_{1-3}\right)$ that are believed to develop during post-translational interactions with accessory proteins as well as the formation of opioid receptor complexes (5761). Opioid receptor subtype variants are suggested to play similar roles in pain modulation and antinociception within that specific receptor subtype (62). Exogenous opioids induce their effects by mimicking endogenous opioid peptides.

1.3.1. Endogenous Opioid Peptides. The three well-characterized families of endogenous opioid peptides are the endorphins, enkephalins and dynorphins, which are primarily selective for the $\mu, \delta$ and $k$ receptor subtypes, respectively (63). All opioid peptides share a common N-terminal amino acid motif Tyrosine-Glycine-Glycine-PhenylalanineMethionine/Leucine (Tyr-Gly-Gly-Phe-Met/Leu) (64). The aromatic "A" ring of the traditional opioid pharmacophore is believed to mimic the Tyr residue that begin each opioid receptor peptide sequence (65). C-terminal extensions of this motif are unique for opioid peptides, ranging from 5 to 31 residues (57). Anatomical regions associated with nociception (e.g. the spinal cord, thalamus, periaqueductal gray, midbrain, limbic system and cortex) all contain neurons containing endogenous opioid peptides (62). Each of the three families is derived from 
distinct precursor proteins, termed proopiomelanocortin (POMC), proenkephalin (PENK) and prodynorphin (PDYN) respectively, each of which is encoded by their corresponding gene.

POMC undergoes post-translational modifications resulting in different biologically active endorphins, including the $\mu$-selective ligand $\beta$-endorphin (66). Endorphins regulate physiological responses to stress and pain, producing analgesia as well as a state of well being (67). Endomorphins (i.e. endomorphin-1, endomorphin-2) are endogenous opioid tetrapeptides that also have high affinity for the $\mu$ receptor subtype (68). Unlike endorphins, endomorphins have not yet been linked as cleavage products to a larger precursor protein. Both have been shown to produce antinociceptive or "pain-relieving" effects (68). Furthermore, endomorphin-1 is thought to regulate sedation and arousal behaviors (69).

The PENK gene has similar structural organization to the human POMC gene (70). Posttranslational modifications result in the formation of the $\delta$-selective pentapeptides metenkephalin and, to a lesser extent, leu-enkephalin (71), located in both central and peripheral nervous system regions (72). Enkephalins have vital regulatory roles associated with pain perception, anxiety as well as aggression (73).

PDYN post-translational modifications produce $\mathrm{K}$-selective dynorphins, specifically dynorphin $A$, dynorphin $B$ and $\alpha / \beta$ neoendorphins (74). Primary dynorphin-induced effects concern the stress responses of analgesia, dysphoria and anxiety (75).

Genetic targeting has furthered research in vivo, as mice lacking the respective receptor subtypes and endogenous peptides have uncovered the physiological functionalities of opioid receptors. Mice that are $\mu$ receptor subtype deficient have shown complete reductions in physiological responses to morphine, including: analgesia, reward, withdrawal, respiratory depression, constipation, hyperlocomotion and immunosupression $(76,77)$. However, $\mu$ receptor subtype deficient mice treated with $\delta$ agonists also demonstrated reduced antinociceptive capabilities compared to wild-type mice, suggesting cross-interactions between the $\mu$ and $\delta$ receptor subtypes $(78,79)$. As expected, $\delta$ receptor subtype deficient mice failed to 
maintain antinociceptive properties when treated with $\delta$ agonists (80). $\mathrm{k}$ receptor subtype deficient mice confirm the critical role of the receptor in visceral pain perception, antinociception, hypolocomotion and dysphoria (81).

1.3.3. Nociceptin Receptor. The nociceptin receptor (NOP-R) is sometimes classified as the fourth opioid receptor, whose endogenous peptide is known as nociceptin/orphanin FQ (82, 83) and is encoded by the OPRL1 gene (84). Nociceptin is derived from the pronociceptin protein (85). NOP-R shares $\sim 60 \%$ sequence homology with the three classical opioid receptor subtypes (86). However, NOP-R does not exhibit binding affinity for traditional opioid ligands like that of the three classical subtypes (44). Furthermore, the peptide nociceptin does not act at the traditional opioid receptor subtypes nor are its actions antagonized by the non-selective opioid antagonist naloxone (87). While NOP-R activity is linked to nociception (88), the NOP-R has been shown to induce some differing physiological responses to that of the classical opioid receptor subtypes (86). Furthermore, nociceptin-induced effects have also been linked to opioidinduced hyperalgesia (89).

\subsection{Opioid Mechanism of Action}

Opioid analgesic activity is primarily associated with the activation of $\mu$ receptors located within the central nervous system (77). Specifically, spinal and supraspinal analgesia are induced through ascending and descending pathways (90). Nervous system regions involved in pain transmission include nociceptor fibers, the spinal cord, the midbrain and the thalamus (62). Nociception is "the neural processes of encoding and processing noxious stimuli," (91) noxious stimuli being of thermal, chemical and/or mechanical means detected by sensory nociceptor fibers (92). Families of ion channel transducers (i.e. transient receptor potential (TRP) channel, acid-sensing ion channel (ASIC)) respond to noxious stimuli by activating voltage-dependent sodium $\left(\mathrm{Na}^{+}\right)$channels and initiating action potentials through nociceptor fibers projected to the dorsal horn of the spinal cord (92). There are two types of nociceptor fibers imperative in pain transmission signaling to the dorsal horn of the spinal cord; thinly myelinated $A \delta$-fibers sense 
the initial quick and shallow first pain and unmyelinated C-fibers that respond slowly to nonspecified high intensity stimuli (93).

1.4.1. Spinal Analgesia. Opioids induce spinal analgesia by activating pre-synaptic and post-synaptic opioid receptors resulting in decreased ascending neurotransmitter signaling from peripheral afferent fibers. Pre-synaptic activation of the classical opioid receptor subtypes decreases calcium $\left(\mathrm{Ca}^{2+}\right)$ influx, which in turn decreases pain-modulating neurotransmitter release into the synapse of the dorsal horn of the spinal cord. Post-synaptic activation of $\mu$ receptors alters potassium $\left(\mathrm{K}^{+}\right)$channel conduction creating an inhibitory postsynaptic potential (IPSP) and ultimately depressing neuronal transmission. These neurotransmitters include tachykinin, substance $P$, glutamate and calcitonin gene-related peptide (CGRP) (94, 95). Other chemicals released at the site of injury include amines (e.g. histamine and serotonin) and excitatory amino acids (e.g. glutamate and aspartate) (96). Increased levels of prostaglandin inflammatory mediators enhance pain sensations (96).

1.4.2. Supraspinal Analgesia. At the supraspinal level, analgesic effects are mediated by the activation of serotonergic and noradrenergic systems. Specifically, $\mu$ opioid receptor activation results in the disinhibition of GABA conitaining neurons synapsing on serotonin $(5-\mathrm{HT})$ and norepinephrine (NE) neuronal pathways $(90,97) . \mu$ receptor activation decreases $\mathrm{Na}^{+}$and $\mathrm{Ca}^{2+}$ influx and inhibits GABA neurotransmitter release. This prevents GABA-mediated inhibition upon descending 5-HT and NE containing neurons. Increased 5-HT and NE neurotransmitter release decreases pain sensation via descending pain transmission that terminates in the dorsal horn of the spinal cord.

1.4.3. Cellular Responses to Opioids. As mentioned, opioid receptors are GPCRs that primarily induce their effects through the recruitment of pertussis toxin-sensitive $G_{i} / G_{0}$ proteins. At the cellular level, opioid agonist binding results in the activation of a heterotrimeric G-protein complex consisting of a $\mathrm{G}_{\alpha}$-guanosine diphosphate (GDP) and a $\mathrm{G}_{\beta \gamma}$ subcomplex. GDP bound to the $G_{a}$ subcomplex is replaced by guanosine triphosphate (GTP), thereby forcing a 
dissociation of both the $G_{\alpha}$ and $G_{\beta \gamma}$ subcomplexes. Both the $G_{\alpha}$ and $G_{\beta \gamma}$ subcomplexes mediate second messenger and effector activity. Finally, GTPase activity, where GTP is hydrolyzed to GDP, enables the reassociation of the $G_{\alpha}$ and $G_{\beta y}$ subcomplexes with the GPCR. GTPase activity is be modulated by regulators of G-protein signaling (RGS proteins) that can influence the exchange of GTP for GDP bound to the $\mathrm{G}_{\alpha}$ subcomplex (98).

Traditional responses of second messengers and effectors are associated with the inhibition of vesicular neurotransmitter release and signaling due to the inhibition of adenylate cyclase $(\mathrm{AC})$, the inhibition of $\mathrm{Ca}^{2+}$ influx through voltage sensitive $\mathrm{N}$-type channels and the activation of G-protein gated inwardly rectifying potassium channels (GIRKs) (99). Additional studies have linked opioid-induced effects via the activation of protein kinase C (PKC) (100) and the mitogen-activated protein kinase (MAPK) cascade (99), as well as the release of $\mathrm{Ca}^{2+}$ ions from internal stores (101). These effects can direct transcription factor pathways and influence signaling stemming from the plasma membrane to the nucleus (102).

\subsection{Opioid Induced Tolerance}

The mechanisms regarding opioid induced tolerance remain elusive with no clinically viable therapeutic agent shown to prevent it. In terms of opioid narcotic use, tolerance requires escalating dosages to provide adequate pain relief. In turn, susceptibility to additional opioidinduced side effects markedly increases. Several hypotheses have been drawn as to the underlying components of tolerance.

1.5.1. Role of Receptor Internalization. Upon receptor activation, opioid receptors traditionally undergo regulatory mechanisms including receptor desensitization, internalization, down-regulation and resensitization processes through receptor phosphorylation via GPCR kinases (GRKs) and the recruitment of $\beta$-arrestins, clathrin and other adapter proteins (103). Simply, the phosphorylated GPCR is bound to $\beta$-arrestin cytosolic proteins that uncouple the receptor from its respective G-protein and signal for clathrin-coated receptor internalization (104). Upon proper internalization, the receptor can become resensitized and return to the 
cellular surface for further activation. Partial $\mu$ agonists, including morphine, are unable to properly replicate receptor internalizing mechanisms upon prolonged exposure $(105,106)$. The resulting effect is an uncoupling of the G-protein from the receptor, leading to receptor desensitization, or reduced responsiveness, of signaling mechanisms (103). Other $\mu$ agonist classes and their respective compounds have demonstrated variations in this initial hypothesis, where tolerance develops from multiple points within the endocytotic machinery (107). For example, the highly efficacious $\mu$ agonist etorphine undergoes proper internalization mechanisms upon chronic exposure, but instead induces tolerance through excessive downregulation of $\mu$ receptors (108).

1.5.2. Adenylate Cyclase Superactivation. AC superactivation is another highly popular mechanistic theory surrounding opioid-induced tolerance (109). As described above, opioid receptors are members of the $G_{i} / G_{0}$ superfamily of GPCRs that inhibit AC. Research suggests that prolonged exposure to $\mu$ agonists, including morphine, results in adaptive changes promoting upregulation of the AC pathway $(110,111)$. This leads to increased concentrations of cyclic adenosine monophosphate (CAMP), thereby leading to protein kinase A (PKA) and, subsequently, cAMP response element-binding protein (CREB) activation (112-116). Elevated cAMP levels are responsible for alterations in gene expression as well as neurotransmitter release $(109,117)$. The mechanisms surrounding these upregulations are still not clear, though may include modified protein phosphorylation $(47,118)$, receptor coupling to the $G_{s}$ family of $G$ proteins $(119,120)$, involvement of the $\mathrm{G}_{\beta \gamma}$ subcomplex (121) or possible upregulation in constitutive receptor activity (122-124). It is clear that AC superactivation can lead to potential transcriptional changes involved in long-term regulation of other proteins involved in cell function.

1.5.3. P-glycoprotein Upregulation. P-glycoprotein (P-gp), a member of the ATP binding cassette (ABC1) family, is an efflux transporter that has been implicated in opioid-induced tolerance $(125,126)$. P-gp expression is noted within the BBB, with the purpose of maintaining 
the integrity of the central nervous system (CNS). P-gp has been shown to influence the pharmacokinetic and pharmacodynamic profiles of drugs that are substrates of this transporter (127). Several opioid analgesics, including morphine and oxycodone, have been classified as Pgp substrates that upregulate P-gp expression levels upon chronic administration, thereby reducing antinociceptive effects. Current studies look to further identify P-gp invovlement in opioid-induced tolerance by synthesizing novel opioid compounds with reduced P-gp interactions (128-130).

\subsection{Mu/Delta Opioid Receptor Interactions}

Evidence suggests that opioid narcotics may induce their physiological effects through dimeric and oligomeric complexes formed from the opioid receptor subtypes. Specifically, the $\mu$ and $\delta$ receptor subtypes have been shown to exist as hetero-dimeric (131) as well as heterooligomeric complexes $(132,133)$. It is known that $\delta$ receptor activation produces minimal analgesic activity on its own (134). However, the physiological association between the $\mu$ and $\delta$ receptor subtypes has been shown to improve ligand binding at each subtype through allosteric modulation (135), leading to enhanced analgesic effects (136). In addition, both the $\mu$ and $\delta$ receptor subtypes have been shown to exist on similar neuron populations, such that cell signaling through one receptor subtype is influenced by activation of the other (137).

1.6.1. Joint $\mu$ and $\delta$ Opioid Receptor Subtype Studies. Synergistic analgesic effects have been reported when $\delta$-selective agonists are given in conjunction with traditional $\mu$ agonists (138). Unfortunately, it is believed that simultaneous $\delta$ receptor activation with that of the $\mu$ receptor may play a role in the side effect liabilities associated with chronic opioid use, including tolerance (139). Further exploration has shown that $\delta$-selective antagonists given in conjunction with $\mu$ agonists, including morphine, can elicit potent analgesic properties whilst reducing tolerance liabilities $(139,140)$. In addition, low doses of the non-selective opioid antagonist naloxone have been shown to retain or potentiate analgesia while attenuating tolerance and dependence liabilities $(141,142)$, by antagonizing $G_{s}$ protein induced excitatory functions (143). 
These results have been further confirmed by $\delta$ receptor knockout (144) and antisense oligonucleotide studies (145-147). These findings suggest that opioid ligands depicting dual effects of $\mu$ agonism and $\delta$ antagonism can be effective for patients whom require chronic opioid pain management such that adequate analgesia is achieved with reduced tolerance liabilities.

1.6.2. Mixed $\mu$ Agonist/ $\delta$ Antagonist Opioid Ligands. Opioid peptides depicting dual effects of $\mu$ agonism and $\delta$ antagonism have been synthesized in order to help pinpoint the optimal structural and conformational features needed for binding affinity and functional activity at the selected receptor subtypes $(148,149)$. Several designs have been successful in identifying such peptides, including those that have reduced tolerance liabilities compared to traditional opioid analgesics (150). While useful as research tools, opioid peptides are not clinically viable options for universal human use.

A single opioid agent depicting mixed $\mu$ agonism/ $\delta$ antagonism is more advantageous for clinical use than relying on patient compliance with multiple drugs. The identification of nonpeptidic opioid analgesics which display these properties could convey therapeutic advantages compared to peptides, with regards to ease of administration and delayed metabolic breakdown. Several approaches towards this goal have been undertaken, specifically the characterization of bivalent and bifunctional opioid ligands. Portoghese et al. introduced the concept of bivalent ligands, compounds that embody two specific pharmacophores connected via an optimized linker (151). Bivalent ligands containing both selective $\mu$ agonist and $\delta$ antagonist derived pharmacophores have been shown to exhibit greater analgesic effects, while also reducing tolerance and physical dependence liabilities (152). As previously discussed, the existence of hetero-oligomeric opioid receptor complexes, including a $\mu-\delta$ complex (132), suggests that bivalent opioid ligands are a viable therapeutic tool. However, the physiochemical properties of bivalent ligands may prove problematic with regards to an oral absorption formulation (153).

Bifunctional ligands are based on a single pharmacophore that encompass two binding sites with functional activity distinct for each of the respective sites (154). This approach ideally 
circumvents potential problematic characteristics pertaining to bivalent ligands. Bifunctional ligands include structural moieties seen in traditional $\mu$ agonists as well as $\delta$ antagonists. Ligands depicting mixed $\mu$ agonism/ $\delta$ antagonism functionalities have displayed potent analgesic activity with reduced side effect liabilities, including tolerance $(155,156)$. Previously developed bifunctional ligands explore series of pyridomorphinan and pyrrolomorphinan frameworks derived from non-selective antagonists (i.e. naloxone) as well as highly efficacious $\mu$ agonists (i.e. oxymorphone and hydromorphone) (157). However, those developed are traditionally characterized in vivo by intracerebroventricular administration, a method unsuitable for wide spread therapeutic use. Therefore, in vivo studies need to be performed using less invasive methods that can effectively corroborate reduced tolerance liabilities seen via intracerebroventricular administration.

\subsection{Objectives}

While moderate-to-severe pain management has relied on the use of opioid narcotics, the therapeutically limiting side effects associated with their use remain controversial and has led to the undertreatment of patients. For the past few decades opioid narcotics have been prescribed more readily. However, incidental deaths have risen with increasing dosing regimens. This suggests that opioid-induced tolerance is of major clinical concern, whereby increased use can exacerbate side effect liabilities.

Opioid-induced analgesia is primarily induced through the activation of $\mu$ receptors located within the CNS. It has been shown that $\delta$ antagonists given in conjunction with traditional $\mu$ agonists can maintain potent analgesic properties while reducing the side effect liabilities, specifically tolerance. Our hypothesis is that a novel compound displaying dual properties of $\mu$ agonism and $\delta$ antagonism can be created to provide potent analgesic relief with reduced tolerance liabilities.

A single compound that demonstrates dual effects of $\mu$ agonism and $\delta$ antagonism has several practical clinical advantages over the co-administration of a traditional $\mu$ agonist (i.e. 
morphine) and a $\delta$ antagonist. Patient compliance is always of concern, such that the administration of one is drug is preferred over two drugs. A multicomponent drug regimen can prove problematic if not taken as prescribed, resulting in less than optimal therapeutic levels and poor treatment outcomes (153). Furthermore, it has been shown that antagonism at the $\delta$ receptor must occur simultaneously with agonism at the $\mu$ receptor in order to prevent tolerance development (158). Finally, the abuse liability of traditional $\mu$ agonists can be troublesome, as patients can divert from their therapeutic intent (159). As a result, compounds depicting mixed $\mu$ agonist/ $\delta$ antagonist properties are anticipated to possess reduced abuse liabilities.

Novel UMB opioid ligands have been synthesized by our collaborators at the University of Maryland-Baltimore, under the tutelage of Dr. Andrew Coop. To test our hypothesis, the following specific aims will be addressed:

1. To confirm targeted receptor binding affinities and functionalities of novel UMB opioid ligands in vitro (Chapter 2). Novel UMB opioid ligands were synthetically designed with the intentions of demonstrating agonistic effects through the $\mu$ receptor, whilst having antagonistic effects through the $\delta$ receptor. Confomationally Sampled Pharmacophore (CSP) modeling studies will be utilized to predict ligand functionality at the three receptor subtypes. Binding affinities will be tested at each of the three receptor subtypes using radioligand binding assays. $\left[{ }^{35}\right.$ S]guanosine 5'-O-[gamma-thio]triphosphate (GTPYS) functional assays will be performed to determine the agonistic/antagonistic properties of UMB opioid ligands for the three receptor subtypes.

\section{To demonstrate antinociceptive effects of novel UMB opioid ligands in vivo (Chapter}

3). The acute antinociceptive effects of novel UMB opioid ligands will be determined using tailflick and hot plate thermal nociceptive assays. Antagonist pre-treatment studies will be performed to ensure that the acute effects are induced through opioid mechanisms.

\section{To demonstrate reduced tolerance liabilities of novel UMB opioid ligands in vivo}

(Chapter 4). Mice will undergo a chronic UMB opioid ligand administration regimen to determine 
tolerance development. It is anticipated that the level of UMB opioid ligand induced chronic tolerance will be significantly less than that of morphine itself.

The primary goal of this study is to develop at least one UMB opioid ligand that maintains potent antinociceptive properties while reducing the side effect liabilities associated with chronic opioid use, specifically tolerance. In addition, the studies herein will further advance opioid structure activity relationships (SAR), specifically those of mixed $\mu / \delta$ activity, with respect to the chemical structure modifications and the subsequent pharmacological profiles.

\subsection{Contributions}

All compounds, including UMB 425, were synthesized by the laboratory of Dr. Andrew Coop at the University Of Maryland School Of Pharmacy in Baltimore, Maryland. Pharmacological profiling of all compounds was performed by Jason R. Healy at West Virginia University. 


\section{CHAPTER 2}

STRUCTURAL OPTIMIZATION OF MIXED MU AGONIST/DELTA ANTAGONIST LIGANDS 


\subsection{Introduction}

The synthetic design rationale for mixed $\mu$ agonist/ $\delta$ antagonist opioid ligands stems from the message-address concept first proposed by Robert Schwyzer with regards to adrenocorticotrophic hormones (160) and later adapted by Portoghese and colleagues for the development of non-peptidic opioid ligands (65). Endogenous opioid peptides all share the same tetrapeptide amino acid sequence (Tyr-Gly-Gly-Phe) that can be viewed as the "message" sequence; the message sequence is involved in receptor affinity and downstream signaling. The remaining amino acid sequences of endogenous opioid peptides are viewed as "address" sequences, which provide selectivity as well as additional binding affinity. This concept allows for the design of opioid receptor subtype specific ligands, the $\delta$-selective antagonist naltrindole one of the first. Naltrindole incorporates an indole functional group fused to the " $\mathrm{C}$ " ring of the non-selective opioid antagonist naltrexone, in turn mimicking the $\delta$-selective opioid peptide enkephalin. Thus, the message-address concept introduced conceptual frameworks that enabled researchers to design ligands that could effectively manipulate interactions at the specific opioid receptor subtypes.

Traditional opioid SAR focuses on substituents at one position of the opioid skeleton which allows for the formation of predictive models. Unfortunately, further studies utilize additional substituents at other positions on the opioid skeleton which typically negates previous SAR. Thus, consensus pharmacophore models of opioid ligands at the receptor subtypes remain elusive. However, CSP modeling studies utilize all possible structural configurations between critical functional groups, termed "pharmacophoric descriptors", of opioid ligands in order to create representative pharmacophoric models at each of the opioid receptor subtypes (161). Previous opioid SAR models were traditionally used to predict binding affinities. CSP models are unique in that they utilize functional data from known ligands to best predict efficacy values, thereby predicting the agonistic and antagonistic properties of novel opioid ligands at each of the opioid receptor subtypes. CSP modeling takes into account all geometric angles and 
distances between pharmacophoric descriptors, with the consideration that the most stable lowenergy structural configuration of a ligand may not occur upon receptor binding (162-164). CSP models for $\mu$ receptor ligands employ the aromatic "A" ring, basic nitrogen, $N$-substituent and the "C" ring hydrophobic substituent as the respective pharmacophoric descriptors; these functional groups are deemed the most significant for efficacy at the $\mu$ receptor (161). Pharmacophoric descriptors included in $\delta$ receptor CSP modeling are consistent with those of the $\mu$ receptor, with the exception of the $N$-substituent $(165,166)$.

The design of ligands herein is unique and stems from a class of potent $\mu$ agonists, the orvinols (i.e. etorphine). In addition, the orvinols are also known to interact with the $\delta$ and $\mathrm{k}$ receptor subtype, typically displaying agonism at the $\delta$ receptor subtype (167). It is hypothesized that efficacy at the $\delta$ receptor subtype can be minimized with the introduction of a benzene ring containing moieties seen in two classes of low efficacy $\delta$-selective opioid ligands, specifically the indolomorphinans (e.g. naltrindole) (168) and the opioid benzylidenes (e.g. BNTX) (169). Furthermore, the orvinol series includes 6,14-bridged-morphinan based ligands, a structural moiety that can potentially be modified to influence functionality at the respective opioid receptor subtypes $(170,171)$. As such, specified ligands primarily are or are precursors to 5,14-bridged-morphinan based ligands with the intent of identifying a mixed $\mu$ agonist/ $\delta$ antagonist opioid analgesic with reduced tolerance liabilities.

For all pharmacological testing in vitro, Chinese Hamster Ovary (CHO) cells stably transfected with and overexpressing the three opioid receptor subtypes are used. The rationale for the use of immortalized cell lines, compared to primary tissue membrane, is to isolate receptor subtypes such that data obtained is specific for that subtype alone. Opioid receptor subtypes have been shown to form homo- as well as hetero-dimer (131) and -oligormeric (132, 133) complexes which can influence binding and functionality. As such, it is plausible that the in vitro pharmacological profile may not parallel results obtained in vivo. However, past studies 
have shown that pharmacological activity with the use of isolated cell lines correlate well with results seen in tissue membrane (172).

Competition binding assays are initially performed in vitro to ensure desired interactions between novel compounds with specified receptors. These studies are performed in a recently adopted 96-well format; assay validation using conventional opioid ligands was performed prior to testing of novel ligands. [D-Ala ${ }^{2}, \mathrm{~N}-\mathrm{MePhe}^{4}$, Gly-ol]-enkephalin (DAMGO), [D-Pen ${ }^{2,5}$ ]enkephalin (DPDPE) and U69,593 are synthetic subtype specific opioid ligands used as the positive and negative control standards for the $\mu, \delta$ and $\mathrm{k}$ receptor subtypes, respectively. Radioactive preparations of $\left[{ }^{3} \mathrm{H}\right] \mathrm{DAMGO},\left[{ }^{3} \mathrm{H}\right] \mathrm{DPDPE}$ and $\left[{ }^{3} \mathrm{H}\right] \mathrm{U} 69,593$ are used as the "hot" ligand standards during competition binding assays for the $\mu, \delta$ and $\mathrm{k}$ receptor subtypes, respectively.

$\left[{ }^{35} \mathrm{~S}\right] \mathrm{GTPYS}$ functional assays allow for the determination of the functionalities, or agonist and antagonistic properties, of GPCRs, a family that includes opioid receptors. DAMGO, DPDPE and U69,593 are all highly efficacious agonists and, consistent with previous studies, bookmarked as the $100 \% \mathrm{E}_{\max }$ standards for the $\mu, \delta$ and $\mathrm{k}$ receptor subtypes, respectively.

Morphine and codeine were chosen as drug standards for competition binding and $\left[{ }^{35}\right.$ S]GTPYS functional assays performed in vitro, since they are two readily prescribed opioid narcotics used for pain management. Side-by-side comparisons of our novel compounds with commonly used analgesic agents will provide initial indications for potential clinical viability. In addition, the non-selective opioid antagonists, naloxone and naltrexone, are also used as drug standards. Naltrexone is used to validate antagonistic effects in $\left[{ }^{35}\right.$ S GTPYS functional assay preparation.

\subsection{Methods}

2.2.1. Competition Binding Assays. Chinese hamster ovary ( $\mathrm{CHO}$ ) cells were stably transfected with and overexpress the human $\mu$ opioid receptor (hMOR-CHO), the human $\delta$ opioid receptor (hDOR-CHO) or the human k opioid receptor (hKOR-CHO). Cells were grown in 
150-mm dishes (Fisher Scientific, Hanover Park, IL) in DMEM supplemented with 10\% FBS, penicillin-streptomycin and $\mathrm{G} 418$ at $37{ }^{\circ} \mathrm{C}$ in a $5 \% \mathrm{CO}_{2}$ atmosphere. Specifically, DMEM:F12 (1:1) with HEPES, L-Gln solution was used when preparing hMOR-CHO and DMEM $4.5 \mathrm{~g} / \mathrm{l}$ glucose was used when preparing hDOR-CHO and hKOR-CHO. At $80-90 \%$ confluency, cells were scraped from dishes and centrifuged at $2200 \mathrm{RPM}$ for $12 \mathrm{~min}$ at $4{ }^{\circ} \mathrm{C}$. Cell pellets were resuspended in $50 \mathrm{mM}$ Tris buffer, $\mathrm{pH}$ 7.7, and homogenized using a Polytron, then spun down twice more at 13500 RPM for $20 \mathrm{~min}$ at $4{ }^{\circ} \mathrm{C}$. Membrane was suspended in $50 \mathrm{mM}$ Tris buffer, $\mathrm{pH}$ 7.7, at protein concentrations of about $3 \mathrm{mg} / \mathrm{mL}$ for hMOR-CHO and hKOR-CHO and 4 $\mathrm{mg} / \mathrm{mL}$ for hDOR-CHO. Membranes were aliquoted into polypropylene tubes and frozen at -80 ${ }^{0} \mathrm{C}$ for future use. Protein concentration was determined using BCA reagent and BSA protein standard provided by the manufacturer (Pierce, Rockford, IL).

Membranes were incubated with 10-12 concentrations of drug (0.001-100,000 nM) and radiolabeled ligand in $50 \mathrm{mM}$ Tris buffer, $\mathrm{pH} \mathrm{7.7,} \mathrm{at} \mathrm{a} \mathrm{final} \mathrm{volume} \mathrm{of} 1 \mathrm{~mL}$. $\mu$ receptors were labeled using $1.3 \mathrm{nM}\left[{ }^{3} \mathrm{H}\right] \mathrm{DAMGO}$. $\delta$ receptors were labeled using $1.2 \mathrm{nM}\left[{ }^{3} \mathrm{H}\right] \mathrm{DPDPE} . \mathrm{k}$ receptors were labeled using $1.7 \mathrm{nM}\left[{ }^{3} \mathrm{H}\right] \mathrm{U} 69,593$. Non-specific binding was determined using non-labeled equivalents at each receptor subtype: $10 \mu \mathrm{M}$ DAMGO, $1 \mu \mathrm{M}$ DPDPE and $10 \mu \mathrm{M}$ U69,593. Each concentration was tested in triplicates of duplicates with a total volume of $1 \mathrm{~mL}$ for each well. Following a 60 min incubation period reactions were terminated via rapid vacuum filtration over Perkin Elmer Unifilter®-96, GF/B filters (Fisher Scientific, Hanover Park, IL) that were presoaked in $0.5 \%$ polyethyleneimine (173) for $30 \mathrm{~min}$. After filtration, filters were washed three times with $1.5 \mathrm{~mL}$ of cold $50 \mathrm{mM}$ Tris buffer, $\mathrm{pH} 7.7$ and counted in $40 \mu \mathrm{L}$ of Perkin Elmer Microscint 20 (Fisher Scientific, Hanover Park, IL). Mean $K_{i}$ values \pm S.E.M. were determined performing experiments in triplicates of duplicates and calculated using $\mathrm{K}_{d}$ values obtained during saturation binding assays and the Cheng-Prusoff equation (174). Respective $\mathrm{K}_{\mathrm{d}}$ values are $2.3,2.4$ and $2.4 \mathrm{nM}$ for the $\mu, \delta$ and $\mathrm{k}$ receptor subtypes, respectively. 
2.2.2. $\left[^{35}\right.$ SJGTPYS Functional Assays. Membrane preparation for $\left[{ }^{35} \mathrm{~S}\right] \mathrm{GTP \gamma S}$ binding was similar to the aforementioned opioid binding studies, with the exception that $\mathrm{CHO}$ cells expressing hMOR, hDOR and hKOR were resuspended in a final solution ("Buffer A") consisting of $100 \mathrm{mM} \mathrm{NaCl}, 10 \mathrm{mM} \mathrm{MgCl}_{2}, 20 \mathrm{mM}$ Hepes, $\mathrm{pH}$ 7.4. Membranes were incubated with 10-12 concentrations of drug and $0.1 \mathrm{nM}\left[{ }^{35} \mathrm{~S}\right] \mathrm{GTPYS}$ in "Buffer A" at a final volume of $1 \mathrm{~mL}$. Basal activity was determined in the presence of exogenous GDP $(10 \mu \mathrm{M})$ in the absence of agonist; exogenous GDP is required for all samples, basal or otherwise, to suppress the unstimulated basal radioligand binding to the G-protein. Non-specific binding was determined in the presence of $10 \mu \mathrm{M}$ unlabelled GTPYS. Following a 60 min incubation period, reactions were terminated via rapid vacuum filtration over Perkin Elmer Unifilter®-96, GF/B filters that were presoaked in a $1 \%$ bovine serum albumin (BSA) solution for $30 \mathrm{~min}$. After filtration, filters were washed three times with a total of $1.5 \mathrm{~mL}$ of cold $50 \mathrm{mM}$ Tris buffer, $\mathrm{pH} 7.7$ and counted in $40 \mu \mathrm{L} /$ well of Perkin Elmer Microscint 20. Data are presented as the percentage of agonist stimulation $\left(\% \mathrm{E}_{\max }\right)$ of $\left[{ }^{35} \mathrm{~S}\right] \mathrm{GTPYS}$ binding normalized against maximal stimulating concentrations of $10 \mu \mathrm{M}$ DAMGO, $1 \mu \mathrm{M}$ DPDPE or $10 \mu \mathrm{M}$ U69,593. \% $\mathrm{E}_{\max }$ values were determined using the equation: $\left[\left(\mathrm{CPM}_{\text {bound }}-\mathrm{CPM}_{\text {basal }}\right) /\left(\mathrm{CPM}_{\max }-\mathrm{CPM}_{\text {basal }}\right)\right] \times 100$. Antagonistic properties at $\delta$ were determined by constructing dose-response curves of DPDPE $(0.01-1000 \mathrm{nM})$ in the presence and absence of naltrexone control, UMB 425 or UMB 426. Test compound concentrations were 1x, 3x, and 10x the estimated $\mathrm{K}_{\mathrm{i}}$ value obtained from binding studies. $\mathrm{pA}_{2}$ values are indicative of antagonistic potency at a particular receptor subtype and were determined using a Schild plot, whereby the plot's $\mathrm{x}$-intercept equals $\mathrm{pA}_{2}$. Corresponding slope values at or near -1 indicate competitive antagonism for the compound at that particular receptor subtype. For compounds displaying $\% \mathrm{E}_{\max }<50$, potential antagonistic properties can be determined. Mean \pm S.E.M. were determined by performing experiments in triplicates of duplicates. 
2.2.3. Synthesis of UMB 425. The synthetic scheme for 4a,9-dihydroxy-7a(hydroxymethyl)-3-methyl-2,3,4,4a,5,6-hexahydro-1H-4,12-methanobenzofuro[3,2-e]isoquinolin 7(7aH)-one (UMB 425) is shown in Figure 2.1.

Ethyl 7,9-dimethoxy-3-methyl-2,3,4,7a-tetrahydro-1 H-4,12-methanobenzofuro[3,2-e] isoquinoline-7a-carboxylate (178): A solution of $\mathbf{1}(1 \mathrm{~g})$ in $20 \mathrm{~mL}$ of tetrahydrofuran (THF) was placed in a flame-dried round-bottom flask, and $1.92 \mathrm{~mL}$ (1.5equiv) of a $2.5 \mathrm{M}$ solution of $\mathrm{n}$ butyllithium in hexane was added while stirring at $-78{ }^{\circ} \mathrm{C}$ under nitrogen. The mixture immediately turned deep wine-red and was stirred for $45 \mathrm{~min}$ at $-78{ }^{\circ} \mathrm{C} .0 .36 \mathrm{~mL}$ (1.2 equiv) of ethyl chloroformate was added and the mixture was stirred for $4 \mathrm{~h}$ at $-78{ }^{\circ} \mathrm{C}$. The color changed to orange-yellow. $5 \mathrm{~mL}$ saturated $\mathrm{NH}_{4} \mathrm{Cl}$ was then added per drop and most part of the solvent was removed under reduced pressure. The residual brown product was dissolved in chloroform, washed with brine solution, dried $\left(\mathrm{Na}_{2} \mathrm{SO}_{4}\right)$ and concentrated. The residue was subjected to column chromatography on silica gel using chloroform-methanol (95:5) as eluent to isolate $0.786 \mathrm{~g}(64 \%$ yield) of 2 as a yellow liquid (179).

\section{(7,9-dimethoxy-3-methyl-2,3,4,7a-tetrahydro-1H-4,12-methanobenzofuro[3,2-}

e]isoquinolin-7a-yl)methanol (3): Lithium aluminum hydride (LAH) $(0.00496 \mathrm{~g}, 0.13 \mathrm{mmol})$ was added to a stirred solution of $2(0.050 \mathrm{~g}, 0.13 \mathrm{mmol})$ in dry THF $(2 \mathrm{~mL})$ at $0{ }^{0} \mathrm{C}$ and allowed to warm to room temperature. After $2 \mathrm{~h}$ quenching, saturated sodium sulfate was added to the reaction mixture and stirred for $30 \mathrm{~min}$. The reaction mixture was filtered through celite; the organic layer was separated, concentrated and purified by silica gel column chromatography (15:85 methanol-chloroform) to yield the pure product 3 as a pale yellow solid $(0.036 \mathrm{~g}, 81 \%$ yield) with $\mathrm{mp} 169-171^{\circ} \mathrm{C}(180)$.

\section{4a-hydroxy-7a-(hydroxymethyl)-9-methoxy-3-methyl-2,3,4,4a-tetrahydro-1 H-4,12-}

methanobenzofuro[3,2-e]isoquinolin-7(7aH)-one (4): An ice-cold mixture of $0.4 \mathrm{~mL}$ of $0.7 \%$ $\mathrm{H}_{2} \mathrm{SO}_{4}, 0.125 \mathrm{~mL}$ of $88 \% \mathrm{HCO}_{2} \mathrm{H}$, and $0.251 \mathrm{~mL}$ of $30 \% \mathrm{H}_{2} \mathrm{O}_{2}$ was added to $0.3 \mathrm{~g}(0.879 \mathrm{mmol})$ of 3. The mixture was stirred at $0{ }^{\circ} \mathrm{C}$ until transparent ( $\left.30 \mathrm{~min}\right)$. The resulting solution was kept 
for $70 \mathrm{~h}$ in a refrigerator $\left(4^{\circ} \mathrm{C}\right)$, then poured into $3 \mathrm{~mL}$ of ice water which was made alkaline by the addition of concentrated ammonia solution. The mixture was extracted with 5 portions of chloroform and the organic extracts were combined, dried over sodium sulfate, and evaporated to obtain $0.184 \mathrm{~g}(61 \%)$ of 4 as a white solid (181).

\section{4a-hydroxy-7a-(hydroxymethyl)-9-methoxy-3-methyl-2,3,4,4a,5,6-hexahydro-1 H-4,12-} methanobenzofuro[3,2-e]isoquinolin-7(7aH)-one (5): To a solution of $4(0.13 \mathrm{~g}, 0.379 \mathrm{mmol})$ in $5 \mathrm{~mL}$ of $1: 1$ ethanol-glacial acetic acid was added $\mathrm{Pd} / \mathrm{C}(10 \%, 15 \mathrm{mg})$. The mixture was evacuated and filled with $\mathrm{H}_{2}$ gas in a hydrogenation flask and maintained under 40 psi $\mathrm{H}_{2}$ pressure for $4 \mathrm{~h}$. The reaction mixture was filtered through celite, the solvent was evaporated and the residue was basified with aqueous ammonia prior to $\mathrm{CHCl}_{3}$ extraction. Organic phases were combined, washed with brine, dried over anhydrous $\mathrm{Na}_{2} \mathrm{SO}_{4}$ and solvent was evaporated. The residue was subjected to column chromatography (7:93 methanol-chloroform) to give $\mathbf{5}$ as white foam $(0.0915 \mathrm{~g}, 70 \%)$.

4a,9-dihydroxy-7a-(hydroxymethyl)-3-methyl-2,3,4,4a,5,6-hexahydro-1 $H-4,12-$ methanobenzofuro[3,2-e]isoquinolin-7(7ah)-one (UMB 425): Compound 5 (0.104g, 0.3 mmol) was dissolved in $2 \mathrm{~mL} \mathrm{CHCl}$ and cooled to $0{ }^{\circ} \mathrm{C}$, followed by the slow addition of $\mathrm{BBr}_{3}$

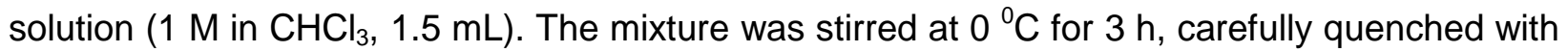
ice and basified with ammonia solution. The resulting mixture was stirred for $30 \mathrm{~min}$ at $0{ }^{\circ} \mathrm{C}$, the aqueous layer was separated and the aqueous phase was extracted with $\mathrm{CHCl}_{3}(3 \times 10 \mathrm{~mL})$. Organic phases were combined, washed with brine and dried over sodium sulfate and the solvent was evaporated. The residue was subjected to column chromatography (20:80 methanol-dichloromethane) to obtain UMB 425 as an off-white solid $(0.0638 \mathrm{~g}, 64 \%)$ with $\mathrm{mp}$ 193-195 ${ }^{\circ} \mathrm{C}$ (182). 


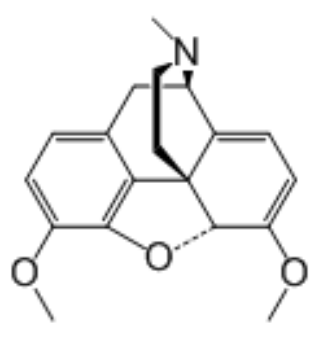

1

(c)

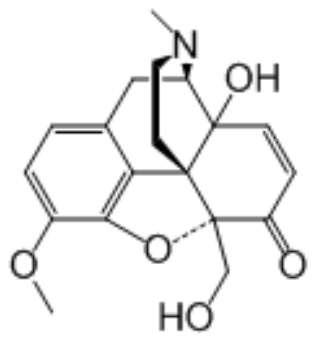

4

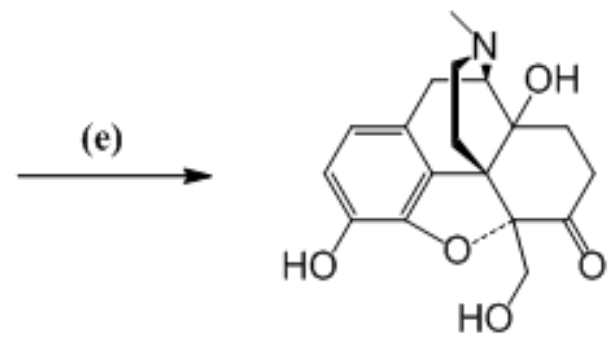

UMB 425

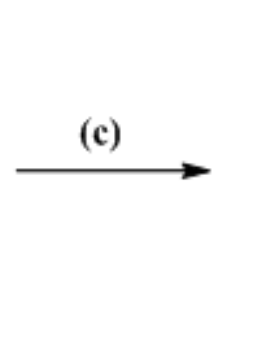

(a)

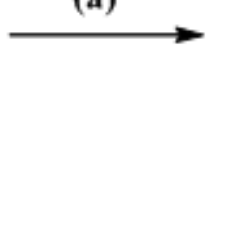

2

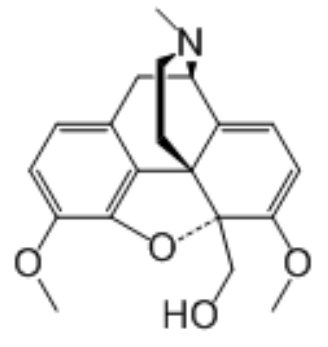

3 (b)

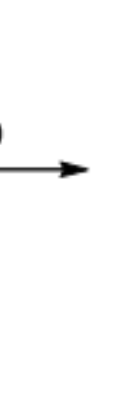

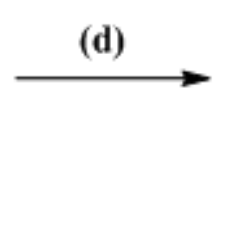

(d)

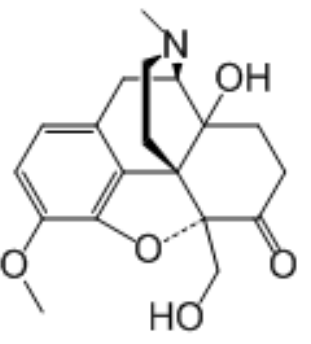

5

Figure 2.1. Chemical synthesis of UMB 425 from thebaine. (a) n-BuLi, Ethyl chloroformate, THF, $-78{ }^{\circ} \mathrm{C}, 4 \mathrm{~h}, 64 \%$; (b) $\mathrm{LiAlH}_{4}$, THF, $0{ }^{\circ} \mathrm{C}$ - rt, 2h, 81\%; (c) $\mathrm{H}_{2} \mathrm{O}_{2}, \mathrm{HCOOH}, \mathrm{H}_{2} \mathrm{SO}_{4}, 4{ }^{\circ} \mathrm{C}, 70 \mathrm{~h}, 61 \%$; (d) $10 \% \mathrm{Pd} / \mathrm{C}, \mathrm{H}_{2}, 1: 1$ Ethanol-Glacial Acetic acid, $4 \mathrm{~h}, 70 \%$; (e) $\mathrm{BBr}_{3}, \mathrm{CHCl}_{3},-20{ }^{\circ} \mathrm{C}, 3 \mathrm{~h}, 64 \%$.

\subsection{4. $\mu$ Agonism/ס Agonism Dual-Profile CSP Model. CSP models developed for $\mu$}

(161) and $\delta(165,166)$ receptor ligands were used for studies herein, with some modifications to the $\delta$ receptor model. Updating of the $\delta$ receptor model was performed prior to predictions of efficacy of UMB 425. As this study involved derivates of 4,5-epoxymorphinans, the training set was limited to small non-peptidic opioids: BW373U86, etorphine, SIOM (7spiroindanyloxymorphone), oxymorphindole, diprenorphine, buprenorphine, naltrexone, naltrindole and (E)-BNTX [(E)-benzylidenenaltrexone]. Figure 2.2 shows the chemical structure 
of compounds used as the training set and their experimental efficacies measured in earlier reported $\left[{ }^{35}\right.$ S $]$ GTPYS assays. For updating the $\delta$ receptor CSP model, the selected ligands were modeled using the CHARMM22/CMAP and CHARMM General Force Field (CGenFF) with Replica Exchange Molecular Dynamics (REX-MD) for conformational sampling, as previously described. Pharmacophoric descriptors were designated for calculations of distances and angles between varying functional groups and are identified as an aromatic ring $(A)$, a basic nitrogen (N) and a hydrophobic group (B) (Figure 2.2). BW373U86 was used as the reference compound for model development. Statistical models were trained using both agonists and antagonists to differentiate overlapping patterns between the two classes of compounds as well as develop a model that allows for quantitative estimations of efficacy. Changes with respect to the original $\delta$ receptor model, include: 1) for BW373U86, the center of mass of the two piperazine nitrogen groups was designated the $\mathrm{N}$ pharmacophoric descriptor, and 2) 1D overlap coefficients with respect to the reference compound were used to obtain multiple regression models with two independent variables; tests using three independent variables did not lead to significant improvements in the models. 


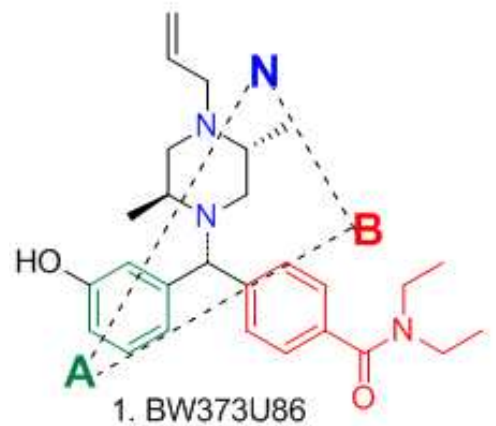

1. BW373U86

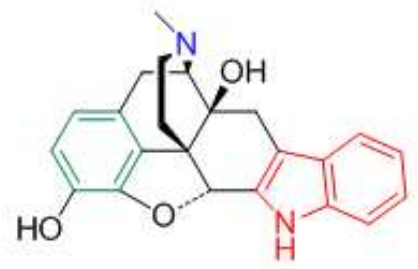

4. Oxymorphindole

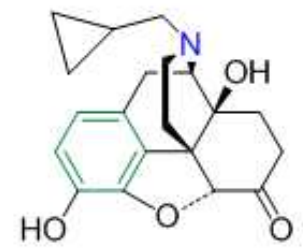

7. Naltrexone ${ }^{\star}$

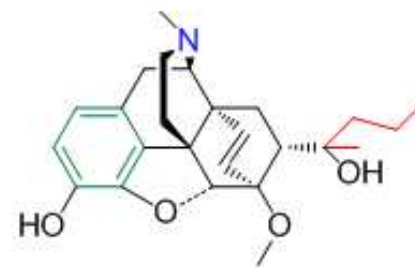

2. Etorphine

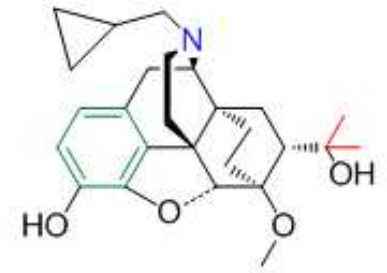

5. Diprenorphine

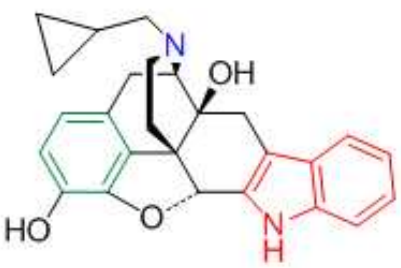

8. Naltrindole

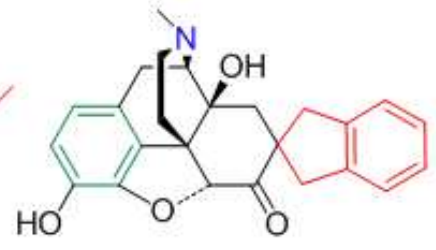

3. SIOM

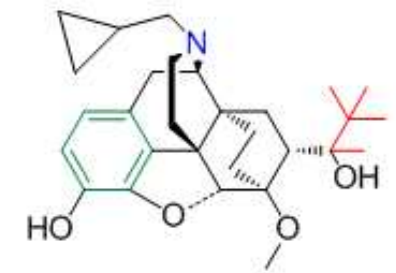

6. Buprenorphine*

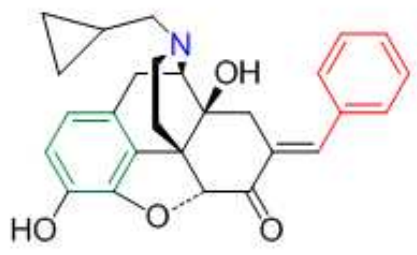

9. (E)-BNTX

Figure 2.2. Compounds included in the $\delta$ receptor CSP training set. Pharmacophoric descriptors are designated in colors where green represents an aromatic ring $(A)$, blue a basic nitrogen $(N)$ and red a hydrophobic group $(B)$.

Prediction of the efficacy of UMB 425 applied previously developed $\mu$ agonism (161) and $\delta$ agonism $(165,166)$ CSP models, with the latter updated to include a larger number of nonpeptidic opioid $\delta$ ligands. CSP updated $\delta$ model generation involved development of multiple individual models based on different pharmacophoric descriptors (Figure 2.2); the top five models of the updated $\delta$ CSP are listed in Table 2.1, each with an $R^{2}$ greater than 0.89 . The final CSP model is based on averaging the predicted efficacies from these top five models. From the model, overlap of the aromatic ring $(A)$ to hydrophobic group $(B)$ distance distributions was identified as the most important descriptor. AB distances of compounds showing agonism at $\delta$ opioid receptors had greater overlap with those of $( \pm)-4-\left(\left(\alpha-R^{\star}\right)-\alpha-\left(\left(2 S^{\star}, 5 R^{\star}\right)-4-a l l y l-2,5-\right.\right.$ dimethyl-1-piperazinyl)-3-hydroxybenzyl)-N,N-diethyl-benzamide (BW373U86) than antagonists; 
however, efficacy was explained not solely by the $A B$ distance, but in combination with the relative position of the hydrophobic group with respect to the aromatic ring and basic $\mathrm{N}$. Accordingly, overlap coefficients of angles ANB, BAN, and ABN were identified as important descriptors by the automated variable selection applied during model construction.

\begin{tabular}{|c|c|c|c|c|c|c|c|c|}
\hline Model \# & $\mathrm{a}$ & $\mathrm{X}_{1}$ & $\mathrm{~b}$ & $\mathrm{X}_{2}$ & $\mathrm{c}$ & $\mathrm{R}^{2}$ & $\mathrm{p}$-value & $\begin{array}{c}\text { Correlation } \\
\text { Coefficient }\end{array}$ \\
\hline 1 & 0.465 & $\mathrm{AB}$ & 0.514 & $\mathrm{BN}$ & 0.028 & 0.962 & 0.00005 & 0.815 \\
\hline 2 & 0.730 & $\mathrm{AB}$ & 0.235 & $\mathrm{ANB}$ & -0.031 & 0.919 & 0.00054 & 0.519 \\
\hline 3 & 0.760 & $\mathrm{AB}$ & 0.187 & $\mathrm{BAN}$ & -0.026 & 0.911 & 0.00071 & 0.442 \\
\hline 4 & 0.749 & $\mathrm{AB}$ & 0.182 & $\mathrm{ABN}$ & -0.037 & 0.893 & 0.00121 & 0.603 \\
\hline 5 & 1.094 & $\mathrm{BN}$ & -0.196 & $\mathrm{ANB}$ & 0.108 & 0.890 & 0.00133 & 0.797 \\
\hline
\end{tabular}

Table 2.1. Top five $\delta$ receptor conformationally sampled pharmacophore models that define the final predictive model. Multiple regression equations, efficacy $=a X_{1}+b X_{2}+c$. N represents the basic nitrogen, $A$ is the aromatic ring and $\mathrm{B}$ is the hydrophobic group, as shown in Figure $\mathrm{X} . \mathrm{X}_{1}$ and $\mathrm{X}_{2}$ are overlap integrals with respect to the reference compound, while $a$ and $b$ are coefficients for variables $X_{1}$ and $X_{2}$ and $c$ is the $y$-intercept in the regression equations. $R^{2}$ is the goodness of fit, $p$-value the significance of models and correlation coefficients between $\mathrm{X}_{1}$ and $\mathrm{X}_{2}$ overlap coefficients.

Calculated efficacies for the training set molecules are shown in Table 2.2 together with experimental values reported previously (183). The model predicts buprenorphine to be a weak partial agonist at $\delta$ receptors due to its resemblance to etorphine, particularly with respect to the AB distances. Oxymorphindole and naltrindole were not differentiated by the model. The only difference between them is the $N$-substituent (N-methyl for oxymorphindole and $N$ cyclopropylmethyl for naltrindole) and the present model did not include the $\mathrm{N}$-substituent as a pharmacophoric descriptor because the length of the $N$-substituent is not as critical for the $\delta$ receptor as it is for the $\mu$ receptor. However, the weak partial agonism of oxymorphindole seems to be due to the short methyl $\mathrm{N}$-substituent. 


\begin{tabular}{|c|c|c|}
\hline & \multicolumn{2}{|c|}{ Relative \% $\mathrm{E}_{\max }$} \\
\hline Name & Experimental & Calculated \\
\hline BW373U86 & 1.00 & 0.96 \\
\hline Etorphine & 0.36 & 0.36 \\
\hline SIOM & 0.18 & 0.13 \\
\hline Oxymorphindole & 0.12 & 0.04 \\
\hline Diprenorphine & 0.08 & 0.01 \\
\hline Buprenorphine & 0.00 & 0.13 \\
\hline Naltrexone & 0.00 & 0.01 \\
\hline Naltrindole & 0.00 & 0.04 \\
\hline (E)-BNTX & 0.00 & 0.07 \\
\hline
\end{tabular}

Table 2.2. Comparison between experimental and calculated efficacy values for compounds in training set. Experimental data, except buprenorphine and naltrexone, is previously reported. Buprenorphine and naltrexone were experimentally designated $\% \mathrm{E}_{\max }=0$ values as both are classified as antagonists at the $\delta$ receptor. BW373U86 $=( \pm)-$

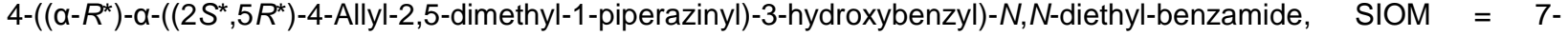
spiroindanyloxymorphone, $(\mathrm{E})$-BNTX $=[(\mathrm{E})$-benzylidenenaltrexone $]$.

\subsection{Results}

\subsubsection{Competition Binding Assays. Table 2.3 summarizes results of reference} compounds for the validation of these assays. Compounds known to be active at each of the respective subtypes were confirmed to have significant affinities herein; compounds known to be active at other subtypes were confirmed to exhibit neglible displacement.

Table 2.3. $\mathrm{K}_{\mathrm{i}}(\mathrm{nM})$ values of standard opioid compounds at various subtypes.

\begin{tabular}{|c|c|c|c|}
\hline & $\boldsymbol{\mu}$ & $\boldsymbol{\delta}$ & $\mathbf{K}$ \\
\hline DAMGO & $1.5 \pm 0.37$ & $>10,000$ & $>10,000$ \\
\hline DPDPE & $618 \pm 64$ & $2.4 \pm 0.33$ & $>10,000$ \\
\hline U69,593 & $>10,000$ & $>10,000$ & $1.1 \pm 0.49$ \\
\hline Naltrexone & $0.46 \pm 0.12$ & $11 \pm 1.1$ & $1.1 \pm 0.06$ \\
\hline Naloxone & $2.2 \pm 0.09$ & $44 \pm 3.6$ & $7.2 \pm 0.24$ \\
\hline Morphine & $1.7 \pm 0.34$ & $87 \pm 6.6$ & $69 \pm 1.3$ \\
\hline Codeine & $624 \pm 8.9$ & $>10,000$ & $>10,000$ \\
\hline
\end{tabular}

Affinities ( $\mathrm{K}_{\mathrm{i}}$ in $\mathrm{nM}$ ) were determined in $\mathrm{CHO}$ cells transfected with and overexpressing the human opioid receptor subtypes. The values in this table represent the mean + S.E.M. from replicate assays performed in triplicate. Values of $>10,000$ signify that there was less than $50 \%$ displacement of the radioligand at that concentration.

The average binding affinities in $\mathrm{nM}$ for $\mathrm{UMB}$ opioid ligands for the three opioid receptor subtypes are shown in Table 2.4. Classical opioid structure activity relationships were applied towards the development of bifunctional ligands using structural characteristics of $\mu$ agonism and $\delta$ antagonism. Therapeutically limiting side effects associated with $\mathrm{k}$ receptor activation, specifically dysphoria (184) and potentially hyperalgesia (185), were undesirable; the overall 
synthetic design was also geared towards minimal, if any interaction, with the $\mathrm{k}$ receptor. As expected, compounds depicting $\delta$-specific moieties (i.e. indole, benzylidene) fused to the C-ring of the opioid pharmacophore exhibited increased selectivity for the $\delta$ receptor to that of the $\mu$ receptor. Overall, compounds displayed high-to-moderate binding affinity for the $\mu$ and $\delta$ receptor subtypes, with moderate-to-poor affinity for the $\mathrm{k}$ receptor subtype. However, within this group of compounds, no structural configuration trended towards increased affinity towards any of the opioid receptor subtypes.

Table 2.4. Chemical structures and binding affinities $\left(K_{i} S\right)$ of UMB opioid ligands.

\begin{tabular}{|l|l|l|l|l|}
\hline & $\begin{array}{c}\text { Compound } \\
\text { Name }\end{array}$ & $\mu: \mathbf{K}_{\mathbf{i}}(\mathbf{n M})$ & $\mathbf{\delta}: \mathbf{K}_{\mathbf{i}}(\mathbf{n M})$ & $\mathbf{K}: \mathbf{K}_{\mathbf{i}}(\mathbf{n M})$ \\
\hline UMB 246 & $18 \pm 1.1$ & $14 \pm 0.65$ & $1067 \pm 39$ \\
\hline UMB 375 & $28 \pm 0.90$ & $2.0 \pm 0.31$ & $186 \pm 2.0$ \\
\hline
\end{tabular}




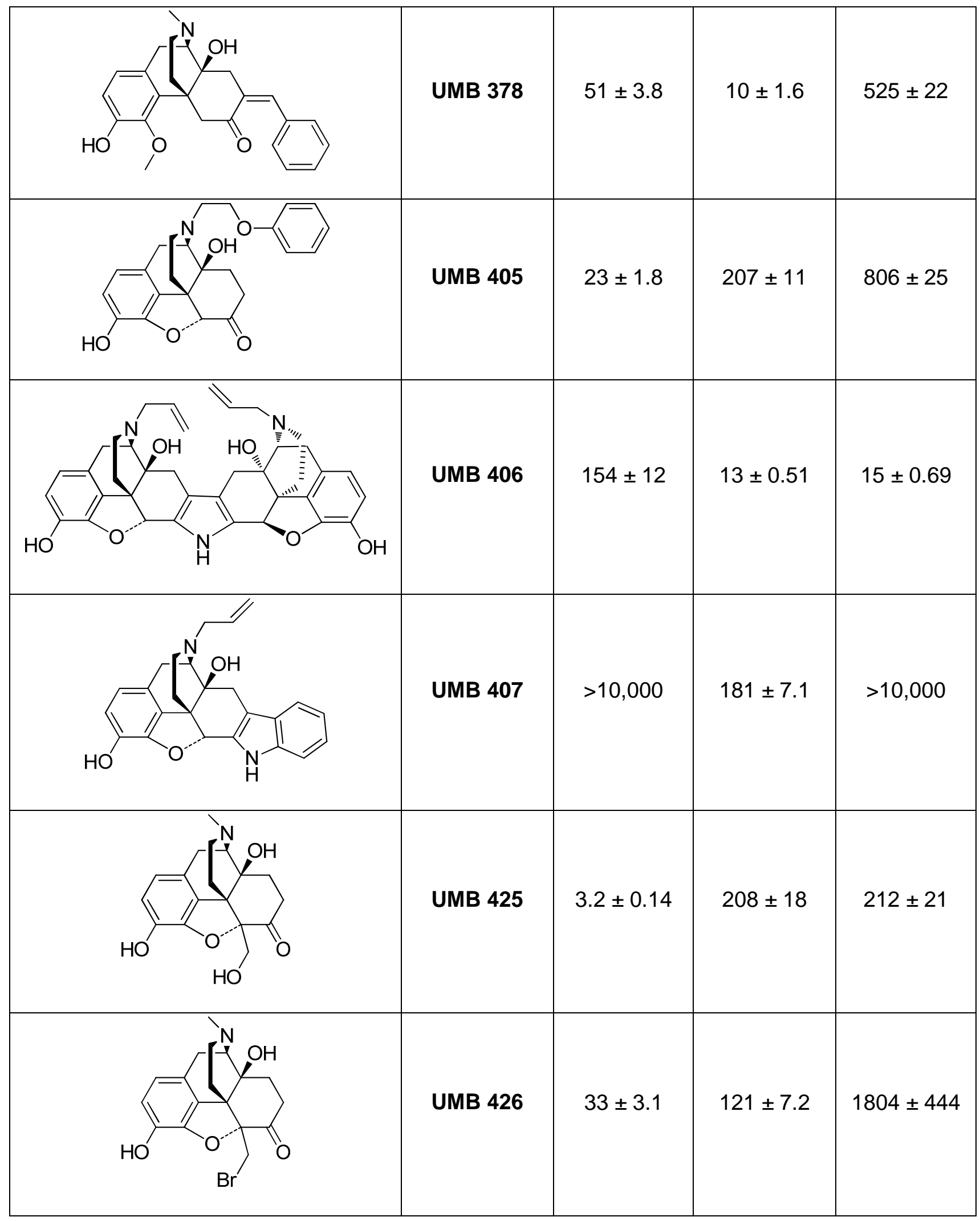




\begin{tabular}{|l|l|l|l|l|}
\hline UMB 427 & $717 \pm 48$ & $353 \pm 79$ & $>10,000$ \\
\hline UMB 437 & $17 \pm 1.5$ & $201 \pm 16$ & $1040 \pm 29$ \\
\hline
\end{tabular}




\begin{tabular}{|l|l|l|l|l|}
\hline & UMB 441 & $313 \pm 23$ & $168 \pm 9.2$ & $793 \pm 58$ \\
\hline
\end{tabular}

Affinities $\left(\mathrm{K}_{\mathrm{i}}\right.$ in $\mathrm{nM}$ ) were determined in $\mathrm{CHO}$ cells transfected with and overexpressing the human opioid receptor subtypes. The values in this table represent the mean + S.E.M. from replicate assays performed in triplicate. Values of $>10,000$ signify that there was less than $50 \%$ displacement of the radioligand at that concentration.

2.3.2. $\left[{ }^{35}\right.$ SJGTPYS Functional Assays. Table 2.5 summarizes the results of $\left[{ }^{35} \mathrm{~S}\right] \mathrm{GTPyS}$ functional assays of reference compounds for validation. For agonists, potency was reported as $\mathrm{EC}_{50} \pm$ S.E.M. $(\mathrm{nM})$, while efficacy was reported as $\% E_{\max } \pm$ S.E.M. $10 \mu \mathrm{M}$ DAMGO was used as the $100 \%$ efficacy standard at the $\mu$ receptor. $1 \mu \mathrm{M}$ DPDPE was used as the $100 \%$ efficacy standard at the $\delta$ receptor. $10 \mu \mathrm{M} \cup 69,593$ was used as the $100 \%$ efficacy standard at the $\mathrm{K}$ receptor.

Table 2.5. $\left[{ }^{35} \mathrm{~S}\right] \mathrm{GTPYS}$ results for standard opioid compounds: $\mathrm{EC}_{50}$ and $\% \mathrm{E}_{\max }$.

\begin{tabular}{|c|c|c|c|c|c|c|}
\hline \multirow{2}{*}{} & \multicolumn{2}{|c|}{$\boldsymbol{M}$} & \multicolumn{2}{c|}{$\boldsymbol{\delta}$} & \multicolumn{2}{c|}{$\mathbf{K}$} \\
\cline { 2 - 7 } & $\mathrm{EC}_{50}$ & $\% \mathrm{E}_{\max }$ & $\mathrm{EC}_{50}$ & $\% \mathrm{E}_{\max }$ & $\mathrm{EC}_{50}$ & $\% \mathrm{E}_{\max }$ \\
\hline DAMGO & $21 \pm 2.7$ & 100 & N.D. & N.D. & N.D. & N.D. \\
\hline DPDPE & N.D. & N.D. & $7.3 \pm 0.85$ & 100 & N.D. & N.D. \\
\hline Morphine & $38 \pm 4.9$ & $81 \pm 2.0$ & N.D. & N.D. & N.D. & N.D. \\
\hline
\end{tabular}

$\left[{ }^{35} \mathrm{~S}\right] \mathrm{GTP}$ S assays were performed in $\mathrm{CHO}$ cells transfected with and overexpressing the human opioid receptor subtypes. $\mathrm{EC}_{50}$ and \% $\mathrm{E}_{\max }$ values in this table represent the mean + S.E.M. from replicate assays performed in triplicate. Those designated as not determined (N.D.) were either not performed or did generate accurate $\mathrm{EC}_{50}$ values. 
Compounds eliciting high affinity for the $\mu$ receptor $\left(\mathrm{K}_{\mathrm{i}}<65 \mathrm{nM}\right)$ and high-to-moderate affinity for the $\delta$ receptor $\left(\mathrm{K}_{\mathrm{i}}<210 \mathrm{nM}\right)$ underwent $\left[{ }^{35} \mathrm{~S}\right] \mathrm{GTPYS}$ functional studies to determine agonistic and antagonistic activity at the respective opioid receptor subtypes. However, UMB 437, 440 and 449 were not tested because the competition binding results did not offer any additional SAR of significance. $\mathrm{EC}_{50}$ and $\% \mathrm{E}_{\max }$ values were calculated to determine the agonistic potency and efficacy, respectively. Table 2.6 depicts the respective $\mathrm{EC}_{50}$ and $\% \mathrm{E}_{\max }$ values for UMB compounds at the respective opioid receptor subtypes. Specifically, UMB 378, 425 and 426 are the three compounds that exhibit the highest efficacy of the compounds tested. UMB 425 displays $\mu$ agonistic properties similar to that morphine $\left(\mathrm{EC}_{50}=38 \pm 4.9 \mathrm{nM}, \% \mathrm{E}_{\max }=\right.$ $81 \pm 2) . \mathrm{pA}_{2}$ values were calculated to determine the antagonistic potency at the $\delta$ receptor. Table 2.7 shows that both UMB 425 and 426 display competitive antagonistic effects at the $\delta$ receptor.

Table 2.6. $\left[{ }^{35}\right.$ S $]$ GTPyS results for UMB opioid ligands: $\mathrm{EC}_{50}$ and $\% \mathrm{E}_{\max }$.

\begin{tabular}{|c|c|c|c|c|c|c|}
\hline \multirow{2}{*}{$\begin{array}{c}\text { Compound } \\
\text { Name }\end{array}$} & \multicolumn{2}{|c|}{$\boldsymbol{\mu}$} & \multicolumn{2}{c|}{$\delta$} \\
\cline { 2 - 7 } & $\mathrm{EC}_{50}$ & $\% \mathrm{E}_{\max }$ & $\mathrm{EC}_{50}$ & $\%_{\max }$ & $\mathrm{EC}_{50}$ & $\%_{\mathrm{max}}$ \\
\hline UMB 246 & $72 \pm 11$ & $39 \pm 1.3$ & N.D. & N.D. & N.D. & N.D. \\
\hline UMB 375 & 89 & 49 & N.D. & N.D. & N.D. & N.D. \\
\hline UMB 376 & N.D. & Est. 78 & N.D. & N.D. & N.D. & N.D. \\
\hline UMB 378 & $250 \pm 24$ & $86 \pm 1.2$ & N.D. & N.D. & N.D. & N.D. \\
\hline UMB 405 & $32 \pm 3.4$ & $31 \pm 5.0$ & N.D. & Est. 15 & N.D. & N.D. \\
\hline UMB 425 & $35 \pm 3.7$ & $73 \pm 7.3$ & N.D. & Est. 16 & N.D. & Est. -2 \\
\hline UMB 426 & $342 \pm 94$ & $79 \pm 7.3$ & N.D. & Est. 1 & N.D. & N.D. \\
\hline
\end{tabular}

$\left[{ }^{35} \mathrm{~S}\right] \mathrm{GTPYS}$ assays were performed in $\mathrm{CHO}$ cells transfected with and overexpressing the human opioid receptor subtypes. $\mathrm{EC}_{50}$ and $\% \mathrm{E}_{\max }$ values in this table represent the mean + S.E.M. from replicate assays performed in triplicate. For UMB 375 , the respective $\mathrm{EC}_{50}$ and \% $\mathrm{E}_{\max }$ values were determined from one set of replicate assays. UMB 376 was predicted to possess high efficacy, but was not further characterized due to solubility issues and a lack of compound. Additional estimated (Est.) values were based on window studies or displayed low [ ${ }^{35}$ S GTPYS stimulation such that a sigmoidal curve could not be established. Those designated as not determined (N.D.) were either window experiments not conducted or were unable to generate accurate $\mathrm{EC}_{50}$ values. 
Table 2.7. $\left[{ }^{35}\right.$ S]GTPYS results for standard opioid compounds and UMB ligands: $\mathrm{pA}_{2}$

\begin{tabular}{|c|c|}
\hline Compound Name & $\delta \mathbf{p A}_{2}$ (slope) \\
\hline Naltrexone & $8.19(-0.94)$ \\
\hline UMB 425 & $6.12(-0.91)$ \\
\hline UMB 426 & $6.31(-1.08)$ \\
\hline
\end{tabular}

$\left[{ }^{35} \mathrm{~S}\right] \mathrm{GTPYS}$ antagonism is determined by using concentrations of $1 \mathrm{x}, 3 \mathrm{x}$ and $10 \mathrm{x}$ that of the compound's respective $\mathrm{K}_{\mathrm{i}}$ for said receptor. Antagonist concentrations were used against a dose range of a standard agonist.

2.3.3. $\mu$ Agonism/ס Agonism Dual-Profile CSP Model. The CSP models for the $\mu$ and $\delta$ receptor ligands were applied to UMB 425 as a result of its in vitro pharmacological profile. Predicted efficacy $\left(\% \mathrm{E}_{\max }\right)$ values for UMB 425 were 101 and 1.4 for the $\mu$ and $\delta$ receptors, respectively, values comparable to those obtained using receptor specific $\mathrm{CHO}$ cell lines.

To better understand the contribution of the 5'-hydroxymethyl to efficacy, additional analysis was performed on conformations of UMB 425 generated during CSP model development. Distances and angle distributions between the basic nitrogen and oxygen in the 5'-hydroxymethyl in UMB 425 or the 19-hydroxyl substituent in the orvinols were calculated and compared. Figure 2.3 shows $\mathrm{N}-\mathrm{O}$ distance and $\mathrm{N}-\mathrm{C} 9-\mathrm{O}$ angle probability distributions of three orvinols and UMB 425. In Figure 2.3, two large distributions are present that are separated by around $1.5 \AA$, although a small peak is noted in the UMB 425 distribution at $6.5 \AA$ that overlaps with that of the orvinols. The $\mathrm{N}-\mathrm{C} 9-\mathrm{O}$ angle indicates the relative position of the hydroxyl group with respect to the plane of the aromatic A-ring. The hydroxyl group of UMB 425 is slightly above the A-ring plane while that of the orvinols is below; however, a small overlap between UMB 425 and the orvinols is observed (Figure 2.3). While preliminary, these results indicate that UMB 425 can assume conformations in which its hydroxyl moiety participates in interactions with the receptors that are similar to those occurring with the orvinols. 
(a)

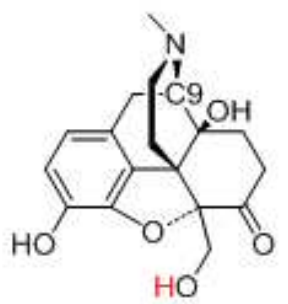

UMB 425

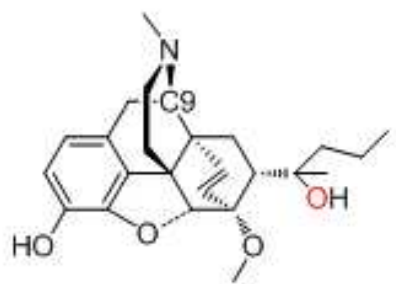

Etorphine
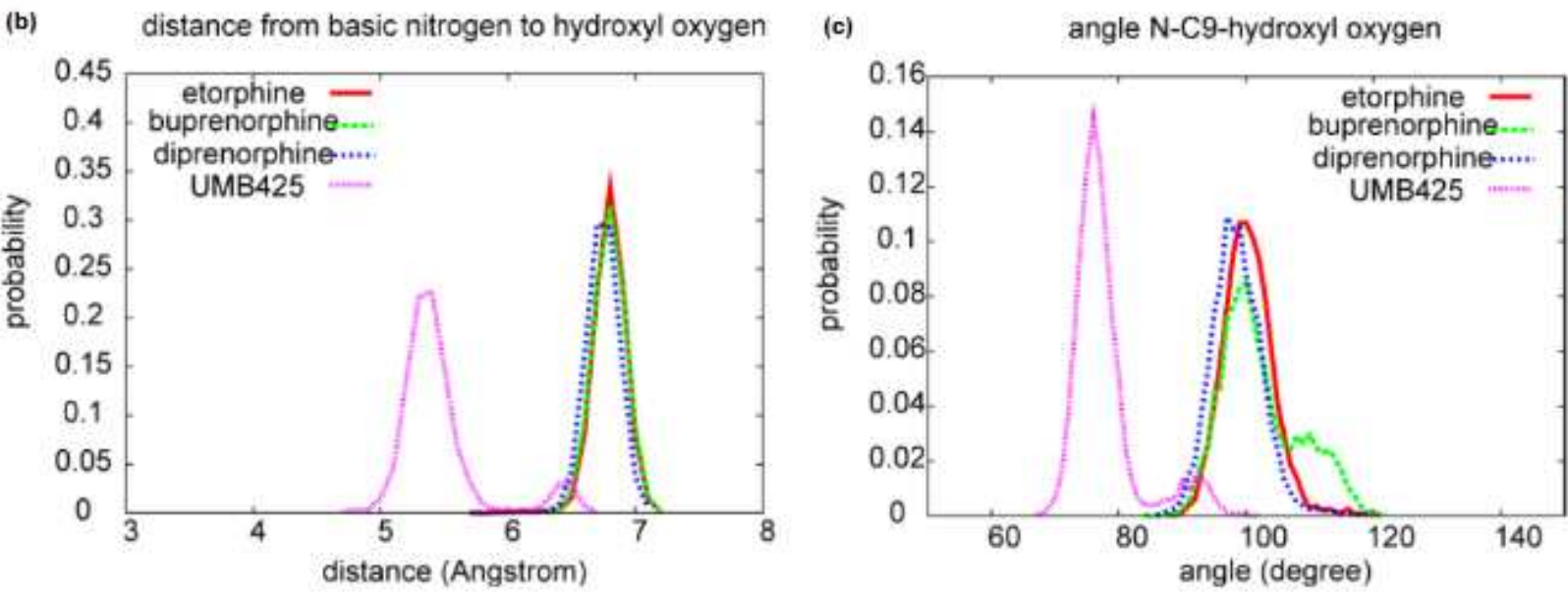

Figure 2.3. N-O distance and N-C9-O angle probability distributions. (a) Images of UMB 425 and etorphine with the hydroxyl oxygen highlighted in red. Probability distributions of the (b) distance from basic nitrogen to hydroxyl oxygen and (c) the basic N-C9-oxygen angle from the simulations used in CSP model development for etorphine (red line), buprenorphine (green dashed line), diprenorphine (blue dashed line) and UMB 425 (purple dashed line).

\subsection{Discussion}

Studies suggest that the development of a bifunctional opioid ligand depicting dual effects of $\mu$ agonism and $\delta$ antagonism can elicit potent analgesic properties with reduced tolerance liabilities compared to traditional opioid analgesics. Herein, a number of ligands were designed using classical opioid receptor SAR and tested for their binding affinity and functionality at the three opioid receptor subtypes: $\mu, \delta$ and $\mathrm{K}$. CSP modeling studies were utilized for our most promising ligand to date, UMB 425, which displays $\mu$ agonistic effects comparable to morphine and, unlike morphine, displays antagonistic effects at the $\delta$ receptor (186).

For the CSP modeling studies, the high efficacy at $\mu$ receptors is consistent with the structural similarity of UMB 425 with morphine or oxymorphone, while the low efficacy at $\delta$ receptors is consistent with the C-ring substituents of naltrexone. The recent availability of X-ray 
crystal structures of the $\mu$ and $\delta$ receptors will allow for future evaluation of the present model in the context of $3 \mathrm{D}$ interactions between UMB 425, as well as other ligands, and the respective receptor subtypes $(187,188)$.

With regards to our other ligands, UMB 449 was synthesized with the intent of increasing the probability of the distance from the basic nitrogen to the hydroxyl oxygen and the basic $\mathrm{N}$ C9-O angle in order to mirror the orvinol standards (Figure 2.3). This should further reinforce our hypothesis that the 5' hydroxyl moiety aids in structural configurations similar to those that are occurring with the orvinols.

UMB 246, 440 and 441 are a part of the benzylideneoxymorphone ("BOM") series of ligands. UMB 246 shows the highest affinity at the $\mu$ receptor of the three, with equipotency for the $\delta$ receptor. While demonstrating promising values of potency in $\left[{ }^{35} S\right] G T P \gamma S$ assays, values of efficacy are markedly lower than morphine. With respect to the structural design of UMB 440 and 441, N-phenyl substituents have previously been shown to possess higher potency than morphine (189).

UMB 375-378 are a series of 3-hydroxy-4-methoxymorphinans that aim to improve $\delta$ selectivity with the addition of the $\delta$-selective indole and benzylidene moieties fused to the Cring. Previously, 3-hydroxy-4-methoxyindolomorphinans have been shown to possess high affinity for the $\delta$ delta receptor with selectivity comparable to $\delta$-selective standards naltrindole and oxymorphindole (190). The opening of the 4,5-bridge is hypothesized to positively influence $\delta$ receptor binding and selectivity (191). Affinity and selectivity ratios for UMB 377 are comparable to values obtained previously, some of which were obtained using modified radioligand binding methods from our own (190). The inclusion of the 5,14-bridge is to identify relative changes in binding affinity and selectivity as previously described. Based on preliminary results, both UMB 376 and 378 demonstrate the highest values of efficacy within this series. Unfortunately, the lack of high affinity and potency at the $\mu$ receptor directed our attention to other ligands herein. 
UMB 406 is similar in structure to the $\mathrm{k}$-selective antagonist nor-BNI, and can be identified as a bivalent ligand as opposed to a bifunctional ligand. Nor-BNI is comprised of two naltrexone units fused at their respective C-rings by a pyrrole spacer and has been shown to antagonize the effects of $\delta$-selective agonists (192). UMB 406 is comprised of two naloxone units fused at their respective C-rings by a pyrrole spacer. UMB 406 demonstrates selectivity for the $\mathrm{K}$ and $\delta$ receptor subtypes to that of $\mu$. Since UMB 406 does not fit our specific research interests, it appears to be best utilized as a research tool for future use.

Overall, additional opioid SAR profiles are difficult to decipher at this point, seeing that many of the ligands included are intermediate reactants, whose products will be synthesized in the future. The binding and functional assay data associated with these future compounds will provide additional opioid SAR with regards to mixed $\mu / \delta$ activity. Ligands that present both potent agonistic properties at the $\mu$ receptor $\left(\mathrm{EC}_{50}<50 \mathrm{nM}, \% \mathrm{E}_{\max }>70 \%\right)$ and antagonistic properties at the $\delta$ receptor $\left(\mathrm{pA}_{2}>6\right)$, specifically UMB 425, will be included in in vivo studies discussed in detail in Chapter 3.

\subsection{Contributions}

Jason Healy performed all competition binding and functional assays. The compounds were synthesized by Vani Bezawada in Andy Coop's lab at the University of Maryland. Jihyun Shim in Alex MacKerell's lab conducted the modeling studies. Dr. Larry Toll at Torrey Pines generously provided the $\mathrm{CHO}$ cells overexpressing each of the opioid receptor subtypes. 


\section{CHAPTER 3}

ANTINOCICEPTIVE ACTIVITY OF NOVEL UMB OPIOID LIGANDS IN VIVO 


\subsection{Introduction}

For those synthesized ligands that display the desired pharmacological profile in vitro, tail-flick and hot plate thermal nociceptive paradigms were designed to demonstrate the acute antinociceptive properties of novel UMB ligands in vivo. The tail-flick assay is traditionally used as a measure of spinal nociceptive responses via the ascending pain pathway discussed above, but has also been shown to be influenced by supraspinal signaling mechanisms $(193,194)$. The hot plate assay is a measure of supraspinal nociceptive reflexes via the descending pain pathway (195). The tail-flick and hot plate are common assays used for initial antinociceptive assessment of novel opioid ligands. Both require minimal preparation time whose nociceptive responses are easily distinguished. Furthermore, both the tail-flick and hot plate assays are Institutional Animal Care and Use Committee (IACUC) friendly as both are escapable, such that nociceptive stimuli is removed once response criteria or a cutoff latency has been met.

Ligands that display high potency and efficacy at the $\mu$ receptor $\left(\mathrm{EC}_{50}<50 \mathrm{nM}, \% \mathrm{E}_{\max }>\right.$ $70 \%)$ in addition to antagonism at the $\delta$ receptor $\left(\mathrm{pA}_{2}>6\right)$ were considered for in vivo testing herein. UMB 425 was the first of our opioid ligands to demonstrate the mandated criteria herein. UMB 425 demonstrates comparable $\mu$ agonistic effects to that of morphine. Yet, surprisingly, UMB 425 was able to demonstrate $\delta$-specific antagonistic properties without the inclusion $\delta$ specific structural moieties. Traditional opioid analgesics, including morphine, demonstrate agonistic effects at the $\delta$ receptor subtype.

Morphine was chosen as the positive control for both paradigms due to its clinical relevance as well as for assay validation purposes with the use of previously reported results. Data obtained for morphine using both in vitro and in vivo assays can be used for comparisons when determining the potential clinical viability of novel opioid ligands herein. Both morphine and UMB 425 were administered subcutaneously (s.c.), intending to mimic less invasive routes, as opposed to intrathecal (i.t.) or intracerebroventicular (i.c.v.) routes commonly used in early drug development in order to conserve product. Naloxone is used for antagonist pretreatment 
studies performed in vivo due to its clinical relevance as a drug treatment to counteract opioid overdose in the clinic. Furthermore, norbinaltorphimine (nor-BNI) is a k-selective antagonist that can be given as a pretreatment prior to novel ligand administration to assess potential $\mathrm{K}$ receptor induced antinociceptive properties. Due to undesirable effects associated with $\mathrm{K}$ receptor activation (i.e. dysphoria), one of the goals of this project was to identify novel opioid agents with limited $\mathrm{k}$ receptor interactions. While in vitro studies for UMB 425 indicate little if any K-mediated agonistic properties, nor-BNI pretreatment in vivo will be performed for further confirmation.

\subsection{Methods}

3.2.1. Animals. Male, Swiss-Webster mice (21-30 g, Harlan, Indianapolis, IN; Frederick, MD) were housed in groups of five in polysulfone cages (Techniplast, Philadelphia, PA) with a 12:12-h light/dark cycle with food and water ad libitum. Animals were acclimated one week prior to experimental use and randomly assigned to treatment groups. All procedures were performed in accordance to the Institutional Animal Care and Use Committee at the West Virginia University Health Sciences Center.

3.2.2. Hot-Plate Antinociceptive Testing. Mice were placed within a plastic cylinder (10.8 $\mathrm{cm}$ ID) atop a black anodized, aluminum plate $(27.9 \mathrm{~cm} \times 26.7 \mathrm{~cm} \times 1.9 \mathrm{~cm})$ uniformly regulated at $53{ }^{\circ} \mathrm{C}$ (IITC Life Science Inc., Woodland Hills, CA). The latency to the first sign of excessive shaking, lifting and/or licking of the hind paws was determined and recorded as the behavioral endpoint. Two baseline latencies (BL) were recorded prior to drug administration, with an average BL within 8-10 sec needed for further testing. Mice were then administered either morphine (0.1-20 mg/kg, s.c.) or UMB $425(0.1-20 \mathrm{mg} / \mathrm{kg}$, s.c.) and testing latencies (TL) for nociceptive responses were recorded at various time points thereafter. Previous studies have reported that the higher doses of morphine herein will induce at or near full antinociceptive activity for thermal nociceptive assays (196). A similar dosing paradigm was used for UMB 425, since in vitro opioid binding and functional data for UMB 425 were comparable to morphine. The 
subcutaneous route of injection was chosen because of its common usage with antinociception regimens. A 30 sec cutoff latency $(\mathrm{CL})$ was predetermined so as to not cause tissue damage. Data obtained were reported as \% Maximum Possible Effect (\%MPE), which is indicative of antinociceptive activity associated with a particular compound. \%MPE is determined using the following formula: \%MPE $=[(T L-B L) /(C L-B L)] \times 100$.

3.2.3. Tail-Flick Antinociceptive Testing. Mice were placed in restraints $(2.5 \mathrm{~cm}$ ID $\times 10.2$ $\mathrm{cm}$ length) and their tails were placed underneath an overhead halogen light source (IITC Life Science Inc., Woodland Hills, CA) whereby the latency to the first sign of a rapid tail flick was determined and recorded as the behavioral endpoint. Two BL values were recorded prior to drug administration, with an average $\mathrm{BL}$ within 2-4 sec needed for further testing. Animals were then administered test compound at dosages reported for hot plate antinociceptive testing and TL values recorded at various time points thereafter. A $10 \mathrm{sec} C L$ was predetermined so as to not cause tissue damage. \%MPE values were determined as described above.

3.2.4. Antagonist Studies. Naloxone and nor-BNI were purchased from Sigma Aldrich (St. Louis, MO). To determine the opioid receptors involved in the antinociceptive effects of UMB 425, mice were pretreated with the non-selective opioid antagonist naloxone $(1 \mathrm{mg} / \mathrm{kg}$ i.p., $t=-30 \mathrm{~min})$ or the $\mathrm{k}$-selective antagonist nor-BNI (30 mg/kg i.p., $t=-24 \mathrm{~h}$ ). Antinociceptive testing was performed 30 min after subcutaneous administration of an $\mathrm{ED}_{90}$ dose of morphine or UMB 425. The selected antagonist dosages and pretreatment time points have been shown to correspond with the intended opioid receptor subtype and peak antagonist effect $(197,198)$.

3.2.5. Data Analysis. For in vivo antinociceptive assays, agonist $\mathrm{ED}_{50}$ values were calculated using a non-linear regression model. For antagonist studies, a one-way analysis of variance (ANOVA) followed by Tukey's post-hoc tests were used to determine significance between groups. For all analyses, $p<0.05$ was considered statistically significant. GraphPad Prism (San Diego, CA) was used for all data analyses. 


\subsection{Results}

3.3.1. Thermal Antinociceptive Testing. Mice given subcutaneous injections of morphine and UMB 425 both demonstrated antinociceptive effects in a time- and dose-dependent manner for the thermal nociceptive assays (Figure 3.1). Table 3.1 summarizes respective $E_{50}$ values for morphine and UMB 425 from testing performed 30 min after drug treatment. The potency of the antinociceptive activity of UMB $425\left(\mathrm{ED}_{50}=4.30\right.$ and $8.83 \mathrm{mg} / \mathrm{kg}$ for the hot plate and tailflick assays, respectively) was comparable to morphine $\left(E D_{50}=2.73\right.$ and $6.85 \mathrm{mg} / \mathrm{kg}$ for the hot plate and tail-flick assays, respectively). While not as potent as other opioid compounds previously tested (199), UMB 425 was able to achieve a maximal antinociceptive respsonse at comparable doses to morphine.
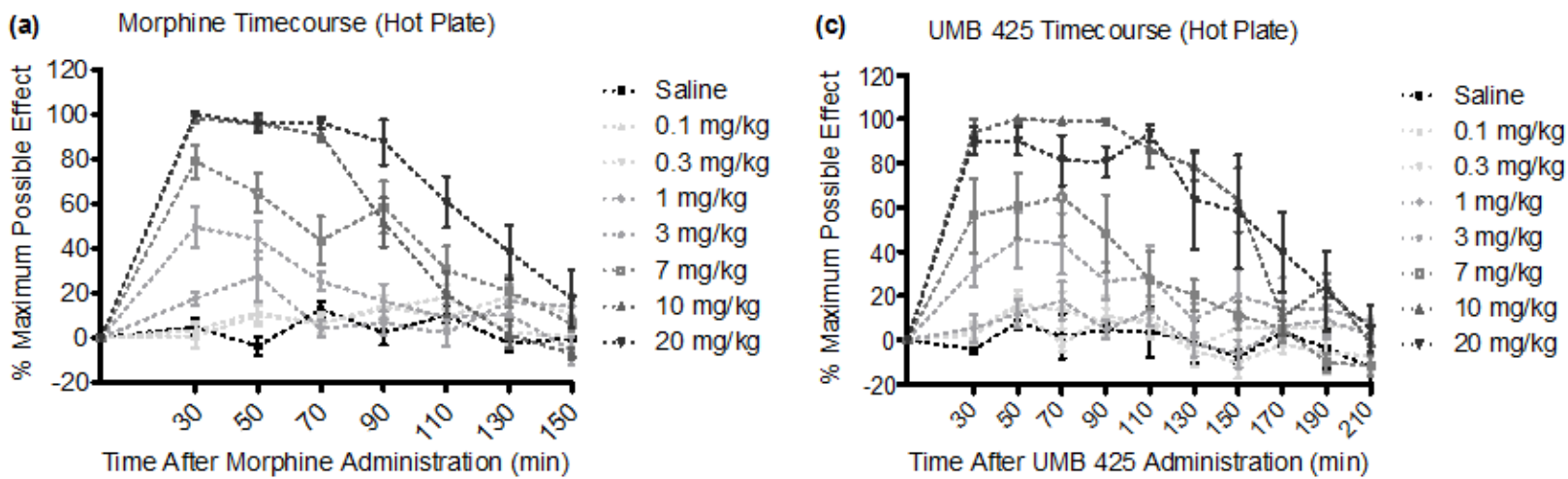

(b) Morphine Timecourse (Tail-Flick)

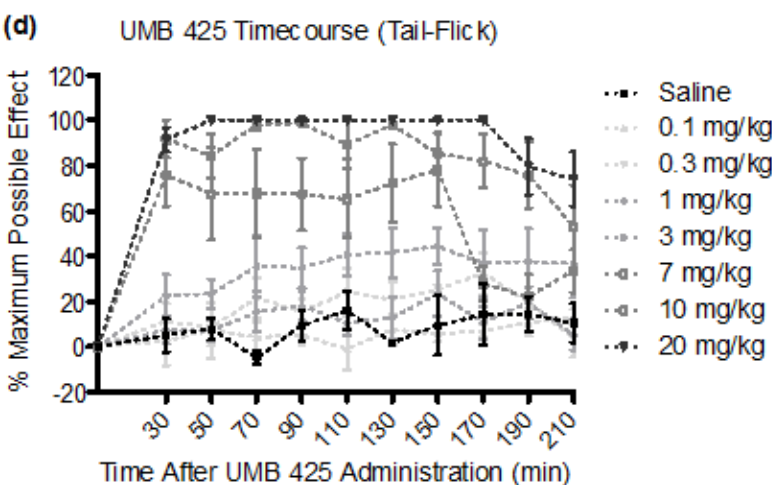

Figure 3.1. Acute dose- and time-response curves for s.c. morphine and UMB 425 treatment for the hot plate and tail-flick assays. Male, Swiss-Webster mice were treated with morphine $(0.1-20 \mathrm{mg} / \mathrm{kg}$, s.c.) or UMB 425 (0.1$20 \mathrm{mg} / \mathrm{kg}$, s.c.). Latencies were recorded $30 \mathrm{~min}$ after drug administration and every 20 min thereafter for 150 or 210 min. (a) Dose- and time-response curves for s.c. morphine in the hot plate assay. (b) Dose- and time-response curves for s.c. morphine in the tail-flick assay. (c) Dose- and time-response curves for s.c. UMB 425 in the hot plate assay. (d) Dose- and time-response curves for s.c. UMB 425 in the tail-flick assay. 


\begin{tabular}{|c|c|c|}
\hline ED $_{\mathbf{5 0}}(\mathbf{m g} \mathbf{k g})$ & Morphine & UMB 425 \\
\hline Hot Plate & 2.73 & 4.30 \\
\hline Tail-Flick & 6.85 & 8.83 \\
\hline
\end{tabular}

Table 3.1. $E D_{50}$ values for morphine and UMB 425 in the acute treatment paradigm. Summary of antinociceptive activity of acute morphine (0.1-20 mg/kg, s.c.) and UMB $425(0.1-20 \mathrm{mg} / \mathrm{kg}$, s.c.) treatment in Swiss, Webster mice for the hot plate and tail-flick assays. Respective $\mathrm{ED}_{50}$ values (in $\mathrm{mg} / \mathrm{kg}$, s.c.) were obtained at the $30 \mathrm{~min}$ time point after drug administration.

3.3.2. Antagonist Studies. To corroborate opioid-induced antinociception, various antagonist pretreatments were given in conjunction with UMB 425 administration. One-way analysis of variance (ANOVA) indicated differences amongst mice pretreated with saline, naloxone and nor-BNI $(F(2,12)=8.88, p<0.005 ; F(2,13)=22.61, p<0.0001$ for the hot plate and tail-flick assays, respectively). UMB 425's partial agonistic effects through the $\mu$ receptor appear primarily responsible for the observed antinociceptive effects seen in vivo as naloxone significantly attenuated UMB 425-mediated antinociception (Figure 3.2; $q=4.55, p<0.05 ; q=$ 8.48, $\mathrm{p}<0.001$ for the hot plate and tail-flick assays, respectively; Tukey's post-hoc). In contrast, pretreatment with the $\mathrm{K}$ antagonist nor-BNI failed to significantly attenuate UMB 425mediated antinociception (Figure 3.2; $q=0.01$, n.s.; $q=1.39$, n.s. for the hot plate and tail-flick assays, respectively; Tukey's post-hoc). Consistent with the lack of agonist activity observed in the $\left[{ }^{35} \mathrm{~S}\right] \mathrm{GTPYS}$ assay at $\mathrm{k}$ receptors by UMB 425 , the $\mathrm{\kappa}$ receptor does not appear to contribute significantly to the antinociceptive effects of UMB 425. 

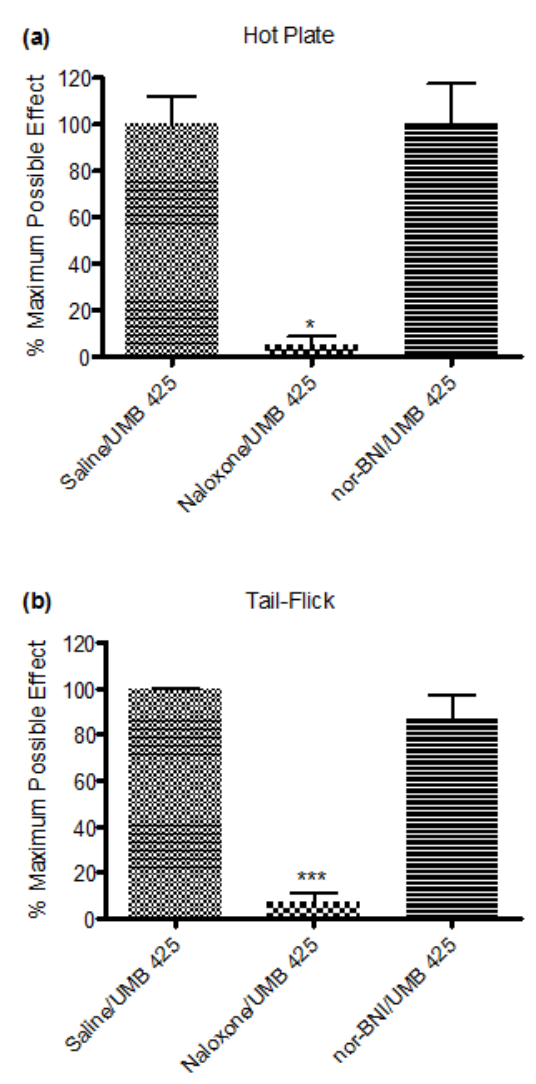

Figure 3.2. Antagonism of UMB 425 antinociception using various opioid antagonists. Male, Swiss Webster mice received a pre-treatment of the non-selective opioid antagonist, naloxone $(1 \mathrm{mg} / \mathrm{kg}$, i.p. $\mathrm{t}=-30 \mathrm{~min})$ or the Kselective antagonist, nor-BNI (30 mg/kg, i.p. $\mathrm{t}=-24 \mathrm{~h})$ prior to an s.c. injection with an ED90 dose of UMB 425 (15 $\mathrm{mg} / \mathrm{kg}$ ). Latencies were determined 30 min after UMB 425 administration. (a) Antagonism of UMB 425 antinociception in the hot plate assay by naloxone, but not nor-BNI. ${ }^{*} p<0.05$. (b) Antagonism of UMB 425 antinociception in the tailflick assay by naloxone, but not nor-BNI. ${ }^{\star * *} p<0.001$.

\subsection{Discussion}

UMB 425 is the first proposed ligand to be tested in vivo due to comparable $\mu$ agonistic effects to that of morphine seen in vitro. A similar dosing paradigm is used for UMB 425, since in vitro $\mu$ receptor binding and functionality for UMB 425 were comparable to morphine. These data show that UMB 425's mixed $\mu$ agonist/ $\delta$ antagonist effects seen in vitro, translate well to antinociceptive effects seen in vivo.

Results seen in Figure 3.1 suggest that the acute antinociceptive effects for UMB 425 are sustained longer than morphine. Differing pharmacokinetic and pharmacodynamic profiles between UMB 425 and morphine can explain this disparity. 
With regards to sustained antinociceptive effects seen in the tail-flick to that of the hot plate assays, as discussed previously, both assays are associated with differing pathways in response to thermal nociceptive stimuli. Respective $\mathrm{ED}_{50}$ values obtained for both morphine and UMB 425 at the $30 \mathrm{~min}$ time point were comparable (Table 3.1), indicating similar antinociceptive effects between the two assays. These results demonstrate that UMB 425 is able to induce its antinociceptive effects through both ascending and descending pain signaling pathways.

Stress induced analgesia is a potential problem that exists for the thermal nociceptive assays that can potentially create problematic bias within these data (200). During acute studies, mice are enclosed in a plastic restraint with an exposed tail for over three hours, potentially stressful for mice not previously exposed to the plastic restraint. To limit experimental bias, mice were acclimated to the plastic restraints $30-60$ min the day prior and the day of testing. In addition, drug solutions are prepared by outside individuals not responsible for data collection in order to limit observer bias.

Pretreatment studies using naloxone are performed to confirm opioid-induced antinociceptive effects. As expected, naloxone is able to abolish the antinociceptive effects upon UMB 425 administration. As shown in the previous chapter, UMB 425 has comparable binding affinity for the $\mathrm{k}$ receptor to that of the $\delta$ receptor, suggesting potential $\mathrm{k}$-mediated effects. However, nor-BNI pretreatment is unable to attenuate the antinociceptive effects of UMB 425 as expected, ensuring that UMB 425 induces little, if any, of its antinociceptive properties through the $\mathrm{k}$ receptor. In the future, pretreatment with the $\mu$-selective antagonist $\beta$-funaltrexamine $(\beta$ FNA) will further corroborate that UMB 425 induced antinociception is mediated through the $\mu$ receptor subtype (201). 


\subsection{Contributions}

Jason Healy performed the thermal antinociceptive experiments as well as the antagonist pretreatment studies. UMB 425 was synthesized by Padmavani Bezawada in the laboratory of Dr. Andrew Coop at the University Of Maryland School Of Pharmacy. 


\section{CHAPTER 4}

EVALUATION OF TOLERANCE LIABILITIES OF NOVEL UMB OPIOID LIGANDS IN VIVO 


\subsection{Introduction}

Opioid induced tolerance is one of several alarming adverse effects produced by chronic use, especially since nearly $90 \%$ of all chronic pain patients are administered opioids (178, 202). Tolerance necessitates that increased dosing be provided to individuals in need of pain relief. However, increased dosing also runs the risk of a patient experiencing additional opioid mediated adverse effects, including physical and psychological dependence (21). As such, the end goal of this project is to identify a novel opioid ligand with potent antinociceptive effects with reduced tolerance liabilities. Therefore, lower therapeutic doses would be needed for pain relief and adverse side effect risks minimized.

As discussed above, several multicomponent opioid-based pharmacotherapies have shown reduced tolerance of antinociceptive effects, specifically by antagonizing the $\delta$ receptor subtype. In addition, several other non-opioid drugs offer promise with regards to reduced tolerance liabilities in conjunction with traditional $\mu$ agonists. Excessive activation of $N$-methyl-Daspartate (NMDA) receptors due to nociceptor-induced glutamate release can cause central sensitization; central sensitization can result in excessive responses from nociceptive stimuli and also reduce opioid analgesic sensitivity (94). As such, concurrent administration of an NMDA antagonist with a traditional $\mu$ agonist may attenuate tolerance liabilities. In fact, methadone possesses NMDA antagonistic capabilities and is able to attenuate morphine induced tolerance development (203). However, methadone still possesses potential tolerance and dependence liabilities $(204,205)$. In addition, certain NMDA antagonists have unfavorable side effect profiles, including acute neurodegenerative changes and psychotic reactions, thereby limiting their potential use in the clinic $(206,207)$. In addition, peptidase inhibitors that prolong the effects of opioid neuropeptides also provide possibilities in reducing tolerance development when administered simultaneously with traditional $\mu$ agonists (208). However, as previously discussed, a multicomponent pharmacotherapy can lend concerns regarding drug 
misuse and diversion. As such, a single component pharmacotherapeutic agent is most advantageous for the treatment individuals suffering from moderate-to-severe pain.

Our tolerance regimen was performed using previously published methods, with some modifications $(156,196)$. In order to identify discernible differences in tolerance development, animals were given $\mathrm{ED}_{90}$ doses of morphine or UMB 425 twice daily and underwent thermal nociceptive testing until a significantly higher level of antinociception was observed for UMB 425 to morphine in both the tail-flick and hot plate assays. This paradigm ensures distinguishable right-ward shifts seen in subsequent dose-response challenges.

\subsection{Methods}

4.2.1. Animals. Male, Swiss-Webster mice (21-30 g, Harlan, Indianapolis, IN; Frederick, MD) were housed in groups of five in polysulfone cages (Techniplast, Philadelphia, PA) with a 12:12-h light/dark cycle with food and water ad libitum. Animals were acclimated one week prior to experimental use and randomly assigned to treatment groups. All procedures were performed in accordance to the Institutional Animal Care and Use Committee at the West Virginia University Health Sciences Center.

4.2.2. Tolerance to Thermal Antinociceptive Effects. Mice were administered twice daily (8 AM and 8 PM) subcutaneous injections of a test compound at respective $E D_{90}$ doses for a five day period. On Day 6, animals were given varying doses of morphine $(0.1-20 \mathrm{mg} / \mathrm{kg})$ or UMB $425(0.1-20 \mathrm{mg} / \mathrm{kg})$ and antinociceptive activity was determined using both the hot plate and tail-flick assays to determine tolerance development. Respective $\mathrm{ED}_{50}$ values determined during the tolerance assay were then compared to values obtained in the acute treatment paradigm. On Days 1-5, the order of the antinociceptive measurements were counterbalanced so that half the mice were assessed for hot plate latencies in the AM and tail-flick latencies in the PM; the other half were tested for tail-flick latencies in the AM and hot plate latencies in the PM. On Day 6, animal test latencies were determined, first with the tail-flick assay followed 15 min later by the hot-plate assay. 
4.2.3. Data Analysis. For the tolerance assay, repeated measures one-way ANOVA followed by Dunnett's post-hoc tests were used to determine significance between treatment days for test compound treatment. Repeated measures two-way ANOVA and Bonferroni's posthoc tests were used to determine significance between groups. For all analyses, $p<0.05$ was considered statistically significant. GraphPad Prism (San Diego, CA) was used for all data analyses.

\subsection{Results}

4.3.1. Tolerance to Thermal Antinociceptive Effects. The results of administration of $E D_{90}$ doses of morphine and UMB 425 to mice twice daily for a period of five days, with test latencies determined 30 min after drug administration are summarized in Figure 4. One-way repeated measures ANOVA demonstrated statistical differences amongst treatment days for morphine administration in both the hot plate (Figure 4.1a; $F(4,76)=15.22, p<0.0001$ ) and tail-flick assays (Figure 4.1b; $F(4,76)=8.52, p<0.0001$ ). Dunnett's post-hoc analysis revealed that morphine administration significantly decreased antinociceptive activity on Day 4 and 5 of the tolerance paradigm for both the hot plate (Figure 4.1a; $q=4.45, p<0.01 ; q=6.52, p<0.01$; respectively) and tail-flick assays (Figure 4.1b; $q=2.72, p<0.05 ; q=5.12, p<0.01$; respectively). One-way repeated measures ANOVA also demonstrated statistical difference amongst treatment days for UMB 425 administration in the hot plate assay (Figure 4.1a; F(4,84) $=9.32, p<0.0001$ ) but not for the tail-flick assay (Figure $4.1 b, F(4,76)=1.53$, n.s.). Dunnett's post-hoc analysis revealed that UMB 425 administration significantly decreased antinociceptive activity on Day 4 and 5 of the tolerance paradigm in the hot plate assay (Figure 4.1a; $q=3.43, p$ $<0.01 ; q=5.11, p<0.01 ;$ respectively).

Two-way repeated measures ANOVA revealed statistical differences between morphine and UMB 425 treatment in time points for both the hot plate (Figure 4.1a; $p<0.0001$ ) and tail flick assays (Figure 4.1b; $p<0.0001$ ). Bonferroni's post-hoc analysis demonstrated that UMB 425 maintained statistically greater antinociceptive activity than morphine on Day 4 and 5 for the 
hot plate assay (Figure 4.1 a; $\mathrm{t}=2.86, \mathrm{p}<0.05 ; \mathrm{t}=4.15, \mathrm{p}<0.001 ;$ respectively) and on Day 5 for the tail-flick assay (Figure 4.1b; $t=2.88, p<0.05$ ).

Our tolerance paradigm involves thermal nociceptive testing on a daily basis to ensure that a statistical difference in antinociceptive activity is seen between morphine and UMB 425 prior to a dose-response challenge. Table 4.1 summarizes respective $\mathrm{ED}_{50}$ values for morphine and UMB 425 from the dose-response challenge on Day 6 of the tolerance paradigm. UMB 425 $\left(E D_{50}=12.96\right.$ and $11.58 \mathrm{mg} / \mathrm{kg}$ for the hot plate and tail-flick assays, respectively) produced markedly less tolerance development than morphine $\left(E D_{50}=21.31\right.$ and $44.11 \mathrm{mg} / \mathrm{kg}$ for the hot plate and tail-flick assays, respectively), as evident by the respective rightward shifts in $E D_{50}$ values (7.8- vs. 3.0-fold and 6.4- vs. 1.3-fold for morphine vs. UMB 425 in the hot plate and tailflick assays, respectively).

Hot Plate

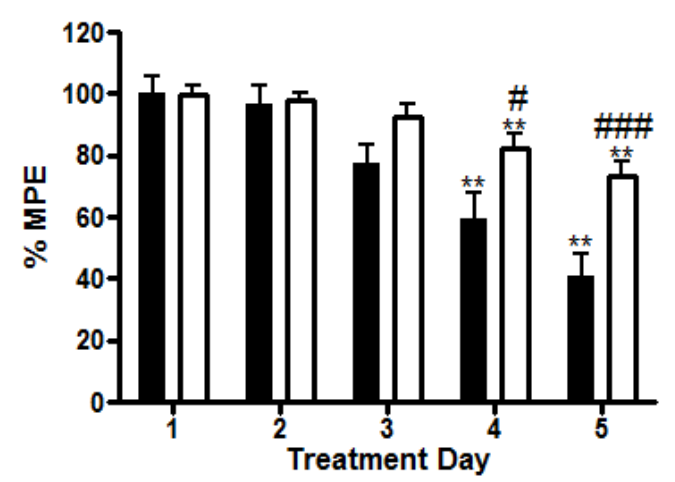

Tail-Flick

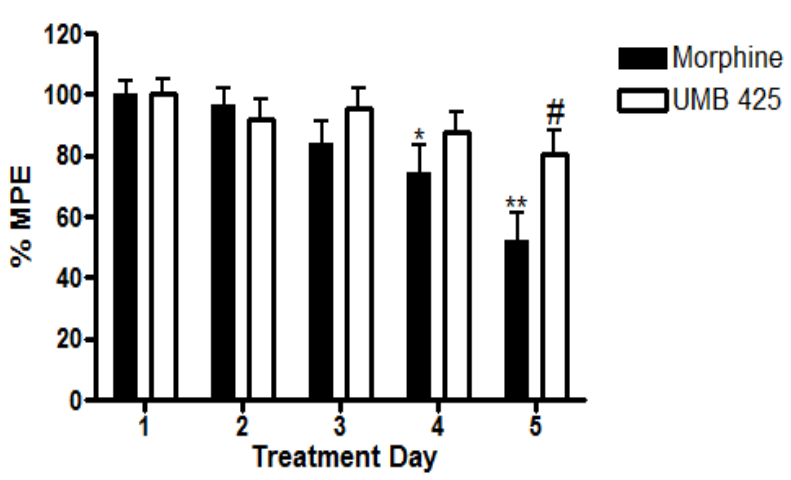

Figure 4.1. Antinociceptive tolerance development for morphine and UMB 425 for the hot plate and tail-flick assays. Male, Swiss-Webster mice were given an ED90 dose of morphine (15 mg/kg, s.c.) or UMB 425 (15 mg/kg, s.c.) twice daily for a five day period. Latencies were determined 30 min after drug administration. (a) Antinociceptive tolerance development in the hot plate assay. ${ }^{* *} p<0.01$ vs. Morphine Day 1/UMB 425 Day 1 ; \# $p<0.05$ vs. Morphine Day 4; \#\#\# p < 0.001 vs. Morphine Day 5. (b) Antinociceptive tolerance development in the tail-flick assay. ${ }^{*} p<0.05,{ }^{* *} p<0.01$ vs. Morphine Day $1 ; \# p<0.05$ vs. Morphine Day 5. 


\begin{tabular}{|c|c|c|c|c|}
\hline \multirow{2}{*}{$\mathrm{ED}_{50}(\mathrm{mg} / \mathrm{kg})$} & \multicolumn{2}{|c|}{ Morphine } & \multicolumn{2}{c|}{ UMB 425 } \\
\cline { 2 - 5 } & Tolerance & Shift & Tolerance & Shift \\
\hline Hot Plate & 21.31 & 7.8 & 12.96 & 3.0 \\
\hline Tail-Flick & 44.11 & 6.4 & 11.58 & 1.3 \\
\hline
\end{tabular}

Table 4.1. $\mathrm{ED}_{50}$ values for morphine and UMB 425 in the tolerance treatment paradigms. Summary of antinociceptive activity obtained for the tolerance paradigm for morphine and UMB 425 for the hot-plate and tail-flick assays. Mice were treated with the EDgo dose of morphine $(15 \mathrm{mg} / \mathrm{kg})$ or UMB $425(15 \mathrm{mg} / \mathrm{kg})$ determined in the acute treatment paradigm, twice a day for five days. $\mathrm{ED}_{50}$ values for the tolerance paradigm were obtained during a dose-response challenge on Day 6 of treatment, whereby latencies were determined 30 min after drug administration (tolerance columns). The shifts represent fold-shifts in the $\mathrm{ED}_{50}$ determined in the acute vs. tolerance treatment paradigms.

\subsection{Discussion}

UMB 425 maintains greater levels of antinociceptive activity compared to morphine during a six day paradigm used to mimic opioid-induced chronic tolerance. Dose-response curves generated on Day 6 using varying doses of UMB 425 or morphine indicate a greater right-ward shift in respective $\mathrm{ED}_{50}$ values for morphine compared to UMB 425 . While we used male, Swiss-Webster mice, respective $\mathrm{ED}_{50}$ shifts in the morphine-treated tolerance paradigm seen on Day 6 were comparable to tolerance paradigms previously performed using male ICR mice (156). Regimen variations regarding drug dosing, route of administration, number of injections per day as well as the time length of the paradigm can lead to slight variations.

The antagonistic potency of UMB 425 through the $\delta$ receptor reported in Chapter $2\left(\mathrm{pA}_{2}\right.$ $=6.12)$ is lower than previously highlighted $\mu$ agonist/ $\delta$ antagonist analgesics, notably 11-(4chlorophenyl)-7-(cyclopropylmethyl)-8a-(3-phenylpropoxy)-6,7,8,8a,9,13b-hexahydro-5H-4,8 methanobenzofuro[3,2- $h$ ]pyrido[3,4-g]quinolin-1-ol or "17d" $\left(\delta \mathrm{K}_{\mathrm{e}}=0.091 \pm 0.01 \mathrm{nM}\right)(155)$, as well as the $\delta$-selective antagonist naltrindole $\left(\mathrm{pA}_{2}=10.92\right)(186)$. Yet, UMB 425 demonstrates a significant reduction in tolerance liabilities compared to morphine itself, specifically a 2.6- and 4.9-fold reduction in respective $\mathrm{ED}_{50}$ shifts for the hot plate and tail-flick assays. The recently reported mixed $\mu$ agonist/ $\delta$ antagonist analgesic $17 \mathrm{~d}$ was found to have a 5.6 -fold decrease in respective $A_{50}$ shifts compared to morphine itself in the warm-water tail-withdrawal assay (155). The respective shift-fold variations between the in vivo studies are thus quite comparable despite the lower affinity and antagonist potency of UMB 425 compared to $17 d$ for the $\delta$ 
receptor in vitro. Thus, equipotence at the $\mu$ and $\delta$ receptor does not seem required to improve tolerance liabilities of opioid analgesics.

The molecular mechanisms surrounding opioid-induced tolerance are still not clear, although many efforts have been taken to discern the labyrinth of potential components involved. Morphine, a partial $\mu$ agonist, is unable to properly internalize the $\mu$ receptor upon activation, whereby desensitization and uncoupling of the G-protein lead to the development of tolerance (103). $\delta$ receptor recruitment to the plasma membrane has been shown to increase with extended exposure to $\mu$ agonists (209). Furthermore, $\delta$ antagonists can provide synergistic effects in combination with $\mu$ agonists that enhances $\mu$ receptor binding and signaling in cells expressing $\mu-\delta$ hetero-dimers, potentially through altered G-protein activation (131). It is conceivable that the $\mu$ agonist/ $\delta$ antagonist interactions through UMB 425 allow for proper internalization, driven by the $\delta$ receptor in the hetero-oligomeric complex, and subsequent $\mu$ receptor mediated recycling and resensitization thereby leading to reduced tolerance development.

In addition, G protein recruitment may be altered upon UMB 425 administration, compared to chronic administration of traditional $\mu$ agonists or opioid naive systems. Opioid receptors induce their inhibitory effect through the $\mathrm{G}_{\mathrm{i} / \mathrm{o}}$ family of $\mathrm{G}$-proteins. However, opioid receptors have also been linked to $G_{z}$ proteins, which, as a part of the $G_{i}$ family, induce similar inhibitory effects, as well as $\mathrm{G}_{\mathrm{s}}$ proteins, which induce upregulation of cAMP and subsequent downstream effectors. Studies have shown that $\mu-\delta$ hetero-oligomers switch G-protein preference from $G_{i}$ to $G_{z}(210)$. Interestingly, $G_{z}$ proteins recruited by $\mu$ receptors are not involved in sensitization of $A C$ (49), suggesting reduced tolerance liabilities associated with $G_{z}$ protein recruitment. Furthermore, $\mathrm{G}_{\mathrm{z}}$ deficient mice develop tolerance to morphine at a faster rate and to a greater degree than their wild-type counterparts (211).

Lastly, GPCR kinase (GRKs) and $\beta$-arrestin regulatory processes have been linked to opioid-induced tolerance (212). Concurrent $\mu$ agonist/ $\delta$ antagonist activity may alter 
phosphorylation and recruitment mechanisms involved with these processes, potentially limiting GPCR desensitization. Follow up studies will be needed to delineate the underlying mechanisms through which UMB 425 reduces the development of tolerance compared to morphine.

\subsection{Contributions}

Jason Healy performed the tolerance regimens using thermal nociceptive apparatuses. UMB 425 was synthesized by Padmavani Bezawada in the laboratory of Dr. Andrew Coop at the University Of Maryland School Of Pharmacy. 


\section{CHAPTER 5}

\section{CONCLUSIONS \& FUTURE STUDIES}




\subsection{Summary}

The studies herein demonstrate that a mixed $\mu$ agonist $/ \delta$ antagonist opioid analgesic is able to reduce tolerance liabilities with chronic administration without demonstrating equipotency for both the $\mu$ and $\delta$ receptor subtypes. UMB 425, a 5,14-bridged morphinan-based orvinol precursor lacks $\delta$-selective motifs fused to the C-ring of the traditional opioid pharmacophore. CSP models predicted that UMB 425 would demonstrate high efficacy at the $\mu$ receptor with near pure antagonist capabilities at the $\delta$ receptor. $\left[{ }^{35} \mathrm{~S}\right] \mathrm{GTPYS}$ functional assays confirmed these predictions in $\mathrm{CHO}$ cells transfected with and overexpressing the respective human opioid receptor subtypes. UMB 425 displayed potent antinociceptive effects in vivo, comparable to morphine, which was subsequently blocked by naloxone pretreatment. During a six day tolerance paradigm, UMB 425 was able to maintain significantly higher levels of antinociception compared to morphine.

\subsection{Future Studies and Direction}

5.2.1. Future studies involving UMB 425. The results herein for UMB 425 are promising, though additional studies need to be performed in order to develop a more comprehensive pharmacological profile. From a clinical stand point, the concerns surrounding respiratory depression and constipation liabilities are most concerning. Traditional $\mu$ agonists used for pain management have been shown to decrease both respiration as well as gastrointestinal motility (21). Research has shown that $\delta$-selective antagonists can attenuate respiratory depression liabilities (213) and promote colonic propulsion (214). Blood gas analysis and whole body plethysmography paradigms can be used for extensive respiration studies in vivo (215-217). Charcoal meal and ricinus oil paradigms are used to assess alterations in gastrointestinal motility and propulsion in vivo $(218,219)$.

Furthermore, long-term pain management that includes chronic $\mu$ agonist administration can leave a patient more susceptible to the damaging side effects of psychological and physical dependence (21). $\delta$-selective antagonists and $\delta$ opioid receptor knockout mice have been 
shown to attenuate the rewarding properties of morphine $(220,221)$. Conditioned place preference and self-administration paradigms can assess the psychological rewarding effects associated with UMB 425 administration $(222,223)$. In addition, mixed $\mu$ agonist/ $\delta$ antagonist opioid analgesics have been shown to reduce physical dependence liabilities (156). Physical dependence liabilities can be assessed by acute and chronic administration of UMB 425 prior to naloxone administration to precipitate and assess withdrawal symptoms; symptoms include vertical jumps, teeth chattering, wet-dog shakes, tremors and diarrhea $(76,156)$.

UMB 425 should also be tested for its antinociceptive effects using tonic nociceptive stimuli. The two thermal nociceptive testing apparatuses, hot plate and tail-flick, used for in vivo studies herein are succinct and escapable and thus indicative of phasic nociceptive stimuli (195). Physiological adaptations have been shown to occur as a result of chronic pain and are thought to manifest in paradigms of tonic nociceptive stimuli, such as the writhing (224) and formalin assays (225-227). Chemically induced visceral nociception is observed during writhing assays, while the formalin and Freund's adjuvant assays can be used to demonstrate inflammatory nociception $(195,228)$. The orvinol buprenorphine is a unique opioid analgesic with mixed $\mu$ agonist/ $\delta$ antagonist properties that has been shown to induce differing antinociceptive responses via phasic nociceptive stimuli to that of tonic nociceptive stimuli (229). UMB 425 may interact with the respective receptor subtypes similarly to that of buprenorphine, such that differing antinociceptive responses may be plausible. Peripheral neuropathic pain is a result of damage to primary afferent axons and nerve inflammation (230). Since it has been shown that pathophysiological responses to peripheral nerve injury and acute noxious stimuli differ from one another (231), numerous rodent models have been devised that aim to mirror the underlying mechanisms associated with neuropathic pain. These models include the constriction and ligation of spinal nerves (232) which assess behavioral responses to temperature-related noxious stimuli believed to mimic the clinical pain conditions hyperalgesia and allodynia $(233,234)$. Nociceptive models of bone pain have also been devised to mimic 
hyperalgesic and allodynic conditions (235). The von Frey test uses mechanical nociceptive stimuli to mimic neuropathic pain (195). An assortment of nociceptive models can provide further evidence as to the feasibility of UMB 425 for human use.

In addition, further studies delineating UMB 425's pharmacodynamic and pharmacokinetic properties will further attest clinical viability. Preclinical ADME studies can be performed to investigate the absorption, distribution, metabolism and excretion of UMB 425 both in vitro and in vivo. The cytochrome p450 pathway is involved in the oxidative metabolism of many opioid narcotics. UMB 425 treatment with human liver microsomes and cDNA-expressed p450's (CYP1A2, 2C8, 2C9, 2C19, 2D6 or 3A4) can determine pharmacokinetic variables and identify subsequent metabolites using standard analytical techniques, including high performance liquid chromatography (HPLC) and liquid chromatography/tandem mass spectrometry (LC/MS/MS) systems (236-240). Known cytochrome p450 inducers/inhibitors can be examined at their respective isoforms to determine alterations in oxidative metabolism of UMB 425 (241). One of the primary advantages of metabolic paradigms performed in vivo is the determination of pharmacokinetic profiles with various routes of administration (241). Varying concentrations of UMB 425 can be used with blood and urine samples taken at varying time points and analyzed using standard analytical techniques.

As discussed above, opioid induced tolerance has been linked to multiple GPCR regulatory functions, including receptor phosphorylation, internalization, desensitization and resensitization (103). Studies that dissect GPCR regulatory functions upon treatment with UMB 425 will provide further examination on to the underlying mechanisms associated with mixed $\mu$ agonist/ $\delta$ antagonist opioid ligands and reduced tolerance liabilities. Whole cell phosphorylation assays can be performed via imunnoprecipitation studies utilizing epitope tagged cells expressing both the $\mu$ and $\delta$ receptor subtypes under various treatment regiments, including UMB 425 in addition to DAMGO and morphine controls (242). cAMP accumulation studies can be performed to determine the desensitization/resensitization effects in the presence of UMB 
425 (242); studies which will further explore the AC superactivation theory of tolerance development with respect to UMB 425. Endocytotic studies can be performed using fluorescently labeled epitope tagged cells that determine receptor internalization levels upon exposure to UMB 425 and agonist controls (242). Furthermore, bioluminescence resonance energy transfer (BRET) assays can be utilized to determine UMB 425-induced G protein preference under varying experimental conditions (210). The GPCR regulatory protein $\beta$-arrestin 2 has been shown to induce differing cellular responses depending on $\mu$ agonist treatment. Chronic morphine administration does not induce tolerance development in $\beta$-arrestin 2 knockout animals; however, chronic administration of methadone, fentanyl, and oxycodone show no difference in tolerance development compared to wild type animals (243). Chronic UMB 425 antinociceptive effects can be assessed using $\beta$-arrestin 2 knockout animals to further delineate the role of $\beta$-arrestin 2 in opioid-induced tolerance.

These studies can and should be performed using alternative forms of pain management pharmacotherapy to ensure that UMB 425, or any another ligand identified within this series, serves as the best combination of reducing pain while minimizing side effect liabilities. Preclinical studies performed in vitro and in vivo can provide initial assessments; however, further assessment in the clinic will provide medical care providers with the most pertinent information. Unfortunately, the fact remains that we still have yet to identify discernible factors that can pinpoint chronic pain patients for opioid narcotic misuse and diversion, a fact which concerns physicians of potential legal ramifications. As such, federal and state agencies have implemented laws and programs, including prescription monitoring programs (PMPs), to not only circumvent prescription opioid diversion and abuse but also to ensure that patients are not denied prescriptions opioids when necessary $(159,173)$. Reports have shown that past histories of alcohol and drug abuse and criminal convictions are statistically higher risk factors associated with prescription opioid misuse (244). Yet, one of the best ways for the physician to ensure 
patient compliance is to develop prescription management plans which include treatment goals, follow-up scheduling and urine testing if necessary (245).

5.2.2. Future studies involving additional opioid ligands targeted for mixed $\mu$ agonist/ $\delta$ antagonist profiles. UMB 425 is a 5,14-bridged morphinan-based precursor. Opioid SAR has previously shown that structural modifications made to the 6,14-bridge associated with the orvinols and related opioids can possibly influence both binding affinity and functionalities at the respective opioid receptor subtypes $(170,171)$. Additional compounds can and will be synthesized that better delineate the SAR between the 5,14-bridge and the $\delta$-selective motifs fused to the C-ring, including the indole group of the indolomorphinans and the benzylidene moiety in the opioid benzylidenes.

Questions regarding equipotency between $\mu$ and $\delta$ and tolerance development can be further explored. Since UMB 425 does not possess traditional $\delta$-selective motifs, we can step back and reexamine the $\mu$ agonist/ $\delta$ antagonist assumptions previously made. For UMB 425 , the 5'-hydroxymethyl substituent is hypothesized to possess the necessary $\delta$ antagonistic properties that aids in tolerance reduction. CSP modeling studies herein have demonstrated probabilistic overlaps between UMB 425 and orvinol standards with regards to conformational distances and angles. The most recent compound tested, UMB 449, has extended the 5'hydroxymethyl into a 5'-hydroxypropyl substituent chain. This slight structural modification should improve upon the probabilistic overlap for the distance between the basic nitrogen and the hydroxyl oxygen and mirror results seen for the orvinol standards. These modifications will provide further insight into the binding affinity and level of functionality necessary for the $\delta$ receptor for reduced tolerance liabilities. 


\section{References}

1. Bonica, J. J. (1979) The need of a taxonomy, Pain 6, 247-248.

2. $\quad$ Carr, D. B., and Goudas, L. C. (1999) Acute pain, Lancet 353, 2051-2058.

3. Turk, D. C., and Okifuji, A. (2001) Pain Terms and Taxonomies of Pain, In Bonica's Management of Pain (Loeser, J. D., Ed.), p 2178, Lippincoot Williams \& Wilkins.

4. $\quad$ Cervero, F., and Laird, J. M. (1999) Visceral pain, Lancet 353, 2145-2148.

5. Bogduk, N. (2002) The physiology of deep somatic pain, Australas Musculoskeletal Med 7, 6-15.

6. Henderson, L. A., Bandler, R., Gandevia, S. C., and Macefield, V. G. (2006) Distinct forebrain activity patterns during deep versus superficial pain, Pain 120, 286-296.

7. Woolf, C. J., and Mannion, R. J. (1999) Neuropathic pain: aetiology, symptoms, mechanisms, and management, Lancet 353, 1959-1964.

8. Nikolajsen, L., and Jensen, T. S. (2001) Phantom limb pain, Br J Anaesth 87, 107-116.

9. Krashin, D., Murinova, N., and Trescot, A. M. (2013) Extended-release hydrocodone gift or curse?, J Pain Res 6, 53-57.

10. Fitzgibbon, D. R., Posner, K. L., Domino, K. B., Caplan, R. A., Lee, L. A., and Cheney, F. W. (2004) Chronic pain management: American Society of Anesthesiologists Closed Claims Project, Anesthesiology 100, 98-105.

11. Verdu, B., Decosterd, I., Buclin, T., Stiefel, F., and Berney, A. (2008) Antidepressants for the treatment of chronic pain, Drugs 68, 2611-2632.

12. Chabal, C., Jacobson, L., Mariano, A., Chaney, E., and Britell, C. W. (1992) The use of oral mexiletine for the treatment of pain after peripheral nerve injury, Anesthesiology 76, 513-517.

13. Fassoulaki, A., Triga, A., Melemeni, A., and Sarantopoulos, C. (2005) Multimodal analgesia with gabapentin and local anesthetics prevents acute and chronic pain after breast surgery for cancer, Anesth Analg 101, 1427-1432.

14. Hunskaar, S., and Hole, K. (1987) The formalin test in mice: dissociation between inflammatory and non-inflammatory pain, Pain 30, 103-114.

15. Toth, P. P., and Urtis, J. (2004) Commonly used muscle relaxant therapies for acute low back pain: a review of carisoprodol, cyclobenzaprine hydrochloride, and metaxalone, Clin Ther 26, 1355-1367.

16. Smith, H., and Elliott, J. (2001) Alpha(2) receptors and agonists in pain management, Curr Opin Anaesthesiol 14, 513-518.

17. Pacher, P., Batkai, S., and Kunos, G. (2006) The endocannabinoid system as an emerging target of pharmacotherapy, Pharmacol Rev 58, 389-462.

18. Munir, M. A., Enany, N., and Zhang, J. M. (2007) Nonopioid analgesics, Med Clin North Am 91, 97-111.

19. Cherny, N. J., Chang, V., Frager, G., Ingham, J. M., Tiseo, P. J., Popp, B., Portenoy, R. K., and Foley, K. M. (1995) Opioid pharmacotherapy in the management of cancer pain: a survey of strategies used by pain physicians for the selection of analgesic drugs and routes of administration, Cancer 76, 1283-1293.

20. Walder, B., Schafer, M., Henzi, I., and Tramer, M. R. (2001) Efficacy and safety of patient-controlled opioid analgesia for acute postoperative pain. A quantitative systematic review, Acta Anaesthesiol Scand 45, 795-804.

21. Benyamin, R., Trescot, A. M., Datta, S., Buenaventura, R., Adlaka, R., Sehgal, N., Glaser, S. E., and Vallejo, R. (2008) Opioid complications and side effects, Pain Physician 11, S105-120.

22. Trescot, A. M., Datta, S., Lee, M., and Hansen, H. (2008) Opioid pharmacology, Pain Physician 11, S133-153. 
23. Grond, S., and Sablotzki, A. (2004) Clinical pharmacology of tramadol, Clin Pharmacokinet 43, 879-923.

24. McQuay, H. J. (1991) Opioid clinical pharmacology and routes of administration, Br Med Bull 47, 703-717.

25. Brunton, L. L., Lazo, J. S., and Parker, K. L. (2005) Goodman \& Gilman's The Pharmacological Basis of Therapeutics, Vol. 11, McGraw-Hill Professional.

26. Stevens, R. A., and Ghazi, S. M. (2000) Routes of opioid analgesic therapy in the management of cancer pain, Cancer Control 7, 132-141.

27. Donnelly, S., Davis, M. P., Walsh, D., and Naughton, M. (2002) Morphine in cancer pain management: a practical guide, Support Care Cancer 10, 13-35.

28. Pasternak, G. W., Bodnar, R. J., Clark, J. A., and Inturrisi, C. E. (1987) Morphine-6glucuronide, a potent mu agonist, Life Sci 41, 2845-2849.

29. Smith, M. T., Watt, J. A., and Cramond, T. (1990) Morphine-3-glucuronide--a potent antagonist of morphine analgesia, Life Sci 47, 579-585.

30. Berkowitz, B. A. (1976) The relationship of pharmacokinetics to pharmacological activity: morphine, methadone and naloxone, Clin Pharmacokinet 1, 219-230.

31. Manchikanti, L. (2007) National drug control policy and prescription drug abuse: facts and fallacies, Pain Physician 10, 399-424.

32. Paulozzi, L. J., Budnitz, D. S., and Xi, Y. (2006) Increasing deaths from opioid analgesics in the United States, Pharmacoepidemiol Drug Saf 15, 618-627.

33. Wanger, K., Brough, L., Macmillan, I., Goulding, J., MacPhail, I., and Christenson, J. M. (1998) Intravenous vs subcutaneous naloxone for out-of-hospital management of presumed opioid overdose, Acad Emerg Med 5, 293-299.

34. Sporer, K. A. (2003) Strategies for preventing heroin overdose, BMJ 326, 442-444.

35. Joranson, D. E., Gilson, A. M., Dahl, J. L., and Haddox, J. D. (2002) Pain management, controlled substances, and state medical board policy: a decade of change, J Pain Symptom Manage 23, 138-147.

36. Parran, T., Jr. (1997) Prescription drug abuse. A question of balance, Med Clin North Am 81, 967-978.

37. Weinstein, S. M., Laux, L. F., Thornby, J. I., Lorimor, R. J., Hill, C. S., Jr., Thorpe, D. M., and Merrill, J. M. (2000) Physicians' attitudes toward pain and the use of opioid analgesics: results of a survey from the Texas Cancer Pain Initiative, South Med J 93, 479-487.

38. Weissman, D. E., Joranson, D. E., and Hopwood, M. B. (1991) Wisconsin physicians' knowledge and attitudes about opioid analgesic regulations, Wis Med J 90, 671-675.

39. Stewart, W. F., Ricci, J. A., Chee, E., Morganstein, D., and Lipton, R. (2003) Lost productive time and cost due to common pain conditions in the US workforce, JAMA 290, 2443-2454.

40. Gottschalk, A., Smith, D. S., Jobes, D. R., Kennedy, S. K., Lally, S. E., Noble, V. E., Grugan, K. F., Seifert, H. A., Cheung, A., Malkowicz, S. B., Gutsche, B. B., and Wein, A. J. (1998) Preemptive epidural analgesia and recovery from radical prostatectomy: a randomized controlled trial, JAMA 279, 1076-1082.

41. Perkins, F. M., and Kehlet, H. (2000) Chronic pain as an outcome of surgery. A review of predictive factors, Anesthesiology 93, 1123-1133.

42. Kalso, E., Edwards, J. E., Moore, R. A., and McQuay, H. J. (2004) Opioids in chronic non-cancer pain: systematic review of efficacy and safety, Pain 112, 372-380.

43. Zacny, J., Bigelow, G., Compton, P., Foley, K., Iguchi, M., and Sannerud, C. (2003) College on Problems of Drug Dependence taskforce on prescription opioid non-medical use and abuse: position statement, Drug Alcohol Depend 69, 215-232.

44. Waldhoer, M., Bartlett, S. E., and Whistler, J. L. (2004) Opioid receptors, Annu Rev Biochem 73, 953-990. 
45. Stein, C., Schafer, M., and Machelska, H. (2003) Attacking pain at its source: new perspectives on opioids, Nat Med 9, 1003-1008.

46. Joost, P., and Methner, A. (2002) Phylogenetic analysis of 277 human G-proteincoupled receptors as a tool for the prediction of orphan receptor ligands, Genome Biol 3, RESEARCH0063.

47. Chakrabarti, S., Rivera, M., Yan, S. Z., Tang, W. J., and Gintzler, A. R. (1998) Chronic morphine augments $\mathrm{G}$ (beta)(gamma)/Gs(alpha) stimulation of adenylyl cyclase: relevance to opioid tolerance, Mol Pharmacol 54, 655-662.

48. Chakrabarti, S., Regec, A., and Gintzler, A. R. (2005) Biochemical demonstration of muopioid receptor association with Gsalpha: enhancement following morphine exposure, Brain Res Mol Brain Res 135, 217-224.

49. Tso, P. H., and Wong, Y. H. (2000) G(z) can mediate the acute actions of mu- and kappa-opioids but is not involved in opioid-induced adenylyl cyclase supersensitization, $J$ Pharmacol Exp Ther 295, 168-176.

50. Pert, C. B., and Snyder, S. H. (1973) Opiate receptor: demonstration in nervous tissue, Science 179, 1011-1014.

51. Wang, J. B., Johnson, P. S., Persico, A. M., Hawkins, A. L., Griffin, C. A., and Uhl, G. R. (1994) Human mu opiate receptor. cDNA and genomic clones, pharmacologic characterization and chromosomal assignment, FEBS Lett 338, 217-222.

52. Evans, C. J., Keith, D. E., Jr., Morrison, H., Magendzo, K., and Edwards, R. H. (1992) Cloning of a delta opioid receptor by functional expression, Science 258, 1952-1955.

53. Mansson, E., Bare, L., and Yang, D. (1994) Isolation of a human kappa opioid receptor cDNA from placenta, Biochem Biophys Res Commun 202, 1431-1437.

54. Kieffer, B. L., and Gaveriaux-Ruff, C. (2002) Exploring the opioid system by gene knockout, Prog Neurobiol 66, 285-306.

55. Ikeda, K., Ide, S., Han, W., Hayashida, M., Uhl, G. R., and Sora, I. (2005) How individual sensitivity to opiates can be predicted by gene analyses, Trends Pharmacol Sci 26, 311317.

56. Chen, Y., Mestek, A., Liu, J., and Yu, L. (1993) Molecular cloning of a rat kappa opioid receptor reveals sequence similarities to the mu and delta opioid receptors, Biochem $J$ 295 ( Pt 3), 625-628.

57. Akil, H., Owens, C., Gutstein, H., Taylor, L., Curran, E., and Watson, S. (1998) Endogenous opioids: overview and current issues, Drug Alcohol Depend 51, 127-140.

58. Cadet, P., Mantione, K. J., and Stefano, G. B. (2003) Molecular identification and functional expression of mu 3 , a novel alternatively spliced variant of the human mu opiate receptor gene, $J$ Immunol 170, 5118-5123.

59. de Costa, B. R., Rothman, R. B., Bykov, V., Jacobson, A. E., and Rice, K. C. (1989) Selective and enantiospecific acylation of kappa opioid receptors by (1S,2S)-trans-2isothiocyanato-N-methyl-N-[2-(1-pyrrolidinyl) cyclohexy I] benzeneacetamide. Demonstration of kappa receptor heterogeneity, J Med Chem 32, 281-283.

60. Jordan, B. A., and Devi, L. A. (1999) G-protein-coupled receptor heterodimerization modulates receptor function, Nature 399, 697-700.

61. Rothman, R. B., France, C. P., Bykov, V., De Costa, B. R., Jacobson, A. E., Woods, J. H., and Rice, K. C. (1989) Pharmacological activities of optically pure enantiomers of the kappa opioid agonist, U50,488, and its cis diastereomer: evidence for three kappa receptor subtypes, Eur J Pharmacol 167, 345-353.

62. Przewlocki, R., and Przewlocka, B. (2001) Opioids in chronic pain, Eur J Pharmacol 429, 79-91.

63. Hughes, J., and Kosterlitz, H. W. (1983) Opioid Peptides: introduction, Br Med Bull 39, 13. 
64. Akil, H., Meng, F., Devine, D. P., and Watson, S. (1997) Molecular and neuroanatomical properties of the endogenous opioid system: implications for treatment of opiate addiction, In Seminars in neuroscience, pp 70-83, Elsevier.

65. Portoghese, P. S., Sultana, M., and Takemori, A. E. (1990) Design of peptidomimetic delta opioid receptor antagonists using the message-address concept, J Med Chem 33, 1714-1720.

66. Schoffelmeer, A. N., Warden, G., Hogenboom, F., and Mulder, A. H. (1991) Betaendorphin: a highly selective endogenous opioid agonist for presynaptic mu opioid receptors, J Pharmacol Exp Ther 258, 237-242.

67. Koneru, A., Satyanarayana, S., and Rizwan, S. (2009) Endogenous opioids: their physiological role and receptors, Global J Pharmacol 3, 149-153.

68. Stone, L. S., Fairbanks, C. A., Laughlin, T. M., Nguyen, H. O., Bushy, T. M., Wessendorf, M. W., and Wilcox, G. L. (1997) Spinal analgesic actions of the new endogenous opioid peptides endomorphin-1 and -2, Neuroreport 8, 3131-3135.

69. Greco, M. A., Fuller, P. M., Jhou, T. C., Martin-Schild, S., Zadina, J. E., Hu, Z., Shiromani, P., and Lu, J. (2008) Opioidergic projections to sleep-active neurons in the ventrolateral preoptic nucleus, Brain Res 1245, 96-107.

70. Comb, M., Rosen, H., Seeburg, P., Adelman, J., and Herbert, E. (1983) Primary structure of the human proenkephalin gene, DNA 2, 213-229.

71. Lord, J. A., Waterfield, A. A., Hughes, J., and Kosterlitz, H. W. (1977) Endogenous opioid peptides: multiple agonists and receptors, Nature 267, 495-499.

72. Hughes, J., Kosterlitz, H. W., and Smith, T. W. (1977) The distribution of methionineenkephalin and leucine-enkephalin in the brain and peripheral tissues, $\mathrm{Br} \mathrm{J}$ Pharmacol 61, 639-647.

73. Konig, M., Zimmer, A. M., Steiner, H., Holmes, P. V., Crawley, J. N., Brownstein, M. J., and Zimmer, A. (1996) Pain responses, anxiety and aggression in mice deficient in preproenkephalin, Nature 383, 535-538.

74. Day, R., Lazure, C., Basak, A., Boudreault, A., Limperis, P., Dong, W., and Lindberg, I. (1998) Prodynorphin processing by proprotein convertase 2. Cleavage at single basic residues and enhanced processing in the presence of carboxypeptidase activity, J Biol Chem 273, 829-836.

75. Chavkin, C. (2013) Dynorphin-still an extraordinarily potent opioid Peptide, Mol Pharmacol 83, 729-736.

76. Kieffer, B. L. (1999) Opioids: first lessons from knockout mice, Trends Pharmacol Sci 20, 19-26.

77. Matthes, H. W., Maldonado, R., Simonin, F., Valverde, O., Slowe, S., Kitchen, I., Befort, K., Dierich, A., Le Meur, M., Dolle, P., Tzavara, E., Hanoune, J., Roques, B. P., and Kieffer, B. L. (1996) Loss of morphine-induced analgesia, reward effect and withdrawal symptoms in mice lacking the mu-opioid-receptor gene, Nature 383, 819-823.

78. Matthes, H. W., Smadja, C., Valverde, O., Vonesch, J. L., Foutz, A. S., Boudinot, E., Denavit-Saubie, M., Severini, C., Negri, L., Roques, B. P., Maldonado, R., and Kieffer, B. L. (1998) Activity of the delta-opioid receptor is partially reduced, whereas activity of the kappa-receptor is maintained in mice lacking the mu-receptor, $J$ Neurosci 18,7285 7295.

79. Sora, I., Funada, M., and Uhl, G. R. (1997) The mu-opioid receptor is necessary for [DPen2,D-Pen5]enkephalin-induced analgesia, Eur J Pharmacol 324, R1-2.

80. Zhu, Y., King, M., Schuller, A., Unterwald, E., Pasternak, G., and Pintar, J. (1997) Genetic disruption of the mouse delta opioid receptor gene, In Soc. Neurosci. Abstr, p 584.

81. Simonin, F., Valverde, O., Smadja, C., Slowe, S., Kitchen, I., Dierich, A., Le Meur, M., Roques, B. P., Maldonado, R., and Kieffer, B. L. (1998) Disruption of the kappa-opioid 
receptor gene in mice enhances sensitivity to chemical visceral pain, impairs pharmacological actions of the selective kappa-agonist $\mathrm{U}-50,488 \mathrm{H}$ and attenuates morphine withdrawal, EMBO J 17, 886-897.

82. Meunier, J. C., Mollereau, C., Toll, L., Suaudeau, C., Moisand, C., Alvinerie, P., Butour, J. L., Guillemot, J. C., Ferrara, P., Monsarrat, B., and et al. (1995) Isolation and structure of the endogenous agonist of opioid receptor-like ORL1 receptor, Nature 377, 532-535.

83. Reinscheid, R. K., Nothacker, H. P., Bourson, A., Ardati, A., Henningsen, R. A., Bunzow, J. R., Grandy, D. K., Langen, H., Monsma, F. J., Jr., and Civelli, O. (1995) Orphanin FQ: a neuropeptide that activates an opioidlike $\mathrm{G}$ protein-coupled receptor, Science 270, 792-794.

84. Mollereau, C., Parmentier, M., Mailleux, P., Butour, J. L., Moisand, C., Chalon, P., Caput, D., Vassart, G., and Meunier, J. C. (1994) ORL1, a novel member of the opioid receptor family. Cloning, functional expression and localization, FEBS Lett 341, 33-38.

85. Nothacker, H. P., Reinscheid, R. K., Mansour, A., Henningsen, R. A., Ardati, A., Monsma, F. J., Jr., Watson, S. J., and Civelli, O. (1996) Primary structure and tissue distribution of the orphanin FQ precursor, Proc Natl Acad Sci U S A 93, 8677-8682.

86. Calo, G., Guerrini, R., Rizzi, A., Salvadori, S., and Regoli, D. (2000) Pharmacology of nociceptin and its receptor: a novel therapeutic target, Br J Pharmacol 129, 1261-1283.

87. Henderson, G., and McKnight, A. T. (1997) The orphan opioid receptor and its endogenous ligand--nociceptin/orphanin FQ, Trends Pharmacol Sci 18, 293-300.

88. Mollereau, C., Simons, M. J., Soularue, P., Liners, F., Vassart, G., Meunier, J. C., and Parmentier, M. (1996) Structure, tissue distribution, and chromosomal localization of the prepronociceptin gene, Proc Natl Acad Sci U S A 93, 8666-8670.

89. Pan, Z., Hirakawa, N., and Fields, H. L. (2000) A cellular mechanism for the bidirectional pain-modulating actions of orphanin FQ/nociceptin, Neuron 26, 515-522.

90. Katzung, B., Masters, S., and Trevor, A. (2009) Basic and Clinical Pharmacology, Vol. 11, McGraw-Hill Medical.

91. Loeser, J. D., and Treede, R. D. (2008) The Kyoto protocol of IASP Basic Pain Terminology, Pain 137, 473-477.

92. Woolf, C. J., and Ma, Q. (2007) Nociceptors--noxious stimulus detectors, Neuron 55, 353-364.

93. Purves, D. (2007) Neuroscience, 4 ed., Sinauer Associates, Inc.

94. Bennett, G. J. (2000) Update on the neurophysiology of pain transmission and modulation: focus on the NMDA-receptor, J Pain Symptom Manage 19, S2-6.

95. Hunt, S. P., and Mantyh, P. W. (2001) The molecular dynamics of pain control, Nat Rev Neurosci 2, 83-91.

96. Brower, V. (2000) New paths to pain relief, Nat Biotechnol 18, 387-391.

97. Furst, S. (1999) Transmitters involved in antinociception in the spinal cord, Brain Res Bull 48, 129-141.

98. Dohlman, H. G., and Thorner, J. (1997) RGS proteins and signaling by heterotrimeric $\mathrm{G}$ proteins, J Biol Chem 272, 3871-3874.

99. Williams, J. T., Christie, M. J., and Manzoni, O. (2001) Cellular and synaptic adaptations mediating opioid dependence, Physiol Rev 81, 299-343.

100. Chen, L., and Huang, L. Y. (1991) Sustained potentiation of NMDA receptor-mediated glutamate responses through activation of protein kinase $\mathrm{C}$ by a mu opioid, Neuron 7 , 319-326.

101. Tang, T., Stevens, B. A., and Cox, B. M. (1996) Opioid regulation of intracellular free calcium in cultured mouse dorsal root ganglion neurons, J Neurosci Res 44, 338-343.

102. Segal, R. A., and Greenberg, M. E. (1996) Intracellular signaling pathways activated by neurotrophic factors, Annu Rev Neurosci 19, 463-489. 
103. Koch, T., and Hollt, V. (2008) Role of receptor internalization in opioid tolerance and dependence, Pharmacol Ther 117, 199-206.

104. Krupnick, J. G., and Benovic, J. L. (1998) The role of receptor kinases and arrestins in G protein-coupled receptor regulation, Annu Rev Pharmacol Toxicol 38, 289-319.

105. Keith, D. E., Murray, S. R., Zaki, P. A., Chu, P. C., Lissin, D. V., Kang, L., Evans, C. J., and von Zastrow, M. (1996) Morphine activates opioid receptors without causing their rapid internalization, J Biol Chem 271, 19021-19024.

106. Keith, D. E., Anton, B., Murray, S. R., Zaki, P. A., Chu, P. C., Lissin, D. V., MonteilletAgius, G., Stewart, P. L., Evans, C. J., and von Zastrow, M. (1998) mu-Opioid receptor internalization: opiate drugs have differential effects on a conserved endocytic mechanism in vitro and in the mammalian brain, Mol Pharmacol 53, 377-384.

107. Zhang, J., Ferguson, S. S., Barak, L. S., Bodduluri, S. R., Laporte, S. A., Law, P. Y., and Caron, M. G. (1998) Role for G protein-coupled receptor kinase in agonist-specific regulation of mu-opioid receptor responsiveness, Proc Natl Acad Sci U S A 95, 71577162.

108. Tao, P. L., Law, P. Y., and Loh, H. H. (1987) Decrease in delta and mu opioid receptor binding capacity in rat brain after chronic etorphine treatment, $J$ Pharmacol Exp Ther 240, 809-816.

109. Nestler, E. J. (2004) Historical review: Molecular and cellular mechanisms of opiate and cocaine addiction, Trends Pharmacol Sci 25, 210-218.

110. Sharma, S. K., Klee, W. A., and Nirenberg, M. (1975) Dual regulation of adenylate cyclase accounts for narcotic dependence and tolerance, Proc Natl Acad Sci U S A 72, 3092-3096.

111. Nevo, I., Avidor-Reiss, T., Levy, R., Bayewitch, M., Heldman, E., and Vogel, Z. (1998) Regulation of adenylyl cyclase isozymes on acute and chronic activation of inhibitory receptors, Mol Pharmacol 54, 419-426.

112. Duman, R. S., Tallman, J. F., and Nestler, E. J. (1988) Acute and chronic opiateregulation of adenylate cyclase in brain: specific effects in locus coeruleus, $J$ Pharmacol Exp Ther 246, 1033-1039.

113. Guitart, X., and Nestler, E. J. (1989) Identification of morphine- and cyclic AMPregulated phosphoproteins (MARPPs) in the locus coeruleus and other regions of rat brain: regulation by acute and chronic morphine, J Neurosci 9, 4371-4387.

114. Lane-Ladd, S. B., Pineda, J., Boundy, V. A., Pfeuffer, T., Krupinski, J., Aghajanian, G. K., and Nestler, E. J. (1997) CREB (cAMP response element-binding protein) in the locus coeruleus: biochemical, physiological, and behavioral evidence for a role in opiate dependence, J Neurosci 17, 7890-7901.

115. Matsuoka, I., Maldonado, R., Defer, N., Noel, F., Hanoune, J., and Roques, B. P. (1994) Chronic morphine administration causes region-specific increase of brain type VIII adenylyl cyclase mRNA, Eur J Pharmacol 268, 215-221.

116. Nestler, E. J., and Tallman, J. F. (1988) Chronic morphine treatment increases cyclic AMP-dependent protein kinase activity in the rat locus coeruleus, Mol Pharmacol 33, 127-132.

117. Nestler, E. J. (2004) Molecular mechanisms of drug addiction, Neuropharmacology 47 Suppl 1, 24-32.

118. Chakrabarti, S., Wang, L., Tang, W. J., and Gintzler, A. R. (1998) Chronic morphine augments adenylyl cyclase phosphorylation: relevance to altered signaling during tolerance/dependence, Mol Pharmacol 54, 949-953.

119. Crain, S. M., and Shen, K. F. (1996) Modulatory effects of Gs-coupled excitatory opioid receptor functions on opioid analgesia, tolerance, and dependence, Neurochem Res 21, 1347-1351. 
120. Tso, P. H., and Wong, Y. H. (2001) Opioid-induced adenylyl cyclase supersensitization in human embryonic kidney 293 cells requires pertussis toxin-sensitive $G$ proteins other than G(i1) and G(i3), Neurosci Lett 299, 25-28.

121. Avidor-Reiss, T., Nevo, I., Levy, R., Pfeuffer, T., and Vogel, Z. (1996) Chronic opioid treatment induces adenylyl cyclase $V$ superactivation. Involvement of Gbetagamma, $J$ Biol Chem 271, 21309-21315.

122. Chavkin, C., McLaughlin, J. P., and Celver, J. P. (2001) Regulation of opioid receptor function by chronic agonist exposure: constitutive activity and desensitization, $\mathrm{Mol}$ Pharmacol 60, 20-25.

123. Liu, J. G., and Prather, P. L. (2001) Chronic exposure to mu-opioid agonists produces constitutive activation of mu-opioid receptors in direct proportion to the efficacy of the agonist used for pretreatment, Mol Pharmacol 60, 53-62.

124. Liu, J. G., Ruckle, M. B., and Prather, P. L. (2001) Constitutively active mu-opioid receptors inhibit adenylyl cyclase activity in intact cells and activate G-proteins differently than the agonist [D-Ala2,N-MePhe4,Gly-ol5]enkephalin, J Biol Chem 276, 37779-37786.

125. Mercer, S. L., and Coop, A. (2011) Opioid analgesics and P-glycoprotein efflux transporters: a potential systems-level contribution to analgesic tolerance, Curr Top Med Chem 11, 1157-1164.

126. Hassan, H. E., Mercer, S. L., Cunningham, C. W., Coop, A., and Eddington, N. D. (2009) Evaluation of the P-glycoprotein (Abcb1) affinity status of a series of morphine analogs: comparative study with meperidine analogs to identify opioids with minimal Pglycoprotein interactions, Int $J$ Pharm 375, 48-54.

127. Balayssac, D., Authier, N., Cayre, A., and Coudore, F. (2005) Does inhibition of Pglycoprotein lead to drug-drug interactions?, Toxicol Lett 156, 319-329.

128. Cunningham, C. W., Mercer, S. L., Hassan, H. E., Traynor, J. R., Eddington, N. D., and Coop, A. (2008) Opioids and efflux transporters. Part 2: P-glycoprotein substrate activity of 3- and 6-substituted morphine analogs, J Med Chem 51, 2316-2320.

129. Mercer, S. L., Hassan, H. E., Cunningham, C. W., Eddington, N. D., and Coop, A. (2007) Opioids and efflux transporters. Part 1: P-glycoprotein substrate activity of $\mathrm{N}$-substituted analogs of meperidine, Bioorg Med Chem Lett 17, 1160-1162.

130. Mercer, S. L., Cunningham, C. W., Eddington, N. D., and Coop, A. (2008) Opioids and efflux transporters. Part 3: P-glycoprotein substrate activity of 3-hydroxyl addition to meperidine analogs, Bioorg Med Chem Lett 18, 3638-3640.

131. Gomes, I., Jordan, B. A., Gupta, A., Trapaidze, N., Nagy, V., and Devi, L. A. (2000) Heterodimerization of mu and delta opioid receptors: A role in opiate synergy, $J$ Neurosci 20, RC110.

132. George, S. R., Fan, T., Xie, Z., Tse, R., Tam, V., Varghese, G., and O'Dowd, B. F. (2000) Oligomerization of mu- and delta-opioid receptors. Generation of novel functional properties, J Biol Chem 275, 26128-26135.

133. Levac, B. A., O'Dowd, B. F., and George, S. R. (2002) Oligomerization of opioid receptors: generation of novel signaling units, Curr Opin Pharmacol 2, 76-81.

134. Gallantine, E. L., and Meert, T. F. (2005) A comparison of the antinociceptive and adverse effects of the mu-opioid agonist morphine and the delta-opioid agonist SNC80, Basic Clin Pharmacol Toxicol 97, 39-51.

135. Gomes, I., ljzerman, A. P., Ye, K., Maillet, E. L., and Devi, L. A. (2011) G proteincoupled receptor heteromerization: a role in allosteric modulation of ligand binding, $\mathrm{Mol}$ Pharmacol 79, 1044-1052.

136. Gomes, I., Gupta, A., Filipovska, J., Szeto, H. H., Pintar, J. E., and Devi, L. A. (2004) A role for heterodimerization of mu and delta opiate receptors in enhancing morphine analgesia, Proc Natl Acad Sci U S A 101, 5135-5139. 
137. Egan, T. M., and North, R. A. (1981) Both mu and delta opiate receptors exist on the same neuron, Science 214, 923-924.

138. Horan, P., Tallarida, R. J., Haaseth, R. C., Matsunaga, T. O., Hruby, V. J., and Porreca, F. (1992) Antinociceptive interactions of opioid delta receptor agonists with morphine in mice: supra- and sub-additivity, Life Sci 50, 1535-1541.

139. Abdelhamid, E. E., Sultana, M., Portoghese, P. S., and Takemori, A. E. (1991) Selective blockage of delta opioid receptors prevents the development of morphine tolerance and dependence in mice, $J$ Pharmacol Exp Ther 258, 299-303.

140. Hepburn, M. J., Little, P. J., Gingras, J., and Kuhn, C. M. (1997) Differential effects of naltrindole on morphine-induced tolerance and physical dependence in rats, $J$ Pharmacol Exp Ther 281, 1350-1356.

141. Crain, S. M., and Shen, K. F. (1995) Ultra-low concentrations of naloxone selectively antagonize excitatory effects of morphine on sensory neurons, thereby increasing its antinociceptive potency and attenuating tolerance/dependence during chronic cotreatment, Proc Natl Acad Sci U S A 92, 10540-10544.

142. Wang, H. Y., Friedman, E., Olmstead, M. C., and Burns, L. H. (2005) Ultra-low-dose naloxone suppresses opioid tolerance, dependence and associated changes in mu opioid receptor-G protein coupling and Gbetagamma signaling, Neuroscience 135, 247261.

143. Crain, S. M., and Shen, K. F. (2000) Antagonists of excitatory opioid receptor functions enhance morphine's analgesic potency and attenuate opioid tolerance/dependence liability, Pain 84, 121-131.

144. Zhu, Y., King, M. A., Schuller, A. G., Nitsche, J. F., Reidl, M., Elde, R. P., Unterwald, E., Pasternak, G. W., and Pintar, J. E. (1999) Retention of supraspinal delta-like analgesia and loss of morphine tolerance in delta opioid receptor knockout mice, Neuron 24, 243252.

145. Kest, B., Lee, C. E., McLemore, G. L., and Inturrisi, C. E. (1996) An antisense oligodeoxynucleotide to the delta opioid receptor (DOR-1) inhibits morphine tolerance and acute dependence in mice, Brain Res Bull 39, 185-188.

146. Sanchez-Blazquez, P., Garcia-Espana, A., and Garzon, J. (1997) Antisense oligodeoxynucleotides to opioid mu and delta receptors reduced morphine dependence in mice: role of delta-2 opioid receptors, J Pharmacol Exp Ther 280, 1423-1431.

147. Suzuki, T., Ikeda, H., Tsuji, M., Misawa, M., Narita, M., and Tseng, L. F. (1997) Antisense oligodeoxynucleotide to delta opioid receptors attenuates morphine dependence in mice, Life Sci 61, PL 165-170.

148. Purington, L. C., Pogozheva, I. D., Traynor, J. R., and Mosberg, H. I. (2009) Pentapeptides displaying mu opioid receptor agonist and delta opioid receptor partial agonist/antagonist properties, J Med Chem 52, 7724-7731.

149. Purington, L. C., Sobczyk-Kojiro, K., Pogozheva, I. D., Traynor, J. R., and Mosberg, H. I. (2011) Development and in vitro characterization of a novel bifunctional muagonist/delta-antagonist opioid tetrapeptide, ACS Chem Biol 6, 1375-1381.

150. Schiller, P. W., Fundytus, M. E., Merovitz, L., Weltrowska, G., Nguyen, T. M., Lemieux, C., Chung, N. N., and Coderre, T. J. (1999) The opioid mu agonist/delta antagonist DIPP-NH(2)[Psi] produces a potent analgesic effect, no physical dependence, and less tolerance than morphine in rats, J Med Chem 42, 3520-3526.

151. Portoghese, P. S. (1989) Bivalent ligands and the message-address concept in the design of selective opioid receptor antagonists, Trends Pharmacol Sci 10, 230-235.

152. Daniels, D. J., Lenard, N. R., Etienne, C. L., Law, P. Y., Roerig, S. C., and Portoghese, P. S. (2005) Opioid-induced tolerance and dependence in mice is modulated by the distance between pharmacophores in a bivalent ligand series, Proc Natl Acad Sci U S A 102, 19208-19213. 
153. Morphy, R., and Rankovic, Z. (2005) Designed multiple ligands. An emerging drug discovery paradigm, J Med Chem 48, 6523-6543.

154. Li, T., Shiotani, K., Miyazaki, A., Tsuda, Y., Ambo, A., Sasaki, Y., Jinsmaa, Y., Marczak, E., Bryant, S. D., Lazarus, L. H., and Okada, Y. (2007) Bifunctional [2',6'-dimethyl-Ltyrosine1]endomorphin-2 analogues substituted at position 3 with alkylated phenylalanine derivatives yield potent mixed mu-agonist/delta-antagonist and dual muagonist/delta-agonist opioid ligands, J Med Chem 50, 2753-2766.

155. Ananthan, S., Saini, S. K., Dersch, C. M., Xu, H., McGlinchey, N., Giuvelis, D., Bilsky, E. J., and Rothman, R. B. (2012) 14-Alkoxy- and 14-Acyloxypyridomorphinans: mu Agonist/delta Antagonist Opioid Analgesics with Diminished Tolerance and Dependence Side Effects, J Med Chem 55, 8350-8363.

156. Wells, J. L., Bartlett, J. L., Ananthan, S., and Bilsky, E. J. (2001) In vivo pharmacological characterization of SoRI 9409, a nonpeptidic opioid mu-agonist/delta-antagonist that produces limited antinociceptive tolerance and attenuates morphine physical dependence, J Pharmacol Exp Ther 297, 597-605.

157. Ananthan, S., Khare, N. K., Saini, S. K., Seitz, L. E., Bartlett, J. L., Davis, P., Dersch, C. M., Porreca, F., Rothman, R. B., and Bilsky, E. J. (2004) Identification of opioid ligands possessing mixed micro agonist/delta antagonist activity among pyridomorphinans derived from naloxone, oxymorphone, and hydromorphone [correction of hydropmorphone], J Med Chem 47, 1400-1412.

158. Roy, S., Guo, X., Kelschenbach, J., Liu, Y., and Loh, H. H. (2005) In vivo activation of a mutant mu-opioid receptor by naltrexone produces a potent analgesic effect but no tolerance: role of mu-receptor activation and delta-receptor blockade in morphine tolerance, J Neurosci 25, 3229-3233.

159. Fishman, S. M., Papazian, J. S., Gonzalez, S., Riches, P. S., and Gilson, A. (2004) Regulating opioid prescribing through prescription monitoring programs: balancing drug diversion and treatment of pain, Pain Med 5, 309-324.

160. Schwyzer, R. (1977) ACTH: a short introductory review, Ann N Y Acad Sci 297, 3-26.

161. Shim, J., Coop, A., and MacKerell, A. D., Jr. (2011) Consensus 3D model of mu-opioid receptor ligand efficacy based on a quantitative Conformationally Sampled Pharmacophore, J Phys Chem B 115, 7487-7496.

162. Perola, E., and Charifson, P. S. (2004) Conformational analysis of drug-like molecules bound to proteins: an extensive study of ligand reorganization upon binding, $J$ Med Chem 47, 2499-2510.

163. Gilbert, K. M., Skawinski, W. J., Misra, M., Paris, K. A., Naik, N. H., Buono, R. A., Deutsch, H. M., and Venanzi, C. A. (2004) Conformational analysis of methylphenidate: comparison of molecular orbital and molecular mechanics methods, J Comput Aided Mol Des 18, 719-738.

164. Misra, M., Banerjee, A., Dave, R. N., and Venanzi, C. A. (2005) Novel feature extraction technique for fuzzy relational clustering of a flexible dopamine reuptake inhibitor, $J$ Chem Inf Model 45, 610-623.

165. Bernard, D., Coop, A., and MacKerell, A. D., Jr. (2003) 2D conformationally sampled pharmacophore: a ligand-based pharmacophore to differentiate delta opioid agonists from antagonists, J Am Chem Soc 125, 3101-3107.

166. Bernard, D., Coop, A., and MacKerell, A. D., Jr. (2007) Quantitative conformationally sampled pharmacophore for delta opioid ligands: reevaluation of hydrophobic moieties essential for biological activity, J Med Chem 50, 1799-1809.

167. Lewis, J. W., and Husbands, S. M. (2004) The orvinols and related opioids--high affinity ligands with diverse efficacy profiles, Curr Pharm Des 10, 717-732.

168. Portoghese, P. S., Sultana, M., and Takemori, A. E. (1988) Naltrindole, a highly selective and potent non-peptide delta opioid receptor antagonist, Eur J Pharmacol 146, 185-186. 
169. Portoghese, P. S., Sultana, M., Nagase, H., and Takemori, A. E. (1992) A highly selective delta 1-opioid receptor antagonist: 7-benzylidenenaltrexone, Eur J Pharmacol 218, 195-196.

170. Cowan, A., and Lewis, J. W. (1995) Buprenorphine: Combatting Drug Abuse with a Unique Opioid, Vol. 1, Wiley-Liss, New York.

171. Greedy, B., Bradbury, F., Thomas, M. P., Grivas, K., Cami-Kobeci, G., Aarchambeau, A., Bosse, K., Clark, M. J., Aceto, M., Lewis, J. W., Traynor, J. R., and Husbands, S. M. (2013) Orvinols with Mixed Kappa/Mu Opioid Receptor Agonist Activity, J Med Chem.

172. Selley, D. E., Liu, Q., and Childers, S. R. (1998) Signal transduction correlates of mu opioid agonist intrinsic efficacy: receptor-stimulated [35S]GTP gamma $S$ binding in mMOR-CHO cells and rat thalamus, J Pharmacol Exp Ther 285, 496-505.

173. Joranson, D. E., Carrow, G. M., Ryan, K. M., Schaefer, L., Gilson, A. M., Good, P., Eadie, J., Peine, S., and Dahl, J. L. (2002) Pain management and prescription monitoring, J Pain Symptom Manage 23, 231-238.

174. Cheng, Y., and Prusoff, W. H. (1973) Relationship between the inhibition constant (K1) and the concentration of inhibitor which causes 50 per cent inhibition (I50) of an enzymatic reaction, Biochem Pharmacol 22, 3099-3108.

175. Emmerson, P. J., Clark, M. J., Mansour, A., Akil, H., Woods, J. H., and Medzihradsky, F. (1996) Characterization of opioid agonist efficacy in a C6 glioma cell line expressing the mu opioid receptor, J Pharmacol Exp Ther 278, 1121-1127.

176. Selley, D. E., Sim, L. J., Xiao, R., Liu, Q., and Childers, S. R. (1997) mu-Opioid receptorstimulated guanosine-5'-O-(gamma-thio)-triphosphate binding in rat thalamus and cultured cell lines: signal transduction mechanisms underlying agonist efficacy, Mol Pharmacol 51, 87-96.

177. Selley, D. E., Cao, C. C., Liu, Q., and Childers, S. R. (2000) Effects of sodium on agonist efficacy for G-protein activation in mu-opioid receptor-transfected $\mathrm{CHO}$ cells and rat thalamus, Br J Pharmacol 130, 987-996.

178. Trescot, A. M., Boswell, M. V., Atluri, S. L., Hansen, H. C., Deer, T. R., Abdi, S., Jasper, J. F., Singh, V., Jordan, A. E., Johnson, B. W., Cicala, R. S., Dunbar, E. E., Helm, S., 2nd, Varley, K. G., Suchdev, P. K., Swicegood, J. R., Calodney, A. K., Ogoke, B. A., Minore, W. S., and Manchikanti, L. (2006) Opioid guidelines in the management of chronic non-cancer pain, Pain Physician 9, 1-39.

179. Gates, M., Boden, R. M., and Sundararaman, P. (1989) Derivatives of the Thebaine Anion. 2. 5-Methylmorphine, 5-Methylcodeine, 5-Methylheroin and Some Related Compounds, J. Org. Chem. 54, 972-974.

180. Woudenberg, R. H., Lie, T.-S., and Maat, L. (1993) Chemistry of opium alkaloids. 38. Synthesis of rigid morphinans doubly bridged at ring C, J. Org. Chem. 58, 6139-6142.

181. Lotfy, H. R., Schultz, A. G., and Metwally, M. A. (2003) Synthesis of 5-Methoxymethyl, 5(2-Methoxyethyl), and 5-Allyl Thebaine, Codeinone, and Morphinone Derivatives, Russian Journal of Organic Chemistry 39, 1256-1260.

182. Rice, K. C. (1977) A rapid, high-yield conversion of codeine to morphine, J Med Chem 20, 164-165.

183. Clark, M. J., Emmerson, P. J., Mansour, A., Akil, H., Woods, J. H., Portoghese, P. S., Remmers, A. E., and Medzihradsky, F. (1997) Opioid efficacy in a C6 glioma cell line stably expressing the delta opioid receptor, J Pharmacol Exp Ther 283, 501-510.

184. Bruchas, M. R., Land, B. B., and Chavkin, C. (2010) The dynorphin/kappa opioid system as a modulator of stress-induced and pro-addictive behaviors, Brain Res 1314, 44-55.

185. Wu, K. M., Martin, W. R., Kamerling, S. G., and Wettstein, J. G. (1983) Possible medullary kappa hyperalgesic mechanism. I. A new potential role for endogenous opioid peptides in pain perception, Life Sci 33, 1831-1838. 
186. Toll, L., Berzetei-Gurske, I. P., Polgar, W. E., Brandt, S. R., Adapa, I. D., Rodriguez, L., Schwartz, R. W., Haggart, D., O'Brien, A., White, A., Kennedy, J. M., Craymer, K., Farrington, L., and Auh, J. S. (1998) Standard binding and functional assays related to medications development division testing for potential cocaine and opiate narcotic treatment medications, NIDA Res Monogr 178, 440-466.

187. Granier, S., Manglik, A., Kruse, A. C., Kobilka, T. S., Thian, F. S., Weis, W. I., and Kobilka, B. K. (2012) Structure of the delta-opioid receptor bound to naltrindole, Nature 485, 400-404.

188. Manglik, A., Kruse, A. C., Kobilka, T. S., Thian, F. S., Mathiesen, J. M., Sunahara, R. K., Pardo, L., Weis, W. I., Kobilka, B. K., and Granier, S. (2012) Crystal structure of the micro-opioid receptor bound to a morphinan antagonist, Nature 485, 321-326.

189. Eddy, N. B. (1956) The search for new analgesics, J Chronic Dis 4, 59-71.

190. Smith, T. A., Thatcher, L. N., and Coop, A. (2007) 3-Hydroxy-4methoxyindolomorphinans as delta opioid selective ligands, Bioorg Med Chem Lett 17, 5175-5176.

191. Coop, A., Rothman, R. B., Dersch, C., Partilla, J., Porreca, F., Davis, P., Jacobson, A. E., and Rice, K. C. (1999) delta Opioid affinity and selectivity of 4-hydroxy-3methoxyindolomorphinan analogues related to naltrindole, J Med Chem 42, 1673-1679.

192. Portoghese, P. S. (2001) From models to molecules: opioid receptor dimers, bivalent ligands, and selective opioid receptor probes, J Med Chem 44, 2259-2269.

193. Millan, M. J. (2002) Descending control of pain, Prog Neurobiol 66, 355-474.

194. Yaksh, T. L., and Rudy, T. A. (1978) Narcotic analgestics: CNS sites and mechanisms of action as revealed by intracerebral injection techniques, Pain 4, 299-359.

195. Barrot, M. (2012) Tests and models of nociception and pain in rodents, Neuroscience 211, 39-50.

196. Lowery, J. J., Raymond, T. J., Giuvelis, D., Bidlack, J. M., Polt, R., and Bilsky, E. J. (2011) In vivo characterization of MMP-2200, a mixed delta/mu opioid agonist, in mice, $J$ Pharmacol Exp Ther 336, 767-778.

197. Heyman, J. S., Koslo, R. J., Mosberg, H. I., Tallarida, R. J., and Porreca, F. (1986) Estimation of the affinity of naloxone at supraspinal and spinal opioid receptors in vivo: studies with receptor selective agonists, Life Sci 39, 1795-1803.

198. Horan, P., Taylor, J., Yamamura, H. I., and Porreca, F. (1992) Extremely long-lasting antagonistic actions of nor-binaltorphimine (nor-BNI) in the mouse tail-flick test, $J$ Pharmacol Exp Ther 260, 1237-1243.

199. King, M. A., Su, W., Nielan, C. L., Chang, A. H., Schutz, J., Schmidhammer, H., and Pasternak, G. W. (2003) 14-Methoxymetopon, a very potent mu-opioid receptorselective analgesic with an unusual pharmacological profile, Eur J Pharmacol 459, 203209.

200. Yamada, K., and Nabeshima, T. (1995) Stress-induced behavioral responses and multiple opioid systems in the brain, Behav Brain Res 67, 133-145.

201. Ward, S. J., Portoghese, P. S., and Takemori, A. E. (1982) Pharmacological characterization in vivo of the novel opiate, beta-funaltrexamine, $J$ Pharmacol Exp Ther 220, 494-498.

202. Manchikanti, L., Damron, K. S., McManus, C. D., and Barnhill, R. C. (2004) Patterns of illicit drug use and opioid abuse in patients with chronic pain at initial evaluation: a prospective, observational study, Pain Physician 7, 431-437.

203. Davis, A. M., and Inturrisi, C. E. (1999) d-Methadone blocks morphine tolerance and Nmethyl-D-aspartate-induced hyperalgesia, J Pharmacol Exp Ther 289, 1048-1053.

204. Glasper, A., Reed, L. J., de Wet, C. J., Gossop, M., and Bearn, J. (2005) Induction of patients with moderately severe methadone dependence onto buprenorphine, Addict Biol 10, 149-155. 
205. Heifetz, S. A., and McMillan, D. E. (1971) Development of behavioral tolerance to morphine and methadone using the schedule-controlled behavior of the pigeon, Psychopharmacologia 19, 40-52.

206. Farber, N. B., Foster, J., Duhan, N. L., and Olney, J. W. (1995) alpha 2 adrenergic agonists prevent MK-801 neurotoxicity, Neuropsychopharmacology 12, 347-349.

207. Quibell, R., Prommer, E. E., Mihalyo, M., Twycross, R., and Wilcock, A. (2011) Ketamine*, J Pain Symptom Manage 41, 640-649.

208. Roques, B. P. (2000) Novel approaches to targeting neuropeptide systems, Trends Pharmacol Sci 21, 475-483.

209. Cahill, C. M., Morinville, A., Lee, M. C., Vincent, J. P., Collier, B., and Beaudet, A. (2001) Prolonged morphine treatment targets delta opioid receptors to neuronal plasma membranes and enhances delta-mediated antinociception, J Neurosci 21, 7598-7607.

210. Hasbi, A., Nguyen, T., Fan, T., Cheng, R., Rashid, A., Alijaniaram, M., Rasenick, M. M., O'Dowd, B. F., and George, S. R. (2007) Trafficking of preassembled opioid mu-delta heterooligomer-Gz signaling complexes to the plasma membrane: coregulation by agonists, Biochemistry 46, 12997-13009.

211. Hendry, I. A., Kelleher, K. L., Bartlett, S. E., Leck, K. J., Reynolds, A. J., Heydon, K., Mellick, A., Megirian, D., and Matthaei, K. I. (2000) Hypertolerance to morphine in G(z alpha)-deficient mice, Brain Res 870, 10-19.

212. Raehal, K. M., and Bohn, L. M. (2005) Mu opioid receptor regulation and opiate responsiveness, AAPS J 7, E587-591.

213. Su, Y. F., McNutt, R. W., and Chang, K. J. (1998) Delta-opioid ligands reverse alfentanilinduced respiratory depression but not antinociception, J Pharmacol Exp Ther 287, 815823.

214. Foxx-Orenstein, A. E., Jin, J. G., and Grider, J. R. (1998) 5-HT4 receptor agonists and delta-opioid receptor antagonists act synergistically to stimulate colonic propulsion, $A m \mathrm{~J}$ Physiol 275, G979-983.

215. Dahan, A., Sarton, E., Teppema, L., Olievier, C., Nieuwenhuijs, D., Matthes, H. W., and Kieffer, B. L. (2001) Anesthetic potency and influence of morphine and sevoflurane on respiration in mu-opioid receptor knockout mice, Anesthesiology 94, 824-832.

216. Drorbaugh, J. E., and Fenn, W. O. (1955) A barometric method for measuring ventilation in newborn infants, Pediatrics 16, 81-87.

217. Verborgh, C. M., Camu, F., and Meert, T. F. (1997) Interaction between sufentanil and $\mathrm{U}-50488 \mathrm{H}$ with respect to antinociception and respiratory depression in rats, Acta Anaesthesiol Scand 41, 895-902.

218. Meert, T. F., and Vermeirsch, H. A. (2005) A preclinical comparison between different opioids: antinociceptive versus adverse effects, Pharmacol Biochem Behav 80, 309-326.

219. Niemegeers, C. J., Lenaerts, F. M., and Janssen, P. A. (1972) Difenoxine (R 15403), the active metabolite of diphenoxylate (R 1132). 2. Difneozine, a potent, orally active and safe antidiarrheal agent in rats, Arzneimittelforschung 22, 516-518.

220. Chefer, V. I., and Shippenberg, T. S. (2009) Augmentation of morphine-induced sensitization but reduction in morphine tolerance and reward in delta-opioid receptor knockout mice, Neuropsychopharmacology 34, 887-898.

221. Shippenberg, T. S., Chefer, V. I., and Thompson, A. C. (2009) Delta-opioid receptor antagonists prevent sensitization to the conditioned rewarding effects of morphine, Biol Psychiatry 65, 169-174.

222. Olmstead, M. C., and Franklin, K. B. (1997) The development of a conditioned place preference to morphine: effects of microinjections into various CNS sites, Behav Neurosci 111, 1324-1334. 
223. Sora, I., Elmer, G., Funada, M., Pieper, J., Li, X. F., Hall, F. S., and Uhl, G. R. (2001) Mu opiate receptor gene dose effects on different morphine actions: evidence for differential in vivo mu receptor reserve, Neuropsychopharmacology 25, 41-54.

224. Le Bars, D., Gozariu, M., and Cadden, S. W. (2001) Animal models of nociception, Pharmacol Rev 53, 597-652.

225. Abbott, F. V., Franklin, K. B., and Westbrook, R. F. (1995) The formalin test: scoring properties of the first and second phases of the pain response in rats, Pain 60, 91-102.

226. Dubuisson, D., and Dennis, S. G. (1977) The formalin test: a quantitative study of the analgesic effects of morphine, meperidine, and brain stem stimulation in rats and cats, Pain 4, 161-174.

227. Tjolsen, A., Berge, O. G., Hunskaar, S., Rosland, J. H., and Hole, K. (1992) The formalin test: an evaluation of the method, Pain 51, 5-17.

228. Stein, C., Millan, M. J., Shippenberg, T. S., Peter, K., and Herz, A. (1989) Peripheral opioid receptors mediating antinociception in inflammation. Evidence for involvement of mu, delta and kappa receptors, J Pharmacol Exp Ther 248, 1269-1275.

229. Roughan, J. V., and Flecknell, P. A. (2002) Buprenorphine: a reappraisal of its antinociceptive effects and therapeutic use in alleviating post-operative pain in animals, Lab Anim 36, 322-343.

230. Eliav, E., Herzberg, U., Ruda, M. A., and Bennett, G. J. (1999) Neuropathic pain from an experimental neuritis of the rat sciatic nerve, Pain 83, 169-182.

231. Wall, P. D., and Gutnick, M. (1974) Properties of afferent nerve impulses originating from a neuroma, Nature 248, 740-743.

232. Decosterd, I., and Woolf, C. J. (2000) Spared nerve injury: an animal model of persistent peripheral neuropathic pain, Pain 87, 149-158.

233. LaBuda, C. J., and Little, P. J. (2005) Pharmacological evaluation of the selective spinal nerve ligation model of neuropathic pain in the rat, $J$ Neurosci Methods 144, 175-181.

234. Wallace, M. S. (2001) Pharmacologic treatment of neuropathic pain, Curr Pain Headache Rep 5, 138-150.

235. Houghton, A. K., Valdez, J. G., and Westlund, K. N. (1998) Peripheral morphine administration blocks the development of hyperalgesia and allodynia after bone damage in the rat, Anesthesiology 89, 190-201.

236. Ando, A., Oshida, K., Fukuyama, S., Watanabe, A., Hashimoto, H., and Miyamoto, Y. (2012) Identification of human cytochrome P450 enzymes involved in the metabolism of a novel small ka, Cyrillic-opioid receptor agonist, nalfurafine hydrochloride, Biopharm Drug Dispos 33, 257-264.

237. Feierman, D. E., and Lasker, J. M. (1996) Metabolism of fentanyl, a synthetic opioid analgesic, by human liver microsomes. Role of CYP3A4, Drug Metab Dispos 24, 932939.

238. Hewitt, N. J., Lechon, M. J., Houston, J. B., Hallifax, D., Brown, H. S., Maurel, P., Kenna, J. G., Gustavsson, L., Lohmann, C., Skonberg, C., Guillouzo, A., Tuschl, G., Li, A. P., LeCluyse, E., Groothuis, G. M., and Hengstler, J. G. (2007) Primary hepatocytes: current understanding of the regulation of metabolic enzymes and transporter proteins, and pharmaceutical practice for the use of hepatocytes in metabolism, enzyme induction, transporter, clearance, and hepatotoxicity studies, Drug Metab Rev 39, 159-234.

239. Moody, D. E., Slawson, M. H., Strain, E. C., Laycock, J. D., Spanbauer, A. C., and Foltz, R. L. (2002) A liquid chromatographic-electrospray ionization-tandem mass spectrometric method for determination of buprenorphine, its metabolite, norbuprenorphine, and a coformulant, naloxone, that is suitable for in vivo and in vitro metabolism studies, Anal Biochem 306, 31-39.

240. Wang, J. S., and DeVane, C. L. (2003) Involvement of CYP3A4, CYP2C8, and CYP2D6 in the metabolism of (R)- and (S)-methadone in vitro, Drug Metab Dispos 31, 742-747. 
241. Thummel, K. E., and Wilkinson, G. R. (1998) In vitro and in vivo drug interactions involving human CYP3A, Annu Rev Pharmacol Toxicol 38, 389-430.

242. Koch, T., Schulz, S., Pfeiffer, M., Klutzny, M., Schroder, H., Kahl, E., and Hollt, V. (2001) C-terminal splice variants of the mouse mu-opioid receptor differ in morphine-induced internalization and receptor resensitization, J Biol Chem 276, 31408-31414.

243. Raehal, K. M., and Bohn, L. M. (2011) The role of beta-arrestin2 in the severity of antinociceptive tolerance and physical dependence induced by different opioid pain therapeutics, Neuropharmacology 60, 58-65.

244. Ives, T. J., Chelminski, P. R., Hammett-Stabler, C. A., Malone, R. M., Perhac, J. S., Potisek, N. M., Shilliday, B. B., DeWalt, D. A., and Pignone, M. P. (2006) Predictors of opioid misuse in patients with chronic pain: a prospective cohort study, BMC Health Serv Res 6, 46.

245. Skolnik, N., and Menichello, G. (2009) Opioid Therapy in Chronic Noncancer Pain, J. Pain 10, 113-130. 


\title{
Jason R. Healy
}

West Virginia University, 1 Medical Center Drive, PO Box 9500, Morgantown, WV 26506 Phone: (630) 247-2904, Email: jrhealy@hsc.wvu.edu

\section{EDUCATION}

\author{
2008-Present West Virginia University, Morgantown, West Virginia \\ Ph.D. Candidate, Integrated Biomedical Sciences, Pharmaceutical \& \\ Pharmacological Sciences \\ 2006-2007 College of DuPage, Glen Ellyn, IL \\ Business/Management, 20+ credit hours \\ 2000-2004 The University of lowa, lowa City, IA \\ B.S. in Chemistry
}

\section{EMPLOYMENT HISTORY}

$\begin{array}{ll}2008-\text { Present } & \text { West Virginia University - Morgantown, WV } \\ \text { Graduate Research Assistant } & \begin{array}{l}\text { Castrol Industrial North America, Division of BP - Naperville, IL } \\ 2006-2008\end{array} \\ \text { Technical Support Assistant Chemist } \\ \text { The University of lowa - lowa City, IA } \\ 2002-2003 & \begin{array}{l}\text { Undergraduate Research Assistant } \\ \text { The University of lowa - lowa City, IA }\end{array} \\ 2002 & \begin{array}{l}\text { Undergraduate Teaching Assistant } \\ \text { Center for Food Safety and Applied Nutrition, Food and Drug } \\ \text { Administration - College Park, MD } \\ \text { Research Intern }\end{array}\end{array}$

ORGANIZATIONS/LEADERSHIP

2013-Present West Virginia University Health Sciences Graduate Student Organization Member of Outreach Committee

2012-Present West Virginia University School of Pharmacy

PCOL 743/744: Pharmacology 1/II Tutor

2010-Present American Association for Pharmaceutical Scientists (AAPS)

Chair-Elect and Treasurer of Student Chapter at West Virginia University

2012 West Virginia School of Medicine, Chestnut Ridge Center

Drug Abuse Liaison for Intensive Outpatient Program

2011 West Virginia University School of Pharmacy

Student Representative for Education Strategic Planning Subcommittee

2010 West Virginia University College of Business and Economics

Representative for Science and Technology Entrepreneurship Academy

2010 West Virginia University School of Pharmacy

Chair for $2^{\text {nd }}$ Annual Research Day

2010 West Virginia University School of Pharmacy

Summer Intern Selection Committee 


\section{PEER REVIEWED PUBLICATIONS}

1. Stavitskaya L., Shim J., Healy J.R., Matsumoto R.R., MacKerell A.D. Jr., Coop A. (2012) Deconstructing 14-phenylpropyloxymetopon: minimal requirements for binding to mu opioid receptors. Bioorganic \& Medicinal Chemistry, 20(14):4556-63 (PMID: 22677527).

2. Healy J.R., Bezawada P., Shim J., Jones J.W., Kane M.A., MacKerell A.D. Jr., Coop A., Matsumoto R.R. (2013) Synthesis, modeling and pharmacological evaluation of UMB 425, a mixed $\mu$-agonist $/ \delta$-antagonist opioid analgesic with reduced tolerance liabilities. ACS Chemical Neuroscience, 4(9):1256-66 (PMID: 23713721).

3. Stavitskaya L., Seminerio M.J., Healy J.R., Noorbakhsh B., Matsumoto R.R., Coop A. (2013) The effect of phenylpropyloxyethylamines on sigma receptors. Bioorganic \& Medicinal Chemistry, 21(17):4923-7 (PMID: 23896610).

4. Motel W.C. ${ }^{*}$, Healy J.R. ${ }^{*}$, Viard E., Pouw B., Martin K., Matsumoto R.R., Coop A. (2013) Chlorophenylpiperazine analogues as high affinity dopamine transporter ligands. Bioorganic \& Medicinal Chemistry Letters, accepted.

5. $\quad$ Nguyen L., Robson M.J., Healy J.R., Scandinaro, A.L., Matsumoto R.R. (2013) Dextromethorphan produces antidepressant-like effects through sigma-1 receptors. European Neuropsychopharmacology, submitted.

6. Healy J.R., Wimsatt J.H., Matsumoto R.R. (2013) Engineering and pharmacological characterization of an extended release formulation of buprenorphine in mice. Journal of the American Veterinary Medical Association, October 2013 anticipated date of submission.

7. Stavitskaya L., Healy J.R., Shim J., Matsumoto R.R., MacKerell A.D. Jr., Coop A. (2013) Deconstructing 14-phenylpropyloxymetopon: Synthesis and pharmacological evaluation of $\mathrm{B}, \mathrm{C}$ and D ring-constrained phenylpropyloxyethylamines. European Journal of Medicinal Chemistry, October 2013 anticipated date of submission.

\section{ABSTRACTS/POSTER PRESENTATIONS (SELECTED)}

1. Healy J.R., Bezawada P., Coop A., Matsumoto R.R. (2012) Neuropharmacological evaluation of mixed, mu/delta opioid analgesic agents intended to lessen chronic tolerance liabilities. Society for Neuroscience Annual Meeting, New Orleans, LA. (Poster Presentation; Travel Award Recipient)

2. Healy J.R., Bezawada P., Metcalf M., Cunningham C., Kudrimoti S., Coop A., Matsumoto R.R. (2012) Pharmacological evaluation of novel opioid ligands: A study to determine the effects of mixed mu/delta activity in vitro and in vivo. International Narcotics Research Conference, Kansas City, MO. (Poster Presentation; Travel Award Recipient)

3. Healy J.R., Bezawada P., Metcalf M., Cunningham C., Kudrimoti S., Coop A., Matsumoto R.R. (2012) Pharmacological characterization of novel opioid agents intended to reduce chronic tolerance. $4^{\text {th }}$ Biennial STaR Symposium $/ 87^{\text {th }}$ Annual West Virginia Academy of Science Meeting, Institute, WV. (Poster Presentation)

4. Healy J.R., Bezawada P., Metcalf M., Cunningham C., Kudrimoti S., Coop A., Matsumoto R.R. (2012) Novel mixed mu/delta opioid analgesic agents aimed at reducing chronic tolerance liability. $7^{\text {th }}$ Annual University of Kentucky Center for Clinical \& Translational Science Spring Conference, Lexington, KY. (Poster Presentation)

5. Healy J.R., Smith T.A., Coop A., Matsumoto R.R. (2011) Pharmacological evaluation of novel agents with mixed mu/delta opioid receptor interactions. $44^{\text {th }}$ Annual Mid-Atlantic AAPS Graduate Student Symposium, Pittsburgh, PA. (Poster Presentation) 


\section{INVITED TALKS/SEMINARS}

1. "UMB 425, a mixed mu agonist/delta antagonist opioid analgesic with reduced tolerance liabilities." E.J. Van Liere Memorial Convocation and Research Day, West Virginia University, Morgantown, WV, 2013.

2. "Pain management therapy with reduced tolerance liabilities." Linking Innovation Industry and Commercialization (LIINC), West Virginia University, Morgantown, WV, 2013.

2, "Pharmacological assessment of UMB 425, a mixed mu/delta opioid analgesic agent intended to reduce chronic tolerance liabilities." Department of Psychiatry Seminar Series, School of Medicine, West Virginia University, Morgantown, WV, 2012.

3. "The drug development process: early drug discovery in a laboratory environment." PHAR 704: Introduction to Research, School of Pharmacy, West Virginia University, Morgantown, WV, 2012.

4. "Searching for novel opioid analgesics." PHAR 704: Introduction to Research, School of Pharmacy, West Virginia University, Morgantown, WV, 2010.

\section{TEACHING ASSISTANT}

- Introduction to Research - West Virginia University School of Pharmacy

- Pharmaceutical Care Laboratory 1 -West Virginia University School of Pharmacy

- Organic Chemistry Laboratory - The University of lowa

\section{PROFESSIONAL SOCIETY MEMBERSHIPS}

- Alpha Chi Sigma - Professional Chemistry Fraternity

- American Association for Pharmaceutical Scientists

- American Society for Pharmacology and Experimental Therapeutics

- National Society of Collegiate Scholars

- Phi Eta Sigma National Honor Society

- Society for Neuroscience

- Rho Chi - National Pharmacy Honor Society

\section{AWARDS}

- National Institute on Drug Abuse (NIDA, Research Diversity Supplement PA-08-190, 2010 - Present

- Young Investigator Travel Award, International Narcotics Research Conference (INRC), 2012

- West Virginia University School of Medicine Travel Award, 2012

- West Virginia University School of Pharmacy Travel Award, 2012

- Behavioral and Biomedical Sciences Training Scholarship, 2009-2010

- Outstanding Contribution to Castrol ILS Technology, 2006 - 2007

- The University of lowa Dean's List, 2000 